\title{
3D Biofabrication for Soft Tissue and Cartilage Engineering
}

Gareth Turnbull, ${ }^{1,2}$ Jon Clarke, ${ }^{2}$ Frédéric Picard, ${ }^{1,2}$ Weidong Zhang ${ }^{3}$, Philip Riches ${ }^{1}$, Bin Li ${ }^{3}$ and Wenmiao Shu ${ }^{1}$

${ }^{1}$ Department of Biomedical Engineering, Wolfson Building, University of Strathclyde, 106 Rottenrow, Glasgow, G4 ONW, United Kingdom.

${ }^{2}$ Department of Orthopaedic Surgery, Golden Jubilee National Hospital, Agamemnon St, Clydebank, G81 4DY, United Kingdom.

3. Department of Orthopaedics, The First Affiliated Hospital of Soochow University, Suzhou, Jiangsu, China, Orthopedic Institute, Soochow University, Suzhou, Jiangsu, China

Corresponding Author: Wenmiao Shu

Email: will.shu@strath.ac.uk

\section{Abstract}

Soft tissue injuries (STIs) affect patients of all age groups and represent a common worldwide clinical problem, resulting from conditions including trauma, infection, cancer and burns. Within the spectrum of STIs a mixture of tissues can be injured, ranging from skin to underlying nerves, blood vessels, tendons and cartilaginous tissues. However, significant limitations affect current treatment options and clinical demand for soft tissue and cartilage regenerative therapies continues to rise.

Improving the regeneration of soft tissues has therefore become a key area of focus within tissue engineering. As an emerging technology, 3D bioprinting can be used to build complex soft tissue constructs "from the bottom up," by depositing cells, growth factors, extracellular matrices and other biomaterials in a layer-by-layer fashion. In this way, regeneration of cartilage, skin, vasculature, nerves, tendons and other bodily tissues can be performed in a patient specific manner.

This review will focus on recent use of 3D bioprinting and other biofabrication strategies in soft tissue repair and regeneration. Biofabrication of a variety of soft tissue types will be reviewed following an overview of available cell sources, bioinks and bioprinting techniques.

Key words: Biofabrication, bioink, cartilage, skin, nerves, blood vessels. 


\section{Introduction}

Soft tissue injuries (STIs) affect patients of all age groups and represent a common worldwide clinical problem, resulting from conditions including trauma, infection, cancer and burns. Within the spectrum of STIs a variety of different tissues can be damaged, extending from skin to underlying nerves, blood vessels, tendons and cartilaginous tissues. In extensive defects with injury to multiple tissue types, major reconstructive surgery may be required. This can range from grafting tissues including skin and nerves to free-flap reconstruction, whereby tissue is lifted from a donor site and moved to a recipient site en bloc with an intact blood supply to cover a defect. Tissue grafts harvested and used within the same patient for reconstruction (autografts) are considered the current gold standard for reconstructive treatment. However, significant limitations can affect autograft usage, including risk of donor site morbidity such as ongoing pain or infection developing following surgery [1]. Furthermore, the amount of autograft tissue that can be harvested in a single patient is inherently limited. Alternative tissue sources are therefore often utilised, including allograft tissue which involves transplanting tissue from one person to another. Depending on the required tissue type, allograft tissue such as skin can be harvested from cadaveric or living sources, and can therefore provide greater volumes of donor tissue for clinical use than autograft sources. However, use of allograft usage carries risk of disease transmission and immune-mediated graft rejection; allograft tissue also lacks the cellular component found within autograft tissue that promotes tissue regeneration [2]. Synthetic biomaterials have also been used to aid soft tissue regeneration, including nerve guidance conduits and skin substitutes. However, limitations of their usage include incomplete integration with host tissue, lack of biological function and risk of further surgery being required.

Given the shortfalls of tissue grafts and other soft tissue reconstructive options, the search for novel, biological methods of soft tissue regeneration has intensified. As a developing technology, 3D biofabrication offers a novel approach to help ease the treatment burden of soft tissue injuries worldwide. Biofabrication as an approach combines biological constituents such as cells, growth factors and biomaterials with precise biomanufacturing techniques such as 3D cell printing, or bioprinting. Complex soft issue constructs can therefore be created de novo "from the bottom up." Regeneration of cartilage, skin, vasculature, nerves, tendons and other bodily tissues can be performed in a patient specific manner by incorporating clinical imaging and autologous cells into the biofabrication process, adding a significant and novel option to the armamentarium of reconstructive surgeons. 
This review will focus on recent use of 3D biofabrication techniques to regenerate cartilage and a range of soft tissue types found in the body. An initial overview of commonly used techniques for 3D biofabrication of cartilage and other soft tissues will be provided, with reference to currently available cell sources, bioinks and biofabrication platforms. A more detailed review of the biofabrication of individual soft tissues will then be provided, with tissues including cartilage, skin, vasculature, neural tissue and musculoskeletal tissue considered. Each soft tissue subsection will begin with a brief overview of the normal soft tissue structure and function, followed by discussion of the limitations of currently available reconstructive treatment options for each individual tissue. Following this, biofabrication of individual soft tissue types is reviewed, with recent and prominent examples of relevant tissue engineered constructs presented. Discussion will focus on the mechanical performance, biocompatibility, bioactivity, method of biofabrication and potential clinical translation of different soft tissue engineered constructs.

\subsection{Bioprinting and the tissue biofabrication process}

Bioprinting is a method of biofabrication, which can be defined as the production of complex living and non-living biological products from raw materials such as living cells, molecules, extracellular matrices, and biomaterials [3, 4]. Bioprinting involves the use of 3D printing technology to spatially pattern viable living cells and other non-living biologic materials [5]. Reconstruction of a patient defect using biofabrication begins with clinical imaging, typically magnetic resonance imaging (MRI) or computed tomography (CT) scanning (Fig. 1). A computer aided design (CAD) model of the patient defect can then be produced from initial clinical imaging.

Cells to be included in bioprinting can be harvested from a variety of sources, including patient blood samples; bone marrow, skin, adipose or other tissue biopsies; donor cells may also be used from other patients. Once a cell source is identified, culture techniques may be deployed to increase the number of cells available for use in the bioprinting process $[6,7]$. Following culture, cells are typically encapsulated in a bioink, along with selected biomaterials such as natural or synthetic polymers, cross-linking agents and growth factors [8-10].

Bioprinters can then be used to dispense the bioink in a precise, pre-determined 3D geometry based on a CAD model of a patient defect. Bioprinters are increasingly sophisticated, often combining multiple print nozzles with inbuilt sterile culture conditions; different bioinks and therefore a range 
of cells and biomaterials can therefore be safely dispensed with a high degree of spatial control to create heterogenous, 3D biological constructs $[4,8,9,11-16]$.

Bioprinted constructs can then be developed further in vitro through culture within biologically active culture environments known as bioreactors. Alternatively, constructs can be implanted directly into patient defects following bioprinting, or subjected to analysis and drug testing [17].

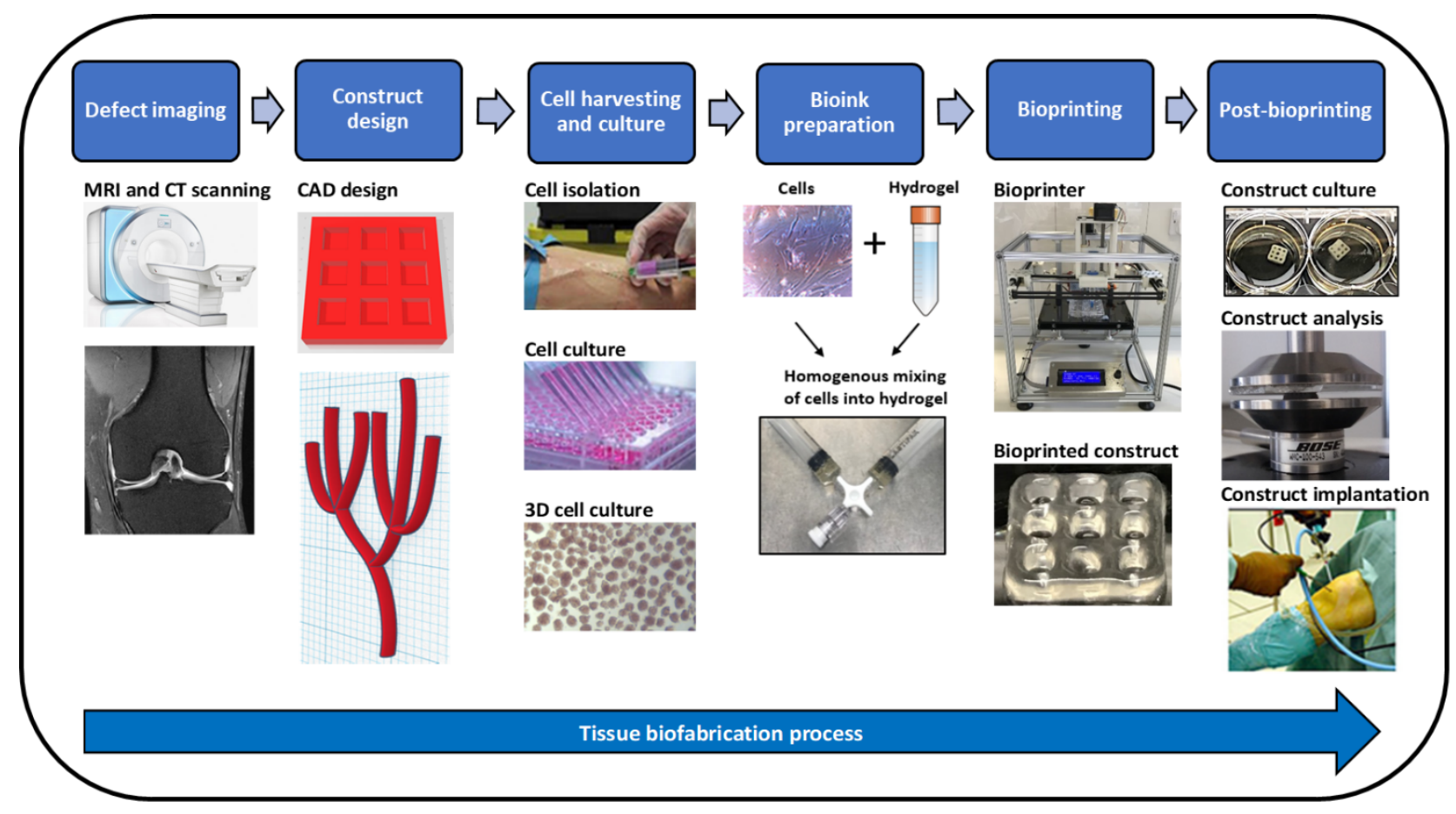

Figure 1. Tissue biofabrication process. Patient tissue defects are initially identified through clinical imaging techniques including magnetic resonance imaging (MRI) or computed tomography (CT) scanning. Computer aided design (CAD) software can then be used to reconstruct the defect for 3D bioprinting. Cells for bioprinting can be taken from blood samples, tissue biopsies or donor sources, and cultured to increase cell numbers available for bioprinting. Following culture, cells are encapsulated in bioink, along with selected biomaterials. Bioink cartridges are then inserted into a bioprinter, which can dispense the bioink in a pre-designed 3D geometry according to a CAD model. Bioprinted constructs can then be matured in vitro, analysed or implanted.

\subsection{Cell Source}

Soft tissues are composed of a range of different cells, which together contribute a range of biological functions that must be reproduced in bioprinted tissue. Soft tissue bioprinting may therefore incorporate multiple primary cell types when trying to replicate native tissue; alternatively, stem cells can be bioprinted and induced to differentiate into the range of cells present in mature adult tissue. To minimise the risk of immune response and disease transmission, cells included in bioinks are ideally autologous, derived from a specific patient for their own treatment. 
Following bioprinting, cells within tissue constructs must also be able to respond to tissue injury, maintain homeostasis and self-renew to ensure successful long-term function [18-20].

Thus far, stem cell types used in the biofabrication of soft tissues have included adult stem cells, embryonic stem cells (ESCs), induced pluripotent stem cells (iPSCs) [21, 22].

Embryonic stem cells originate from the preimplantation embryo and have the capacity to differentiate into somatic cells of all three germ layers. Consequently, ESCs can be used to derive all cell types found within soft tissues including vascular, neural and cartilaginous tissues amongst others [23-25]. Whilst ESCs have high proliferative capacity and pluripotency, they also require complex culture conditions to remain in an undifferentiated and proliferative state and can also cause immunogenic reactions [26]. Abnormal karyotypes can also develop following prolonged culture of undifferentiated ESCs, with risk of teratoma formation following implantation in vivo [2628].

Induced pluripotent stem cells (iPSCs) are stem cells created through the artificial dedifferentiation of adult somatic cells through exposure to selected transcription factors. iPSCs display similar pluripotency, gene expression profiles and ability to form embryonic bodies as ESCs, whilst overcoming the various ethical issues associated with the use of embryos in research. Whilst iPSCs are considered pluripotent, they have a lower differentiation capacity than ESCs and carry an increased risk of teratoma formation. Safer protocols and virus free iPSCs with reduced carcinoma risk have been developed, increasing the potential for use of iPSCs in soft tissue and cartilage regeneration in future [28-30].

Autologous adult stem cells are particularly attractive for inclusion in bioinks, owing to their increased availability relative to ESCs and potential to differentiate into the multiple cell types found in soft tissues. Furthermore, they can be isolated from various tissues including adipose tissue, bone marrow biopsies and peripheral blood samples [31]. Commonly used examples include adiposederived stem cells (ADSCs) and mesenchymal stem cells (MSCs), which can be differentiated into chondrocytes, osteocytes, endothelial cells, neural cells and adipocytes [32-36].

Many examples of successfully bioprinted MSCs already exist for the regeneration of skin, nerves, blood vessels and cartilage [13, 37-39]. Allogenic MSCs are capable of generating a local immunosuppressive microenvironment following implantation, resulting in only a weak immune reaction [40]. Use of autologous MSCs minimises the risk of immune rejection further, although notably for older patients the differentiation and proliferation capacity of autologous MSCs appear 
to be age-dependent [41, 42]. Following in vitro culture, there are also reports that MSCs display unstable phenotypes, reduced chondrogenic matrix formation, undesired mineralisation and cell death on injection $[41,42]$. Cell source also appears to influence MSC characteristics, with some reports suggesting that adipose derived MSCS (AD-MSCS) have higher proliferative capacity and apoptosis tolerance compared to bone marrow derived MSCs (BM-MSCs) [43, 44]. AD-MSCs can also be harvested at up to 500 times the density of BM-MSCs from equivalent volumes of tissue [40, 44], with biopsy from adipose tissue also involving a less painful and invasive procedure with lower risk of morbidity [7].

A range of fully differentiated adult cell types have also been utilised within biofabrication, including keratinocytes, chondrocytes, endothelial cells, fibroblasts and neural cells [4, 45-50]. This strategy has the advantage of avoiding the need to stimulate differentiation of stem cells into desired cell types within tissue constructs. However, some biofabrication attempts have included a mixture of differentiated adult cells and stem cells, seeking to combine the regenerative capacity of stem cells with the specific functionality of differentiated adult cells [51]. Within cartilage regeneration, cartilage progenitor cells have also been used, with favourable growth within gelatin methacryloyl (GelMA)-based hydrogels found as compared to chondrocytes [52].

Following selection of an appropriate cell source, the process of 3D cell culture can also be performed on harvested cells. This allows the creation of cell aggregates to occur, which typically have superior intercellular communication and development of extracellular matrix compared to cells grown in traditional 2D culture. Incorporation of cell aggregates or spheroids into bioinks therefore promotes the development of more mature, functional tissue after bioprinting [53, 54]. There are several examples of bioprinted spheroids used in the fabrication of cartilage, blood vessels and nerves [55-60].

\subsection{Bioinks}

Cells are usually encapsulated within a bioink prior to bioprinting. Bioinks provide cellular protection during the bioprinting process and mimic the extracellular matrix environment, providing a scaffold that promotes cellular adhesion, growth and differentiation following bioprinting [8]. Bioinks are most often created from hydrogels, which can be defined as hydrophilic, crosslinked threedimensional polymeric network structures. Hydrogels can absorb and retain up to 1000 times their original weight in water, making them ideal for supporting cell growth [61]. The high-water content of hydrogels also makes them highly permeable to factors critical for cell growth and survival, including oxygen, nutrients and other water-soluble compounds. Hydrogels are also readily 
amenable to undergoing 3D printing, making them hugely attractive materials for use in biofabrication applications [62-64].

Hydrogels used in biofabrication are most frequently derived from natural or synthetic polymers. Constituents of the extracellular matrix, including collagen, fibrin and hyaluronic acid have frequently been incorporated into hydrogels owing to their naturally high biocompatibility and inclusion of cell adhesion sites; decellularized extracellular matrix (dECM) has also shown promise as a hydrogel source for similar reasons [65-70]. Different combinations of naturally derived polymers have also been included together in bioinks to improve overall hydrogel printability and bioactivity [71]. However, use of natural polymers is subject to limitations, including the potential for uncontrolled degradation of the hydrogel network to occur, resulting in structural compromise of bioprinted constructs.

To improve the robustness of bioprinted constructs, composite hydrogels have been created incorporating synthetic polymers either alone or with natural polymers, allowing greater control over degradation rates and elastic moduli [72-74]. The bioactivity and cell binding of synthetic polymers has also be increased through surface functionalisation with bioactive molecules such as peptides, arginylglycylaspartic acid (RGD) and hyaluronan $[51,75,76]$. Bioactivity of bioinks can be increased further by addition of growth media, biomaterials, drugs, growth factors and nutrients [77-80]. Further features, such as tuneable mechanical stiffness, thermal and UV crosslinking and tailored degradability have been included in synthetic hydrogels for tissue engineering $[62,77,81$ 83]. A range of compounds have also been added to bioinks to modulate printability, mechanical properties, immune response and growth factor delivery, including clay [84] , hydroxyapatite [85] and modified chitin [86]. Within cartilage and soft tissue engineering, hydrogels have been shown to facilitate successful cartilage regeneration, angiogenesis, neurogenesis and skin production $[13,87-$ 92].

\subsection{Bioprinting Techniques}

A range of bioprinting techniques have been developed, allowing high cell viability to be achieved following bioprinting. Included amongst the most commonly used techniques are extrusion, laserassisted, microvalve and inkjet bioprinting [3, 4, 80, 93-95].

Inkjet bioprinting (or drop-on-demand bioprinting) was originally adapted as a technique from desktop inkjet printers and offers a low cost, high print speed option [96]. Inkjet systems rely on the controlled generation of thermal or acoustic forces to eject bioink droplets from a pint head nozzle 
in the same manner as commercial inkjet printers work (Fig. 2A). However, inkjet systems normally require low viscosity bioink, limiting the size of structure that can be bioprinted. Further limitations include the deleterious effects of exposing cells to thermal and mechanical stress during bioprinting, nozzle clogging and variability in droplet size achieved [97-99].

A
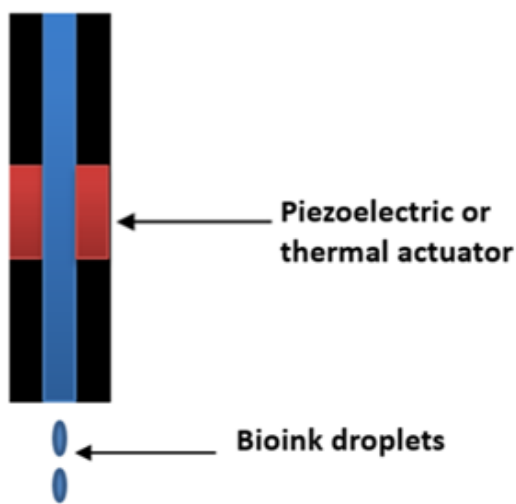

C

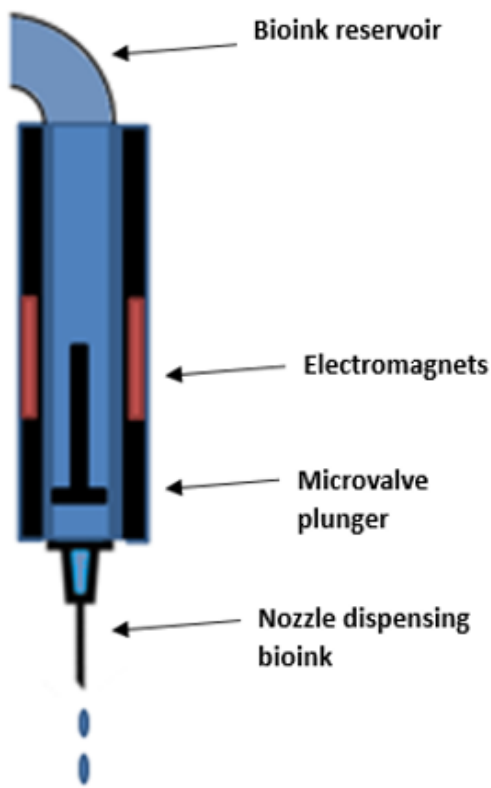

B

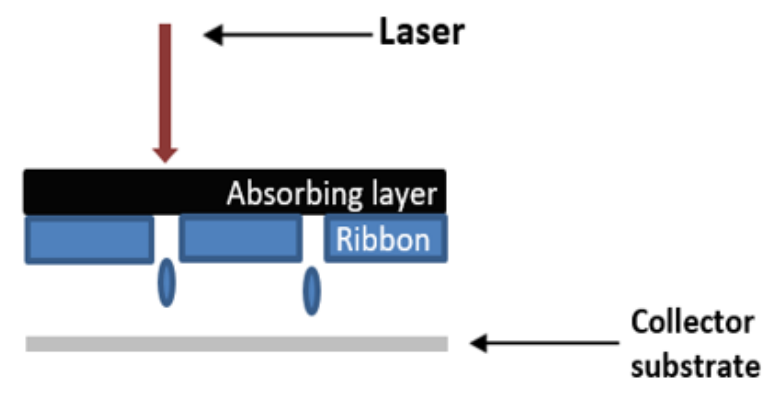

D

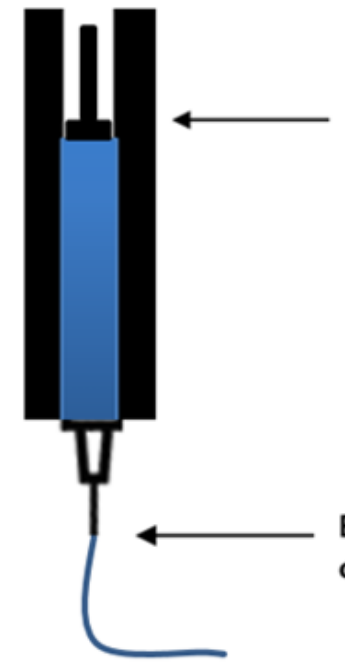

Downwards pressure from plunger or pneumatic source

Extruded filament of bioink

Figure. 2. Common bioprinting techniques: (A) Inkjet. (B) Laser-assisted. (C) Microvalve. (D) Extrusion bioprinting.

Laser-assisted bioprinting (LAB) systems (Fig. 2B) allow the printing of cells and liquid bioinks with cell-level resolution. Laser-induced forward transfer (LIFT) is a common method of LAB that requires a pulsed laser source, an absorbing layer or ribbon, and a collector substrate layer. Pulsed laser beams are initially directed to strike a support layer, often a metal film, inducing vaporisation. This in 
turn results in the release of a droplet of material from the attached ribbon, which is coated in cells and biomaterials to be bioprinted. The droplet containing cells and biomaterials is then deposited on the surface of the receiving substrate. This method allows picoliter-level resolution to be achieved in some cases, making it possible to control cell density and 3D organization down to the single cell level [100]. Limitations of LAB include potential thermal damage to cells during printing, the limited size of structures that can be produced, high running costs and the time required to create cell and biomaterial coated ribbons [101].

Microvalve bioprinting works by opening and closing a small valve to control the release of bioink from a cartridge under constant pneumatic pressure (Fig. 2C). Valve opening can be achieved mechanically, electrically or magnetically, whilst the volume of bioink that is deposited is dependent on nozzle diameter, valve opening time, and bioink viscosity. Microvalve printing can allow synchronized ejection of biomaterials and cells from different print-heads with very high resolution. However, some limitations affect the use of microvalve bioprinting, including the limited range of bioink viscosities that can be printed, potential for nozzle clogging, and changes in bioink cell density that can occur as cells tend to sediment to the bottom of the bioink reservoir. Nevertheless, microvalve systems have successfully printed a range of cells and biomaterials with high viability and resolution achieved $[94,95,102]$.

Extrusion bioprinting offers a different approach to the previously discussed bioprinting techniques, in that it deposits continuous filaments of material instead of using a "drop on demand" method to release individual drops of bioink (Fig. 2D). Typically, a pneumatic or mechanical force is applied to a bioink-filled syringe, resulting in the controlled extrusion of a bioink filament through a nozzle. Advantages of extrusion bioprinting include the capacity to deposit very high cell densities, low running costs, and the ease of including a range of different cell types within prints. The adaptability of extrusion bioprinting has allowed a large array of bioinks to be successfully bioprinted, with some studies even manging to extrude cell filaments without an encapsulating bioink [103]. Scalability and clinical translation are also facilitated by the high print speed possible. Limitations of extrusion include the inability to achieve the high print resolution of some drop on demand methods and cell survival decreasing when higher print pressures and shear stresses are generated (such as when high nozzle gauges or viscous bioinks are used) [10].

\subsection{Biofabrication techniques in soft tissue engineering}

$3 \mathrm{D}$ biofabrication techniques have undergone rapid development and innovation over the last decade $[3,4]$. Bioinks that incorporate beneficial physical and biological characteristics have been combined 
with multi-material and multi-nozzle bioprinting to fabricate increasingly complex structures [104]. However, biofabrication of soft tissue constructs remains challenging as bioinks generally lack the load bearing capacity to support their own weight without incorporation of harsh mechanical enhancement strategies $[9,105]$. A key challenge has been balancing the rheological properties of bioinks, required for printability and structural integrity, with the biocompatibility needed to ensure cellular viability and proliferation after bioprinting $[8,78,106]$.

To address this challenge, elegant approaches have been developed that rely on the use of either dissolvable scaffolding materials or biodegradable materials as sacrificial structures to support soft bioinks following bioprinting. Such techniques allow bioinks that would otherwise move and flow after bioprinting to be maintained in position and therefore be bioprinted with greater predictability. Cellular production of extracellular matrix and crosslinking processes can be allowed to occur before removal of supporting structures, leading to the development of complex, heterogenous, soft tissue constructs with greater structural integrity [19, 107-109].

\subsubsection{Fugitive Inks}

Dissolving "fugitive" hydrogels including the co-polymer pluronic F-127 have frequently been used to provide temporary support to mechanically weaker hydrogels (Fig. 3A) [110]. Fugitive inks have also been printed as a removable, internal scaffolds within a larger block of cell-laden, secondary hydrogel. The fugitive ink in this scenario can be triggered to liquify through a variation in temperature or simply dissolved, leaving patent channels behind within the larger hydrogel structure that can be perfused or seeded with cells and developed into vasculature [108].

\subsubsection{Support baths - the FRESH technique}

In the inverse of this approach, hydrogel support baths have been developed that allow the bioprinting of low viscosity bioinks to occur (Fig. 3B). This approach typically involves bioprinting into a secondary support bath; once cross-linking of the bioprinted bioink has occurred, the support bath can be liquefied, leaving behind a cross-linked structure. A notable example of this approach is provided by Hinton et al., who developed a novel technique allowing bioprinting of complex structures from low viscosity bioinks, termed freeform reversible embedding of suspended hydrogels (FRESH) [111]. 


\subsubsection{Removable rods and needles - the Kenzan method}

Removable rods and needles have also been used to provide structural support to bioprinted tissue constructs [112-114]. Itoh et al. created a temporary scaffold to supporting the fusing of cell spheroids by positioning metallic needles in a circular array (Fig. 3C). Termed the Kenzan method, this approach permitted the fusing together of smooth muscle cell and fibroblast spheroids $(650 \mu \mathrm{m}$, diameter) during culture; when the metallic support needles were removed following culture, a cellular, rigid tubular structure had been created $[115,116]$. In a similar approach, Norotte et al. successfully made use of agarose rods to support the rapid fusing together of high cellular density cylinders into a tubular construct (Fig. 3D) [117].

\subsubsection{Use of biodegradable materials to guide cell growth}

Biodegradable nanofibers have also been used to direct cellular growth towards mature tissue [112, $118,119]$. Choi et al. electrospun poly(epsilon-caprolactone) (PCL)/collagen nanofibers and seeded them with human skeletal muscle cells (hSkMCs). Compared to when cells were seeded on to randomly oriented nanofibers, the use of unidirectionally oriented nanofibers was observed to significantly induced muscle cell alignment and myotube formation. This technique therefore has potential to treat clinical muscle defects by providing either implantable scaffolds for muscle regeneration or biofabricated functional muscle tissues.

\subsubsection{Coaxial printing}

Coaxial printing has been widely deployed as a technique to create microtubular, soft tissue constructs [120,121]. Coaxial nozzles possess an inner and outer orifice, allowing an inner crosslinking agent to be extruded alongside an outer hydrogel shell. This allows rapid cross linking of the outer shell to occur, creating a hollow tube of a diameter determined by the print nozzle (Fig. 3E) $[122,123]$. In some instances multiple orifices have been incorporated into the coaxial needle, allowing cross-linking perfusion to occur in more than one direction during extrusion [124]. Whilst coaxial printing can rapidly create very long conduits, production of more anatomical, bifurcating structures with the hierarchical layers seen in native blood vessels or nerves remains challenging using this technique.

\subsubsection{Scaffold-free approaches - use of spheroids, cell sheets and tissue filaments}

Scaffold-free approaches to the biofabrication of soft tissues have also been developed. Okano et al. developed a successful method of fabricating cell sheets without the use of biodegradable scaffolds. 
Cell culture on temperature-responsive dishes allowed intact cell sheets to be harvested by simply reverting the culture dish temperature from $37^{\circ} \mathrm{C}$ to room temperature, triggering cell release and avoiding the use of proteolytic enzymes (Fig. 3F). Single cell sheets can potentially be directly transplanted onto host tissue defects, such as burns or other skin defects, to aid tissue regeneration; alternatively multi-layered cell-sheets can be biofabricated in vitro prior to clinical use [125]. Larger constructs including vascular grafts have been successfully fabricated by placing layer upon layer of cell sheets together $[126,127]$. By avoiding the use of additional bioinks or scaffolds, this approach minimises the risks of host inflammatory responses occurring [128].

In a similar approach to fusing sheets of cells together, smaller micro-units of cell laden hydrogels have been used as building blocks to create larger tissue constructs in a "micro-masonry" concept $[129,130]$. This approach allows for a high degree of modularity, as a range of hydrogelencapsulated cells be deposited side by side as micro-units with a high degree of precision, to create larger cell-laden constructs [131].

Cell pellets, spheroids and tissue strands have also been used as building blocks to create more complex tissue constructs. Various methods have been used to assemble cell aggregates or spheroids, including culture moulds, cell suspensions and hanging droplet techniques $[53,55,132$, 133]. Spheroids bioprinted in close proximity have successfully fused and matured together to form larger tissue constructs, including functional thyroid gland tissue [134, 135]. Tissue filaments have also been successfully bioprinted to create larger patches of tissue, with Yu et al. bioprinting chondrocyte filaments together to form a larger, fused cartilage patch [103]. Cellular fibres have also been woven together to create cellular fibre scaffolds [136].

\subsubsection{Moulding, dip-coating and rod support methods}

Moulding techniques have also been used to direct the maturation of 3D tissue constructs (Fig. 3G). Pacak et al. cast a mixture of skeletal muscle cells, type 1 collagen, Matrigel ${ }^{\mathrm{TM}}$ and $\mathrm{NaHCO}_{3}$ onto silicon moulds. After one to two days, solidified myoblast-containing tissue constructs could be harvested for in vitro use [137]. Tabriz et al. developed a rapid method of moulding tubular structures by dip-coating metal bars covered in cell-laden alginate hydrogels into cross-linking solutions, including calcium chloride or barium chloride (Fig. 3H). Following cross-linking, cell-laden hollow tubular structures could be released from the metal bars [138, 139]. A similar methodology was developed by Wilkens et al., who utilised motors to rotate and dip the metal rods (Fig. 3I). This approach allowed a high level of control over individual layer thickness within vessels, with use of 
rod-supports allowing successful production of a structural configuration closely resembling natural blood vessels (Fig. 10B) [140].

\section{A Fugative Inks}

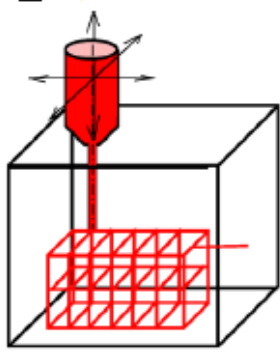

Self supporting network printed

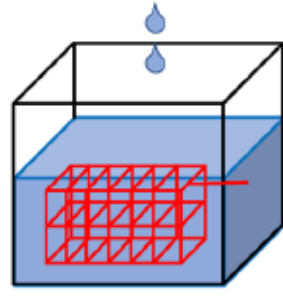

Encapsulated in cell laden hydrogel

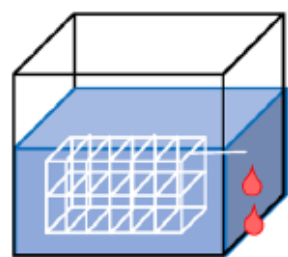

Network ink evacuated and endothelialised to create vascularised tissue

\section{B FRESH printing}

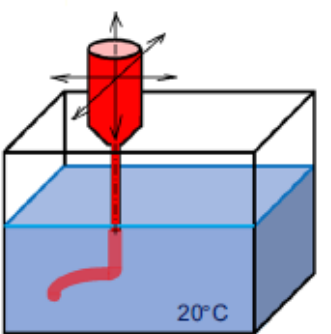

Bath gel behaves as a rigid material at low shear stresses, supporting printed material, and a viscous fluid at high shear stresses, permitting nozzle movement.

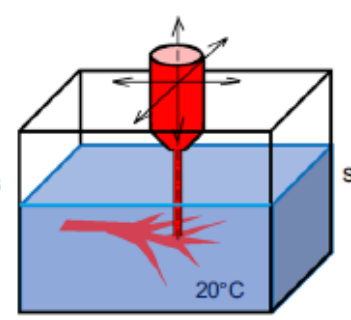

Cell laden gel is printed into the supporting hydrogel in complex tubular geometries.

\section{Kenzan method}

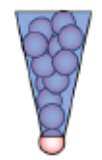

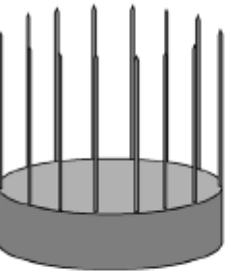
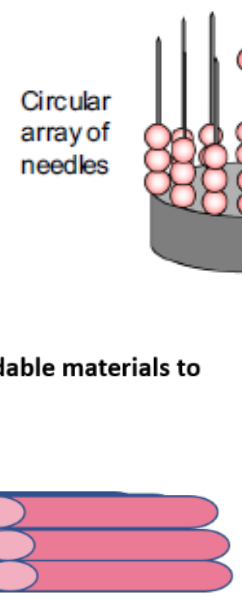

D Use of biodegradable materials to guide cell growth
Cell laden tubes deposited alongside inert support tubes

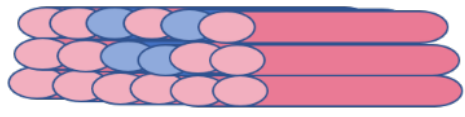

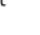
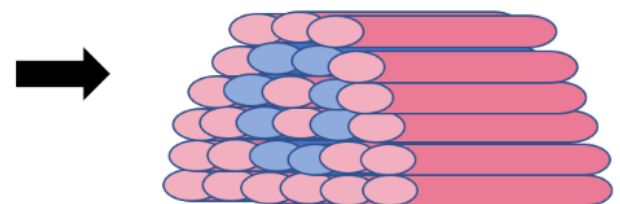

Cell laden tubes allowed to fuse with support from inert tubes

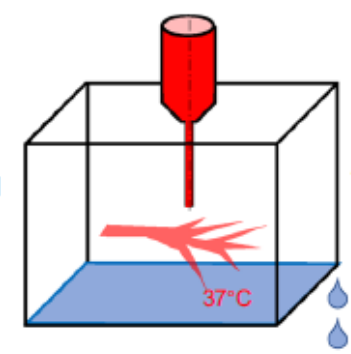

Elevation of temperature melts the hydrogel leaving the self-supporting printed structure

E Use of coaxial nozzle
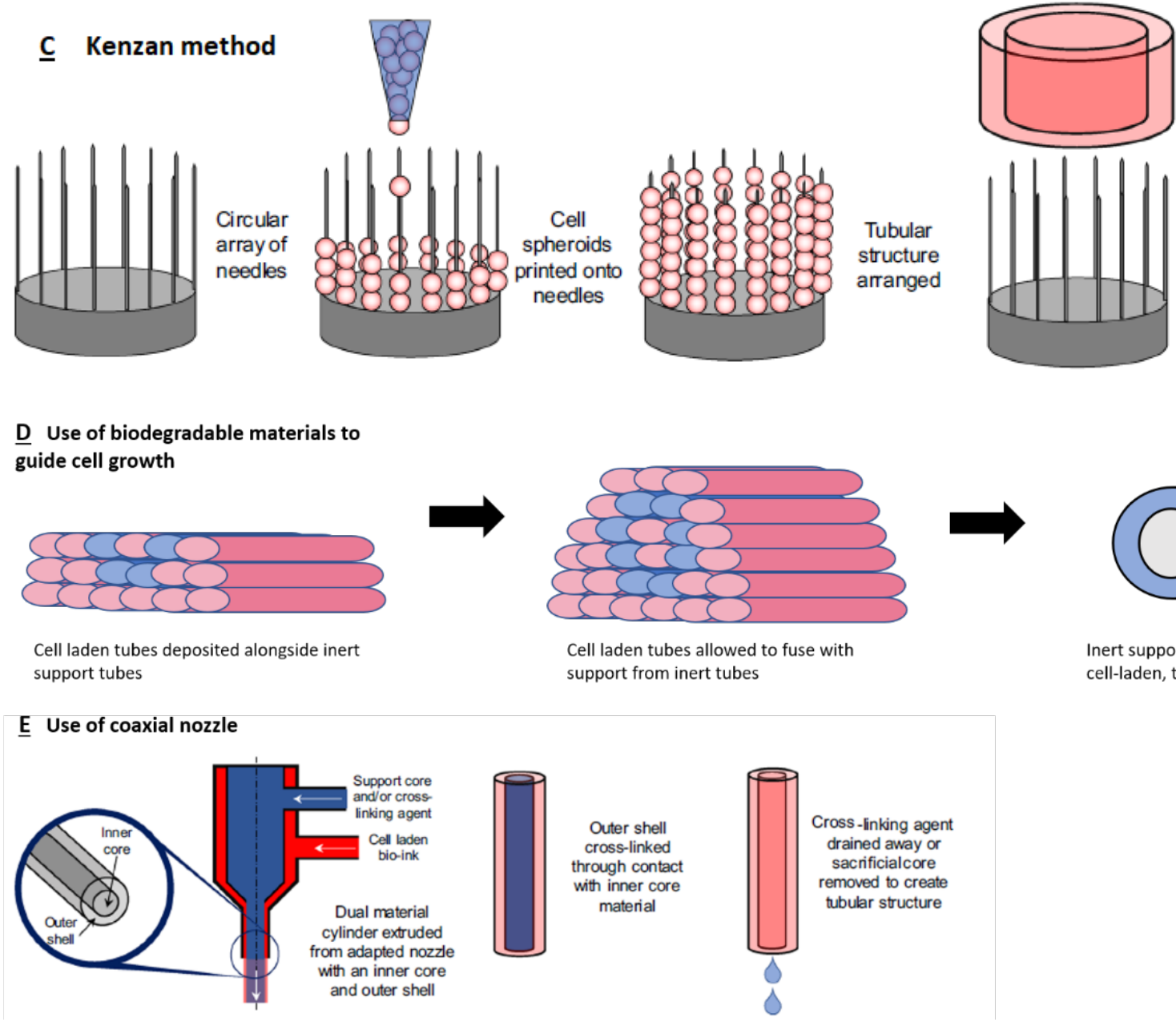

Culture in bio

reactor fuses

spheroids

together and structure allows removal of needles 
F Production of cell sheets and assembly into layered constructs

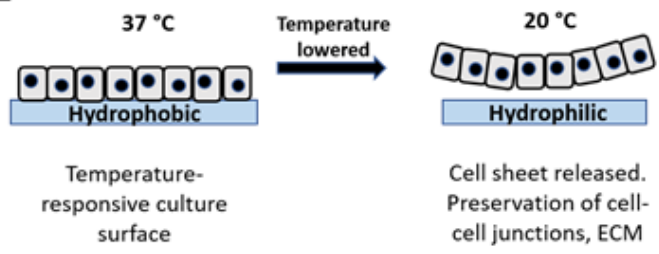

$\underline{\mathbf{G}}$

Moulding of cell-laden hydrogels into constructs

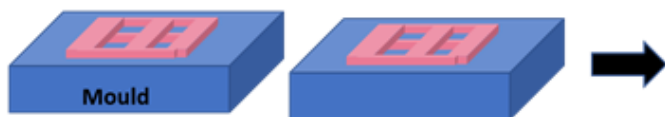

Cell-laden hydrogel dispensed into removeable silicon or fugitive ink mould

\section{H Dip-coating}
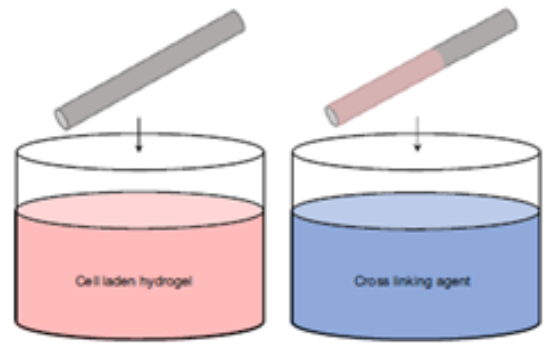

Repeated operations into different hydrogels can build up a tube composed of multiple thin distinct layers
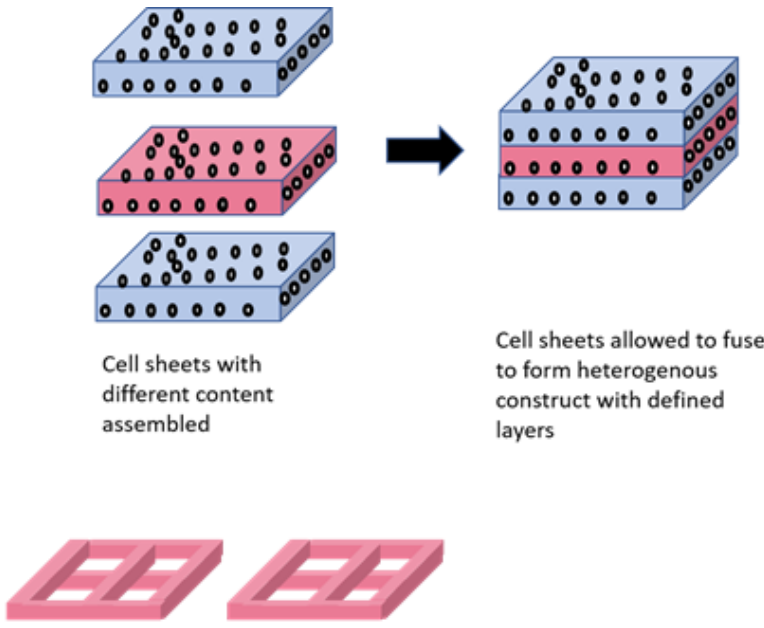

Mould composed of silicon or fugitive ink removed to leave cell-laden hydrogel constructs behind

\section{Rod support}

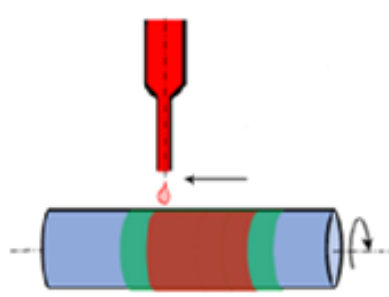

Cell laden hydrogel extruded onto a rotating rod with a release agent substrate

Figure 3. 3D biofabrication techniques allowing bioadditive manufacture of soft tissue structures. $(A)$

Vasculature network creation using fugitive inks. (B) Freeform reversible embedding of suspended hydrogels (FRESH) printing. (C) Kenzan printing of cell spheroids onto needles. (D) Use of biodegradable materials to guide tissue formation. (E) Coaxial tube or filament formation from a modified nozzle. (F) Use of cell sheets to create layered constructs. (G) Use of moulds to allow cell-laden hydrogels to develop into constructs. (H) Dipcoating to create tubular structures. (I) Rod support printing. Adapted from Holland et al. [49]. 


\section{Bioprinted Tissues}

\subsection{Cartilage}

Due to the prevalence of cartilage lesions and arthritis worldwide, and limitations of current treatment options, significant efforts have been made to develop novel strategies to aid cartilage repair. The following section will review cartilage structure, function and currently available techniques of repair before considering recent attempts at cartilage biofabrication.

\subsubsection{Cartilage function and structure}

Articular cartilage (AC) is a highly specialised connective tissue found within articulating joints. It principally acts to facilitate the smooth movement of opposing joint surfaces, providing a lubricated surface with a low frictional coefficient. Despite being only 2 to $4 \mathrm{~mm}$ thick, viscoelastic properties and a deceptively intricate structure also allow $A C$ to shield underlying bone from some of the mechanical stresses applied during locomotion. Structurally, AC can be divided into four zones based on the orientation of type II collagen fibres and proteoglycan content (Fig. 4). The superficial zone (SZ) makes up $10 \%$ to $20 \%$ of AC thickness and has significant tensile properties, containing a high number of flattened chondrocytes and sparse proteoglycans [141]. The middle zone represents $40 \%$ to $60 \%$ of cartilage volume and provides resistance to compressive forces. Thick collagen fibrils are orientated in an oblique or random fashion, with spherical chondrocytes present at low density alongside abundant proteoglycans [142]. The deep zone acts to provide resistance to compressive forces, with large diameter collagen fibrils and round chondrocytes arranged perpendicular to the articular surface. [143]. Below the deep layer a tidemark interface marks the transition between AC and bone, with collagen fibrils anchoring AC to subchondral bone [144].

\subsubsection{Current techniques of cartilage repair}

Despite possessing a highly developed structure, $\mathrm{AC}$ is frequently damaged by acute trauma, chronic repetitive overloading and degenerative processes. However, AC is devoid of blood vessels, nerves or lymphatics and has limited cellular content [142]. These features result in a poor intrinsic capacity for healing and repair, with $5-10 \%$ of people over 40 having high grade AC lesions. Symptoms of pain, instability and mechanical locking can develop, with arthroscopic surgery performed in over 
150000 patients annually in the UK on major joints including the shoulders, knees and ankles [145]. Several techniques can be deployed to treat cartilage defects surgically.

\subsubsection{Microfracture}

Microfracture (MF) involves making multiple holes, or "microfractures," in the subchondral bone underlying full-thickness chondral defects (Fig. 5A). Bone marrow oozes from the holes to form a "super clot" over the cartilage defect, providing an enriched environment for cartilage regeneration [146]. Despite being a relatively cost and time efficient procedure, microfracture most often results in the production of biomechanically inferior fibrocartilage. The fibrocartilage produced typically deteriorates within 24 months as it is exposed to mechanical joint forces; treatment of large defects and lesions in the patellofemoral joint is particularly associated with risk of cartilage deterioration more than 5 years after surgery [147].

\subsubsection{Mosaicplasty}

Mosaicplasty involves the transfer of one or more cylindral osteochondral autografts from a low weight-bearing area of the knee towards a defective site (Fig. 5B). Grafts are harvested by miniarthrotomy and then press-fit into recipient sockets drilled into areas of defective cartilage; grafted cartilage is therefore flush with the surrounding cartilage surface and fills the previous defect [148]. Mosaicplasty is generally restricted to young patients (under 50) with symptomatic cartilage defects under $3 \mathrm{~cm}$ in diameter; limitations include management of joint congruency, achieving osteointegration and inability to treating large lesions $[149,150]$.

\subsubsection{Autologous chondrocyte implantation $(\mathrm{ACl})$ and matrix-induced autologous chondrocyte implantation (MACl)}

Due to the shortcomings of microfracture and mosaicplasty, other techniques have been developed including autologous chondrocyte implantation $(\mathrm{ACl})$ and matrix-induced autologous chondrocyte implantation (MACl) (Fig. 5C). ACl involves two procedures; in the first, a cartilage biopsy is harvested to provide a chondrocyte population that is then expanded in vitro, yielding up to 50 million chondrocytes [151]. During a second procedure via an open incision, the cartilage defect is debrided, removing damaged cartilage to expose fresh subchondral bone. The previously harvested chondrocytes that have been expanded in vitro can then injected into the defect site, secured beneath a periosteal flap or collagen membrane $[152,153]$. ACl has the benefit of using a patient's own cells, as well as minimising the size of initial biopsy taken, compared to techniques such as 
mosaicplasty (Fig. 5B). In MACl, harvested populations of autologous chondrocytes are incubated on absorbable porcine-derived type I and III collagen matrices before implantation; these matrices help to direct and stimulate autologous chondrocyte growth before implantation, whilst maintaining cell phenotype and viability [154]. Drawbacks to $\mathrm{ACl}$ and $\mathrm{MACl}$ include the need for two operations, cost and the prolonged recovery time required to ensure neotissue regeneration $[151,155,156]$.

\subsubsection{Limitations of current treatment options}

Current arthroscopic repair techniques (Fig. 5) unfortunately have critical limitations including the potential to result in mechanically inferior fibrocartilage formation, ongoing pain and morbidity, and an inability to treat globalised AC destruction [157-159]. Over 180000 patients therefore require total joint replacement surgery in the UK annually, a major operation which can result in incomplete satisfaction and residual symptoms, particularly in younger patients [160-163]. A rising number of patients also face the prospect of requiring revision joint replacement, a technically more complex and costly procedure with generally inferior clinical results [164-169]. Extensive efforts have therefore been made to search for novel and alternative strategies to aid and promote cartilage repair. In the following sections, recent use of biofabrication strategies including $3 \mathrm{D}$ bioprinting to promote cartilage repair will be covered. 


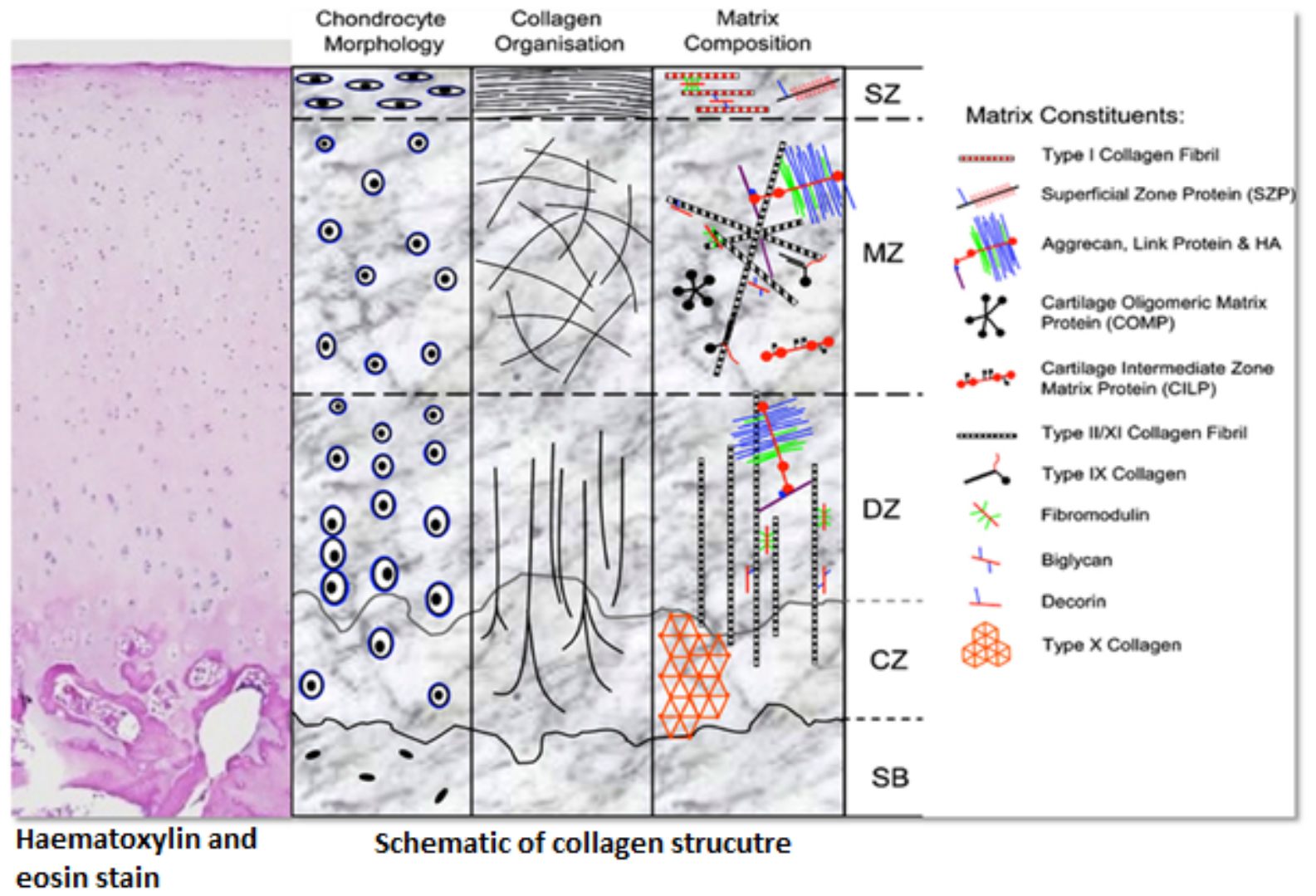

Figure 4. Hyaline cartilage haematoxylin and eosin stain, morphology and structure. SZ, superficial zone; MZ, middle zone; DZ, deep zone; CZ, calcified zone; SB, subchondral bone. Adapted from Di Bella et al. [170]. 


\section{A Bone marrow stimulation: Microfracture}

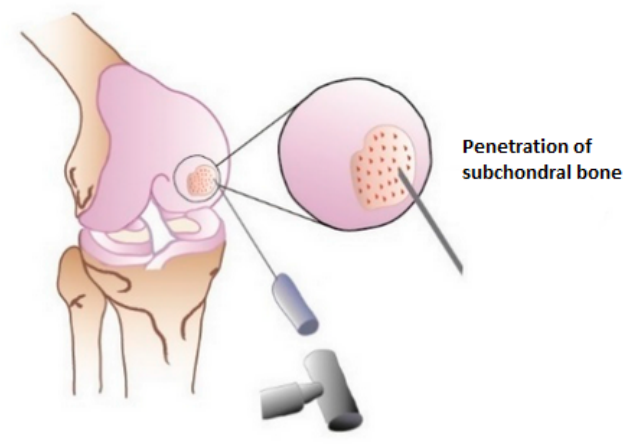

B Mosaicplasty

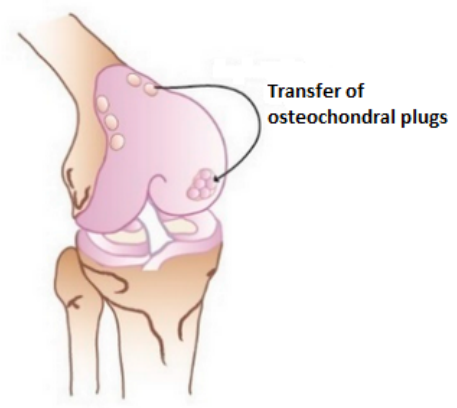

C Autologous chondrocyte implantation ( $\mathrm{ACl}$ ) and matrix-assisted chondrocyte implantation (MACI)

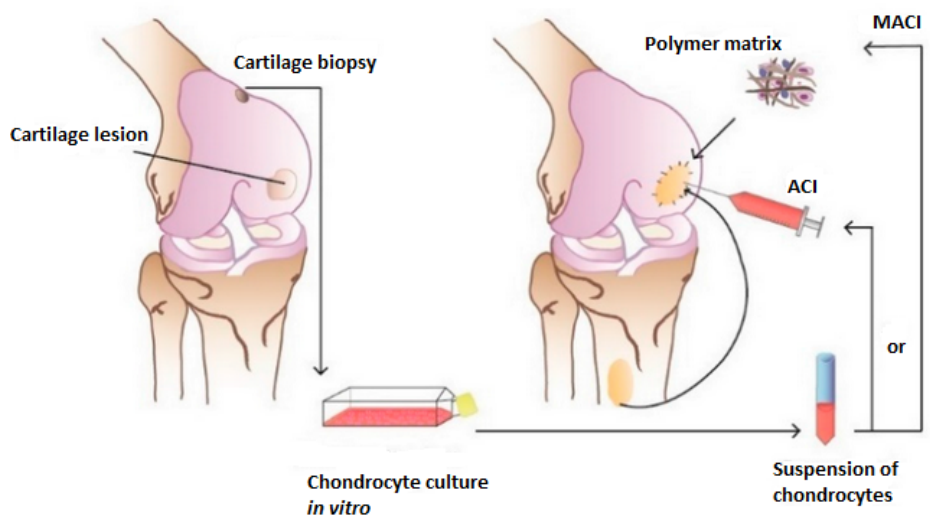

Figure 5. Schematic representation of current regenerative cartilage repair techniques: (A) Microfracture (MF) involves making multiple holes, or "microfractures," in the subchondral bone underlying full-thickness chondral defects. The released bone marrow forms a "super clot" that provides an enriched environment for tissue regeneration [146]. (B) Mosaicplasty is performed by patching up articular cartilage defects using cylindral osteochondral autografts taken from donor, low weight-bearing areas in articular joints. (C) Autologous chondrocyte implantation is performed by injecting a suspension of previously harvested autologous, cultured chondrocytes into a cartilaginous defect, usually beneath a periosteal flap or membrane (ACl). Matrix-assisted chondrocyte implantation (MACl) advances $\mathrm{ACl}$ by incorporating chondrocyte cells into a type-I/III collagen scaffold during the culturing process. Adapted from Jeuken et al. [171].

\subsubsection{Biofabricating cartilage}

The layer-by-layer approach used in many biofabrication strategies to regenerate tissue seems well suited to the task of recreating the intricate, layered structure of cartilage. However, several challenges exist when using a hydrogel-based approach to printing cells. To enable high resolution and consistent printing, hydrogels must display rapid gelation, minimal extrudate swell post-printing and shear-thinning properties $[8,172]$. Although hydrogels replicate the ECM by providing a hydrated environment, they are also limited by low compressive stiffness $[105,173,174]$. Attempts 
have therefore been made to create composite bioinks for cartilage regeneration, by combining the favourable biocompatibility of naturally derived polymer hydrogels with the superior mechanical strength of synthetic biomaterials $[13,45,46,175,176]$.

\subsubsection{Natural polymer bioinks for cartilage regeneration}

Several examples exist of bioinks created for cartilage regeneration from combinations of different natural polymers, as researchers seek to optimise the bioactivity and mechanical properties of bioinks.

Daly et al. evaluated the cartilage regenerative capacity and 3D printability of a range of bioinks including GelMA, BiolNK ${ }^{\mathrm{TM}}$ (a Poly(ethylene glycol) monomethacrylate based hydrogel), agarose and alginate [177]. Formation of articular hyaline-like cartilage was best supported by agarose and alginate hydrogels seeded with MSCs, whilst more fibrocartilage-like tissue was seen to develop with use of GeIMA and BioINK ${ }^{\text {Tw }}$. In terms of printability, GelMA allowed generation of structures with the greatest fidelity, followed by the alginate and agarose bioinks. MSC cell viability was high in all bioinks post-printing ( 80\%)[177].

As a biocompatible and readily available hydrogel, alginate has been incorporated into several investigations of cartilage biofabrication $[13,178]$. Yang et al. mixed either agarose (AG) or collagen type I (COL) with sodium alginate (SA) to create a bioink for bioprinting chondrocytes. Compared to use of SA alone, mechanical strength was improved in both SA/COL and SA/AG hydrogels. The phenotype of chondrocytes was also maintained more effectively in the SA/COL composite bionk compared to SA and SA/AG bioinks [179]. Markestedt et al. blended nanocellulose with alginate (NFC/A) to bioprint chondrocytes (Fig. 6). This combined the desirable, shear thinning properties of NFC with the fast crosslinking capacity of alginate, allowing high fidelity microvalve bioprinting to occur. Using MRI and CT data to create anatomical models, they were able to successfully bioprint scale models of human ears and sheep meniscus with high cell viability found after 7 days [180]. Nguyen et al. also designed bioinks containing nanocellulose with alginate (NFC/A), comparing performance to bioinks composed of nanocellulose with hyaluronic acid (NFC/HLA). Hyaluronic acid was included for its chondrogenic potential, whilst NFC was postulated to help mimic the natural ECM in cartilage. Microvalve bioprinting was again utilised, with Human-derived iPSCs and human chondrocytes successfully bioprinted together [181]. Analysis of the iPSCs found good maintenance of pluripotency after bioprinting in the NFC/HLA bioink, although cell proliferation was relatively slow. By contrast, the NFC/A bioink facilitated good cell growth of the iPSCs and chondrocytes over a 5-week period, with development of hyaline-like cartilaginous tissue seen to occur alongside 
increased cell expression of type II collagen. Park et al. investigated cartilage regeneration using chondrocytes and a composite bioink containing oxidized alginate and HLA (AL/HLA), performing in vivo analysis using nude mice [182]. Chondrocyte-loaded AL/HLA gels were injected subcutaneously into nude mice and examined after 6 weeks of implantation. Histological analysis showed effective cartilage regeneration in the AL/HLA bioink, with significant expression of chondrogenic genes aggrecan, type II collagen, and SOX-9 and elevated glycosaminoglycan deposition compared to control scaffolds. In a further analysis of AL/HLA scaffolds crosslinked with calcium, Park et al. observed that increased scaffold stiffness aided maintenance of chondrocyte differentiation, whilst addition of HLA also aided chondrocyte differentiation compared to use of pure alginate scaffolds [91].

Gelatin methacryloyl (GeIMA) hydrogels have been widely adopted in cartilage biofabrication due to their tuneable physical characteristics and possession of degradable peptide motifs, which facilitate cell adhesion and proliferation [183]. Costantini et al. mixed different combinations of GelMA, chondroitin sulfate amino ethyl methacrylate (CS-AEMA) and hyaluronic acid methacrylate (HAMA) to produce bioinks for chondrocyte bioprinting [184]. Bioinks were loaded with MSCs and crosslinked by including $4 \%$ alginate and $0.3 \mathrm{M} \mathrm{CaCl}_{2}$ solution. A two coaxial-needle bioprinting system was chosen to print the inks, allowing a high cell density and viability to be achieved postprinting. All the hydrogels investigated appeared to support chondrogenic differentiation of MSCs after 3 weeks culture in chondrogenic medium. However, the highest levels of collagen production and greatest neocartilage formation was seen to occur in a composite hydrogel of alginate, GelMA and CS-AEMA.

Focussing more on the role of cell type in successful cartilage biofabrication, Levato et al. used GelMA-based hydrogels to investigate the results of bioprinting articular cartilage-resident chondroprogenitor cells (ACPCS), MSCs and chondrocytes for cartilage regeneration [185]. ACPCS were found to have the greatest levels of neo-cartilage production and had higher levels of expression of PRG4, a key factor in joint lubrication, compared to MSCs. Building on this finding, a bilayered construct was then bioprinted containing ACPCs in one layer and MSCs below them in another layer. This replicated the zonal architecture of native cartilage at a basic level, with a different ECM and cellular content successfully produced in each zone and chondrogenesis supported [185]. 
A

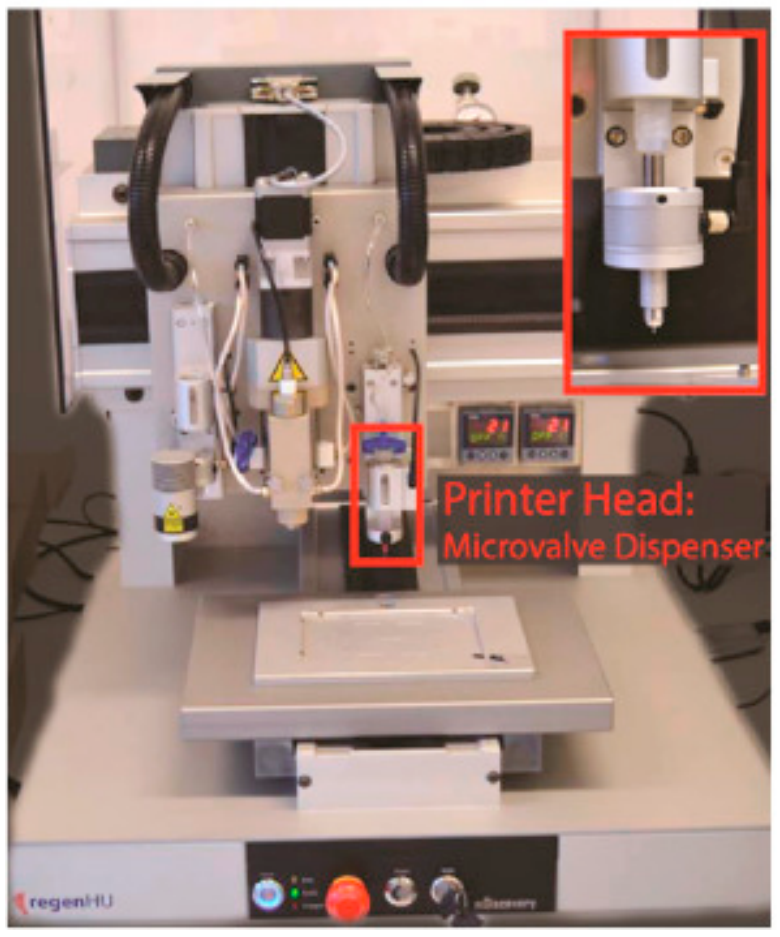

B

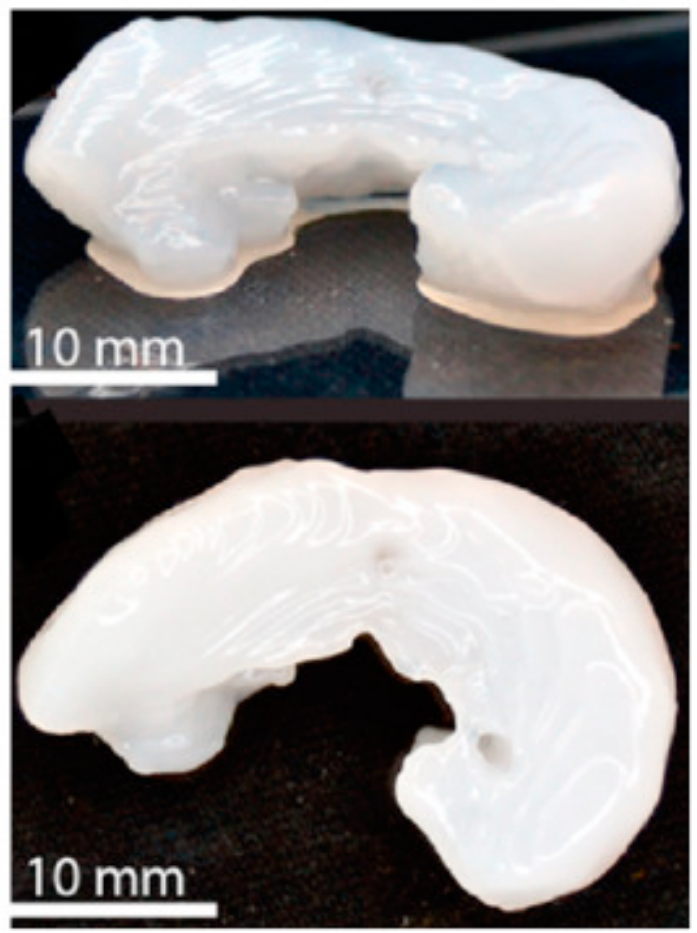

Figure 6. Microvalve bioprinting of cartilaginous structures. (A) The microvalve RegenHu 3D Discovery (Switzerland) bioprinter. (B) Anatomical 3D knee meniscus bioprinted using the composite nanocellulose and alginate (NFC/A) bioink containing chondrocytes. Adapted from Markestedt et al. [180].

\subsubsection{Synthetic polymer composite bioinks for cartilage regeneration}

Whilst natural polymers used in bioinks provide bioactivity and a degree of biomimicry of the native ECM, synthetic polymers provide superior mechanical strength and structural integrity [13]. Interest has therefore grown in the potential to combine the mechanical performance of synthetic polymers with the favourable bioactivity of natural polymers in composite bioinks $[8,104]$.

Bahcecioglu et al. recently attempted to engineer meniscus replacements, impregnating a PCL meniscus scaffold with agarose $(\mathrm{Ag})$ and GelMA hydrogels in the inner and outer regions respectively [45]. Glycosaminoglycan (GAG) production appeared to be enhanced in Ag areas of the scaffold, whilst GeIMA supported enhanced collagen production of fibrochondrocytes over an 8-week period. Furthermore, incorporation of hydrogels into the PCL scaffold was shown to protect cells from mechanical damage under dynamic loading conditions. In summary, a meniscus-like structure was engineered with potential for clinical use. 
Shim et al. used a multi-headed 3D bioprinter to create MSC-Iaden, collagen and hyaluronic acid hydrogel constructs reinforced by PCL[186]. Designed to replicate an osteochondral plug, the biofabricated constructs appeared to integrate well with local bone and cartilage and remain mechanically stable following implantation in a rabbit knee. A porous, 3D PCL network was initially printed and an MSC-rich atelocollagen solution with added rhBMP-2 was dispensed into the bottom $4 \mathrm{~mm}$ of the PCL network, to create an osteogenic layer. Immediately above the osteogenic layer, a hyaluronic-acid-based solution containing MSCs and TGF- $\beta$ was dispensed to create a $1 \mathrm{~mm}$ thick top layer to support chondrogenesis. Integration with host tissues was demonstrated by strong positive staining for calcium deposition, collagen deposition, cell viability and observation of excellent neocartilage formation comparted to PCL control scaffolds [186].

Castro et al. also attempted to create a construct capable of replicating the osteochondral interface. Using a custom-built stereolithography 3D printer and tailored nano-ink, they created a construct with cartilaginous and osseous layers [187]. A cartilaginous layer was created from polyethylene glycol (PEG) diacrylate hydrogel, core-shell poly(lactic-co-glycolic) acid (PLGA) nanospheres and chondrogenic transforming growth-factor $\beta 1$ (TGF- $\beta 1$ ). An osseous layer was also fabricated from nano-crystaline hydroxyapatite nanoparticles. Human bone marrow derived MSCs were directed to undergo chondrogenic and osteogenic differentiation in vitro within the biomimetic, bilayered osteochondral construct [187]. Bernhardt et al. used joint freeze-drying and crosslinking processes to produce biphasic scaffolds using fibrillated jellyfish collagen and biomimetically mineralized salmon collagen. By varying cell densities, applying alginate to the chondral section, predifferentiating cells and using osteogenic media, chondrogenic and osteogenic differentiation was supported in scaffolds fabricated exclusively from marine collagens [188].

Groll et al. utilised a UV crosslinking approach and a synthetic polymer to optimise the printability of hyaluronic acid for chondrogenesis. Allyl-functionalized poly(glycidol)s (P(AGE-Co-G)) was chosen as a cell-friendly cross-linker for thiol-functionalized hyaluronic acid (HA-SH), with incorporation of thermoplastic poly( $\varepsilon$-caprolactone) (PCL) and high molecular weight HA (1.36 MDa) also performed to create mechanically stable constructs for articular cartilage regeneration [189]. Human and equine mesenchymal stem cells (MSCs) cultured in the gels for 3 weeks both demonstrated significant chondrogenic differentiation.

Gao et al. co-printed an acrylated PEG hydrogel with acrylated peptides using an inkjet bioprinter, with ultraviolet light used to initiate photopolymerization of the hydrogel during printing [37]. Excellent MSC viability of $87.9 \pm 5.3 \%$ was observed 24 hours after printing. After 21 days culture in 
chondrogenic media, a significant increase in chondrogenic gene expression and compressive moduli was also seen, alongside abundant collagen and extracellular matrix deposition. The compressive modulus of the printed PEG-Peptide hydrogel was also found to be over 100 times higher than that of some natural hydrogels, exceeding $500 \mathrm{kPa}[190,191]$.

Malda et al. reinforced a GelMA hydrogel matrix with PCL microfibers produced using a meltelectrospinning direct writing process [192]. This approach allowed production of PCL filament diameters as small as $5 \mu \mathrm{m}$, whilst the stiffness and deformation profile (shape of the stress-strain curve) of GelMA could be tailored to mimic native cartilage through PCL reinforcement. Furthermore, the tuneable scaffold supported good cell viability after 7 days in vitro culture.

\subsubsection{Scaffold free approaches}

Although hydrogels are frequently used to facilitate cartilage biofabrication, self-assembly approaches have also been developed recently which use increasingly novel techniques to direct cartilage tissue development without the use of supporting scaffoldsm[58, 193].

Yu et al. developed an interesting approach in bioprinting "tissue strands" without a hydrogel support to facilitate fabrication of biomimetic cartilaginous tissues (Fig. 7) [58]. Initially, harvested chondrocytes were expanded in number and then microinjected into long, tubular alginate capsules created using a co-axial nozzle. Chondrocytes were triggered to aggregate within the tubular alginate capsules, developing long strands of cylindrical cartilaginous tissue. Once matured, the tissue strands were released by dissolving the alginate tubes, leaving stands of cartilage which could then be 3D bioprinted through a specially adapted extrusion nozzle. Strands of cartilage printed layer-by-layer were seen to unite and form larger cartilaginous structures. This approach therefore utilised the self-assembly properties of chondrocytes to develop native-like scale-up cartilaginous tissues. By avoiding the need for a liquid delivery medium during extrusion, and instead printing tissue strands, tissue bioprinting in solid form was achieved in a novel approach [58].

In a further novel, self-assembly approach, Parfenov et al. performed scaffold-free, nozzle-free and label-free magnetic levitation of tissue spheroids to form cartilaginous tissue [193]. Chondrospheres produced from primary sheep chondrocytes using non-adhesive culture were exposed to gadolinium $\left(\mathrm{Gd}^{3+}\right)$ in culture media. Subsequently a magnetic field was produced, and with the aid of mathematical modelling, chondrospheres were predictably directed to move into a pre-designed 3D morphology, controlled by the magnetic field. Assembly of the chondrospheres into a 3D tissue 
construct was seen to occur, showing the promise of magnetic levitation for rapid 3D tissue biofabrication.
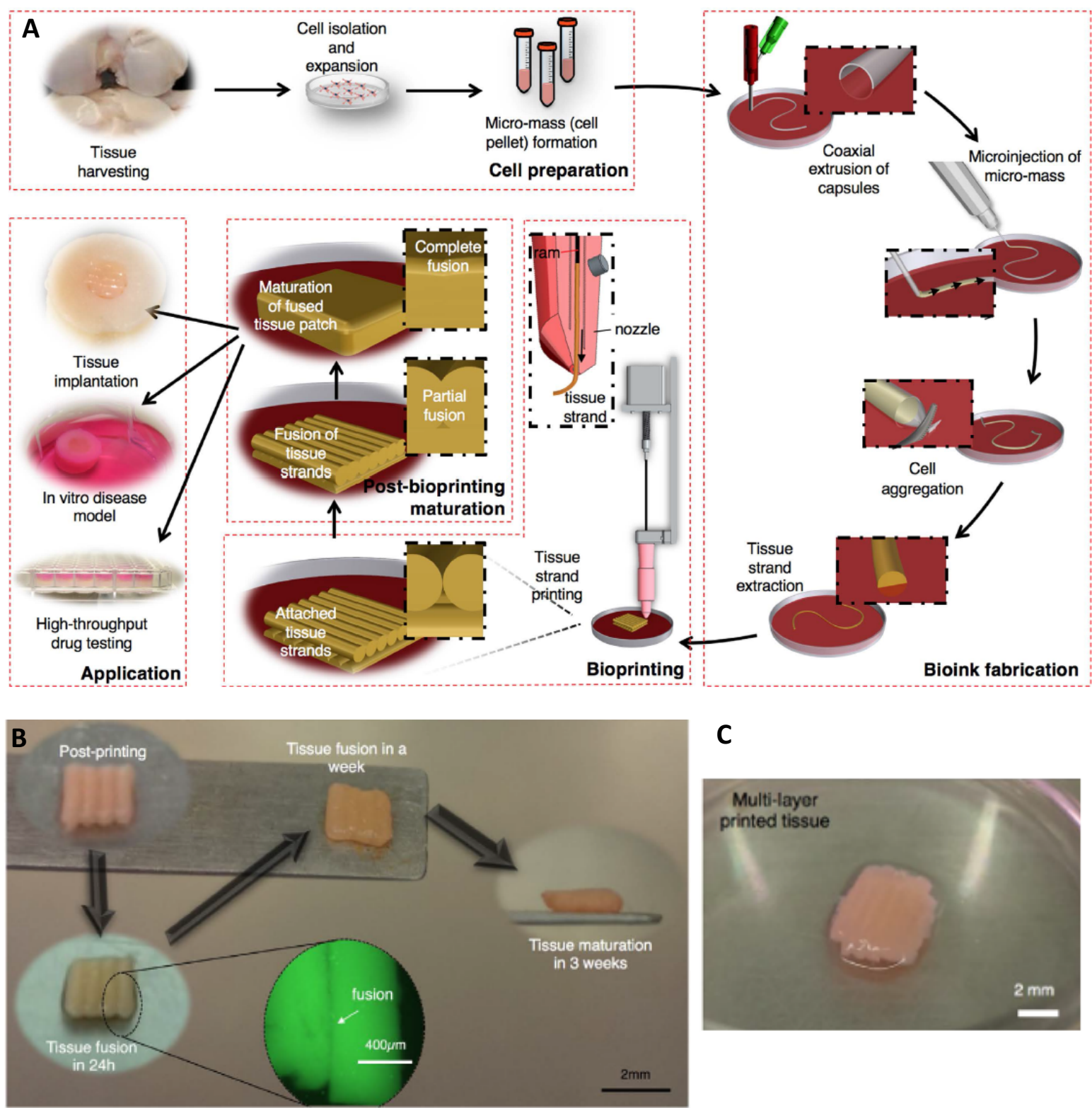

C

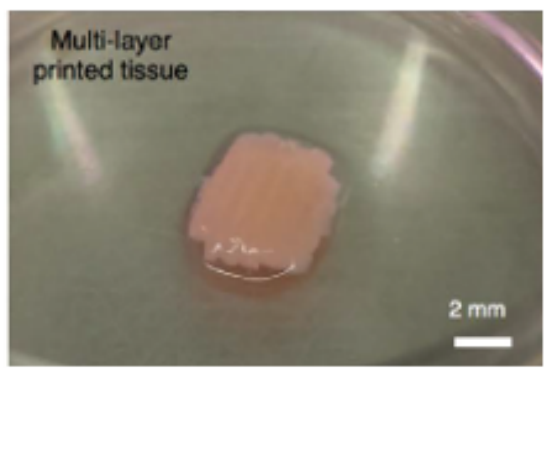

Figure 7. Biofabrication of cartilage using co-axial bioprinting and tissue strands. (A) Demonstration of the tissue strand printing and subsequent fusion process. (B) Images of printed tissue strands gradually fusing over 3 weeks of incubation. (C) 3D bioprinted tissue patches prepared for $4 \mathrm{~mm} \times 4 \mathrm{~mm}$ osteochondral defect with $2 \mathrm{~mm}$ thickness. Adapted from Yu et al. [58].

\subsubsection{Cartilage regeneration using injectable hydrogels}


Injectable hydrogels for cartilage regeneration have attracted significant interest as they offer the potential clinical flexibility of performing minimally invasive injections that can be moulded in-situ to match irregular patient defects [194-196]. Accordingly a range of natural and synthetic polymers and biomaterials have been investigated in attempts to create injectable hydrogel scaffolds for cartilage regeneration [197-205].

Hyaluronic acid (HLA) has proven to be a popular choice for use in prospective injectable hydrogels, as chondrocytes possess surface receptors including CD44 that allow them to bind directly to HLA, promoting chondrocyte differentiation, ECM deposition and proliferation [206-213].

Park et al. produced a composite bioink of methacrylated glycol chitosan (MeGC) and HLA, using a riboflavin photoinitiator to induce crosslinking of the bioink under visible light [214]. Addition of HLA to MeGC hydrogels significantly increased chondrocyte proliferation and ECM deposition, whilst the compressive modulus of the bioink could be increased by increasing the crosslinking time; however, cell viability also decreased with more prolonged crosslinking.

Chen et al. mixed HLA with a RGD-functionalized pectin to produce an injectable composite hydrogel [82]. As a constituent of the natural cell wall, pectins were included in the hydrogel due to their hydrophilic properties and capacity to help replicate the natural ECM around chondrocytes [215, 216]. Chondrocytes grown in the composite hydrogel thrived, with high cell viability and significant production of collagen, glycosaminoglycans and aggrecans demonstrated in vitro. Furthermore, the hydrogel was highly biocompatible when implanted in mice for over 8 weeks, with integration with surrounding subcutaneous tissues seen and minimal inflammation.

Yu et al. created an injectable, double cross-linked HLA/polyethylene glycol (HLA/PEG) hydrogel [217]. Fast gelation of the HLA/PEG hydrogel was achieved through enzymatic crosslinking, producing an injectable material. Excellent chondrocyte proliferation was observed within the hydrogel, which also demonstrated the desirable property of being able to recover from repeated compression and restore back to initial shape.

Guo et al. mixed HLA with chondroitin sulfate and collagen for cartilage regeneration [218]. Crosslinking of chondroitin sulfate-methacrylate (CSMA) and HLA-methacrylate alongside natural collagen self-assembly led to the development of an interpenetrating polymeric network, designed to replicate the native cartilage extracellular matrix. Chondrocyte secretion of glycosaminoglycans and type II collagen was promoted in the composite hydrogel, with good cell viability also found. 
Lee et al. blended HLA with collagen and fibrinogen to create a composite hydrogel, which was then used to encapsulate MSCs. The MSC laden composite hydrogel was then applied into rabbit osteochondral knee defects; after 24 weeks, defect healing was observed to occur, with hyaline-like cartilage formation observed and significant production of glycosaminoglycans and type II collagen also detected, demonstrating strong therapeutic potential [219].

Choi et al. blended type-II collagen (Col II) and chondroitin sulphate (CS) with chitosan to create a composite hydrogel for cartilage regeneration [220]. Riboflavin was then used to crosslink the hydrogel using visible blue light. Increased chondrogenesis, MSC proliferation and ECM deposition was triggered by the addition of Col II or CS to the chitosan hydrogel. It was observed that Col II had the greatest impact on chondrogenesis, suggested to be related to chondrocyte integrin $\alpha 10$ binding to Col II and therefore increasing cell-matrix adhesion.

Biodegradable synthetic polymers such as polyethylene glycol (PEG) and poly (L-glutamic acid) have also been used to produce injectable composite scaffolds for cartilage regeneration with some success [56, 204, 221-223]. Dubbini et al mixed HLA with PEG, producing an injectable hydrogel that could undergo dual cross-linking and thermal gelation at $37^{\circ} \mathrm{C}[224]$. Mechanical properties, degradation rates and gelation kinetics of the hydrogel could all be tuned by altering polymer content and the degree of vinyl sulfonation and thiolation. MSC and fibroblast viability was also preserved in vitro over 21 days in the hydrogel.

\subsection{Biofabrication of skin}

\subsubsection{Skin function and structure}

As the largest organ in the human body, skin has a complex, multi-layered structure containing cells, extra-cellular matrix (ECM), veins, capillaries, hair follicles and nerves [100, 225]. The epidermis, dermis and hypodermis make up the three predominant layers of skin. In the outer epidermis, keratinocytes are the main cell type, providing a barrier to pathogens, water loss and UV radiation. Pigment-producing melanocytes, Langerhans cells providing immune function and Merkel cells essential for light-touch sensation are also found. The intermediate dermis layer contains collagen, fibroblasts critical for healing, hair follicles, sebaceous glands and sweat glands. The hypodermis or deeper subcutaneous tissue contains fat, connective tissue, fibroblasts and macrophages [226]. Acting together, the layers of skin have several functions including providing a barrier against mechanical, thermal and physical injury; preventing loss of moisture; helping regulate temperature; aiding vitamin D production and acting as a sensory organ amongst other functions [227]. As the first line of defence against external stimuli, skin is frequently subject to damage from a wide range of 
aetiologies including burns, infections, trauma, cancer and other genetic and somatic diseases. The World Health Organisation estimates that over 300000 people die from burn injuries annually, with a further 11 million burn patients requiring medical intervention [228].

\subsubsection{Skin defect current treatment options}

Where direct wound closure is not possible, autologous skin grafting is the most commonly performed surgical procedure to achieve coverage of skin defects. Usually split-thickness grafts consisting of the epidermis and part of the dermis are harvested from own-patient donor sites and transferred to cover defects. However, autografts have limitations including limited donor sites available for grafting and donor-site morbidity. Allografting (use of donor patient or cadaveric skin) can also provide coverage in extensive wounds, although risk of rejection is significant, even within blood type matching [229]. Xenografts can also be used, with porcine xenografts having similar performance to allografts, although risk of disease transmission and rejection remain [230]. An alternative approach involves grafting autologous epithelial keratinocytes after in vitro-expansion. Whilst this approach has been used to successfully treat large burns, limitations include prolonged in vitro expansion times, graft mechanical fragility, significant production labour and elevated risk of scar contracture $[231,232]$.

\subsubsection{Skin biofabrication}

The limitations of current treatment options mean that a compelling demand still exists for a novel source of artificial biomimetic skin. With the potential to become a standardised and automated method of producing skin, 3D bioprinting skin is now a major area of research for treating patients and testing drugs and cosmetics [233]. Biomaterials that have commonly been used to engineer skin include natural polymers such as collagen, gelatin, silk and chitosan; a number of synthetic polymers including polycaprolactone (PCL), poly-lactic acid (PLA) and poly-lactic glycolic acid (PLGA) have also been used [225].

A range of bioprinting techniques have been implemented to produce skin constructs. Michael et al. used laser assisted Bioprinting (LaBP) to create a bilayered skin construct, with a collagenkeratinocyte layer printed on top of a collagen-fibroblast layer seated on a sheet of Matriderm ${ }^{\mathrm{TM}}$. After incubation for 24 hours, the construct was grafted onto full-thickness skin defects in mice and left for 11 days (Fig. 8). Histological analysis after in vivo culture was very promising, with formation of a multi-layered epidermis and ingrowth of blood vessels towards the printed cells found [100]. 


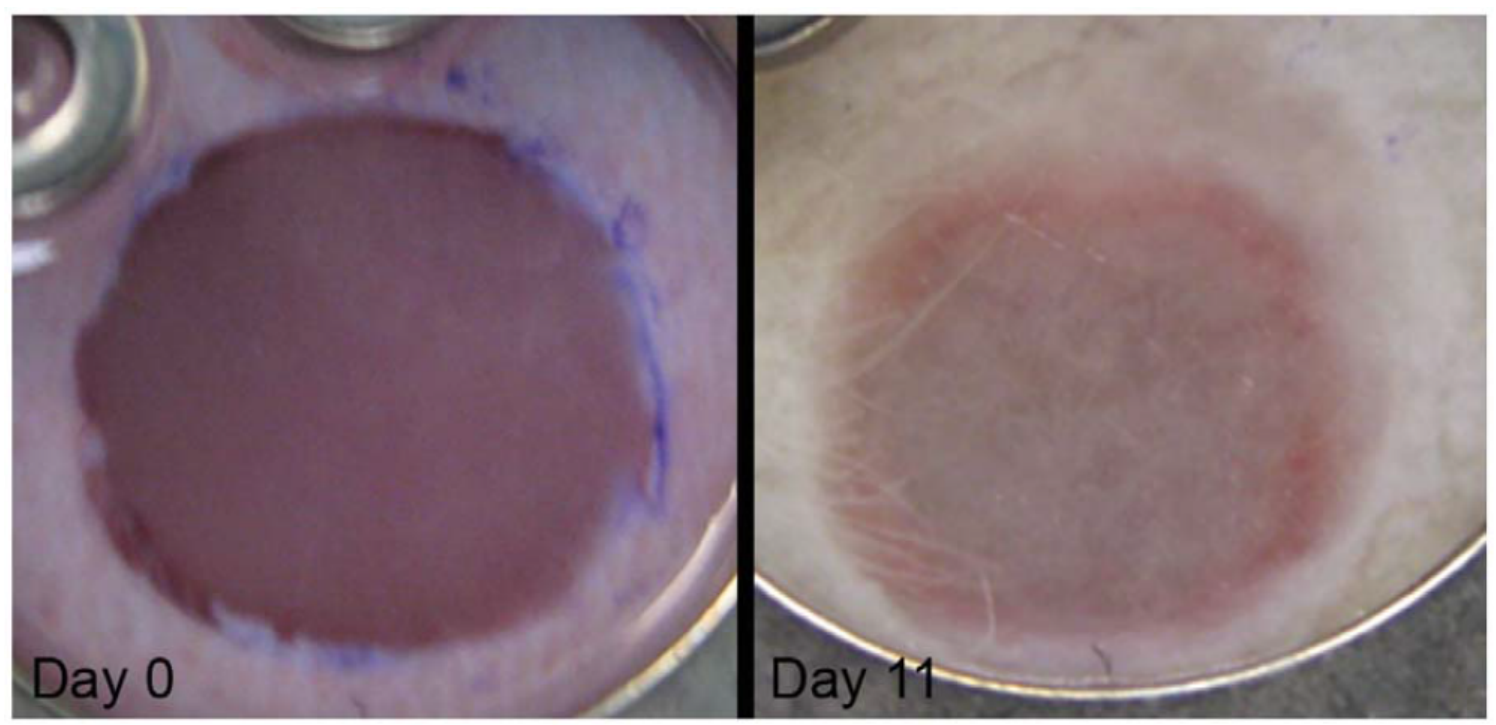

Figure 8. Successful implantation of biofabricated skin constructs by Michael et al. [100] Skin constructs after implantation (left) into nude mice dorsal skin wound and on day 11 (right), with healing evident.

Lee et al. used a microvalve bioprinter to dispense fibroblasts (FBs) and keratinocytes (KCs) within layers of collagen hydrogel, attempting to replicate the natural dermal and epidermal structure. The $3 \mathrm{D}$ constructs were partially submerged in media, allowing the epidermal layer to be exposed to an air-liquid interface, promoting maturation and stratification of an epidermis. Within the dermal layer FBs proliferated and maintained a sparse distribution, whilst KCs were able to proliferate more rapidly on the top of the collagen matrix, fully covering the surface in under 7 days. The skin constructs also retained their dimensions and shape during culture [234].

Cubo et al. extrusion bioprinted bioinks containing human plasma as well as primary human FBs and KCs obtained from skin biopsies to create skin constructs (Fig. 9). Using this method, they successfully produced $100 \mathrm{~cm}^{2}$ of printed skin in less than 35 minutes. Analysis of the printed skin following $3 \mathrm{D}$ in vitro culture and also after transplantation onto immunodeficient mice found a striking histological resemblance to mature human skin (Fig. 8) [235]. 

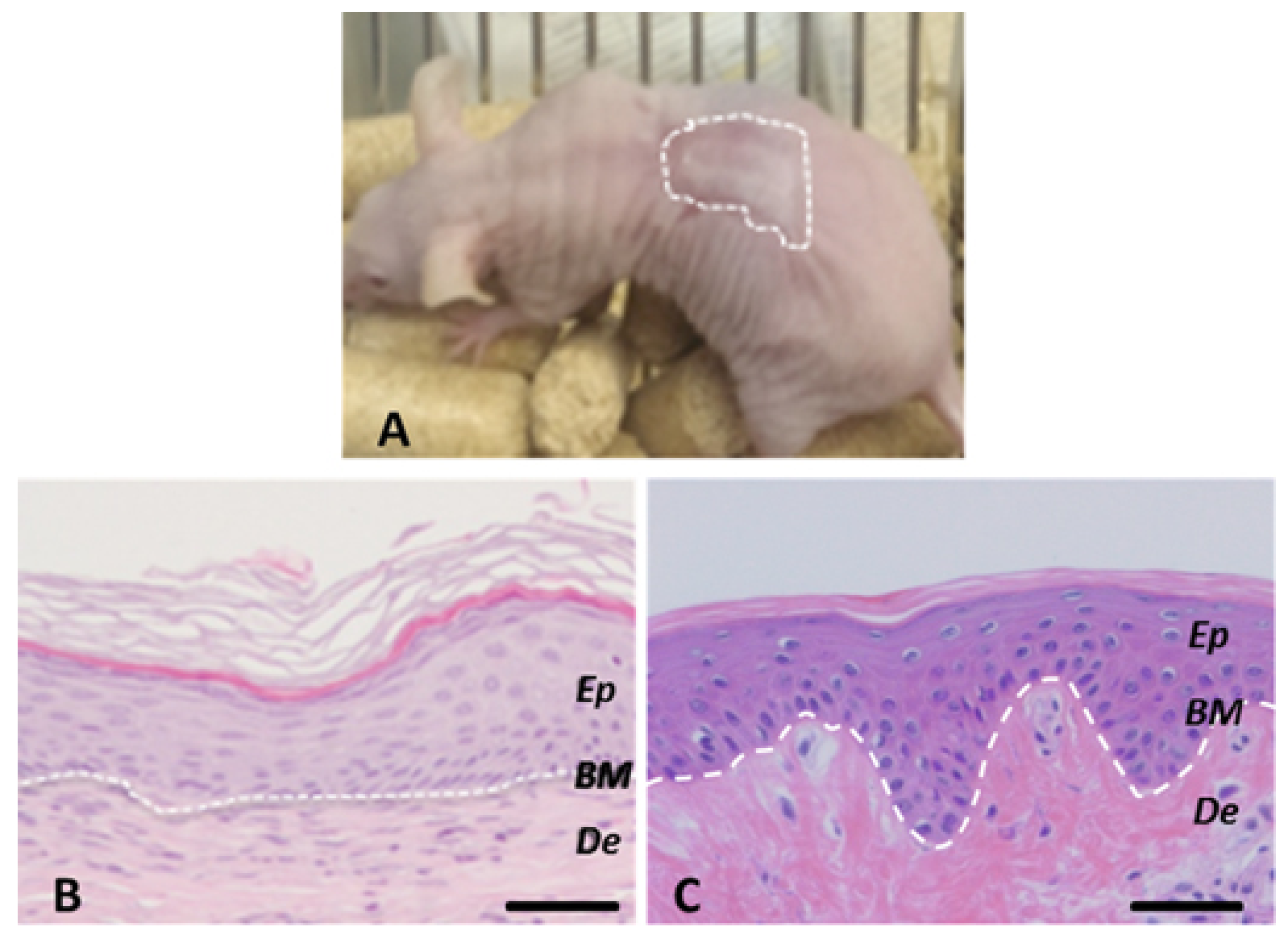

Figure 9. Extrusion bioprinted skin constructs implanted in vivo. (A) Visual appearance of the grafted human skin produced by Cubo et al. [235]. The dotted line demarcates the boundary between human and mouse skin. (B) Regenerated human skin stained with hematoxylin and eosin (H/E). (C) Normal human skin H/E staining. The white dotted line in (B) and (C) indicates the dermo-epidermal junction (basal membrane, BM). Ep and De in (B) and (C) denote the epidermal and the dermal compartments, respectively. Scale bar: $100 \mu \mathrm{m}$.

$\mathrm{Ng}$ et al. used drop-on-demand bioprinting to create pigmented human skin constructs. Taking KCs, melanocytes and FBs from three different skin donors, they used a two-step drop-on-demand bioprinting strategy to create biomimetic structures with hierarchical porosity and cell content, with KCs and melanocytes patterned at desired positions. Compared to manually-cast samples, 3D bioprinted skin constructs more closely resembled native skin tissue, with a well-developed epidermal layer and basement membrane seen to develop [236].

Examples of successful in-situ bioprinting of skin also exist. Binder et al. developed a portable system that coupled a laser-based wound scanning system with a cartridge-based delivery system. This allowed the length, width and depth of a wound to be scanned, making it possible to tailor the bioprinted construct to individual patient need. In vivo experiments on a murine model used autologous cells loaded into a fibrin and type I collagen bioink, with inkjet bioprinted KCs seen to 
proliferate and re-epithelialize a full thickness $(3 \mathrm{~cm} \times 2.5 \mathrm{~cm})$ skin defect. Labelled autologous FBs and KCs were still detectable in the wound after 8 weeks, showing the potential for bioprinted skin cells to proliferate and form skin tissue in a large wound model [237]. A further study successfully extrusion bioprinted amniotic fluid-derived stem cells (AFSCs) onto full-thickness skin wounds $(2 \mathrm{~cm} \times 2 \mathrm{~cm})$ in mice. Compared to fibrin-collagen gel controls, increased wound closure rates and angiogenesis was observed in wounds treated with bioprinted AFSCs. The AFSCs were found to secrete a number of growth factors beneficial to healing in large-scale wounds and burns [238].

\subsection{Biofabrication of vasculature}

\subsubsection{Blood vessel structure and demand for vascular grafts}

Blood vessels have a concentric, layered structure with a thin inner layer of cells known as the endothelium. The endothelium plays a critical role in mediating the flow of nutrients and waste products to and from the blood. Surrounding the endothelium is a basement membrane composed largely of type IV collagen and laminin [239]. An elastic connective tissue layer known as the internal elastic lamina surrounds the basement membrane [240]. A muscular layer which coordinates vessel contraction or dilation through smooth muscle cell activity is then found, named the tunica media. A further outer elastic lamina surrounds this layer, before an outer adventitial layer is found, composed of fibroblasts in a loose collagen matrix [239].

The production of a perfusable, hierarchical vascular network that can replicate the mechanical and biological properties of living vascular tissues remains a great challenge within tissue engineering $[16,241,242]$. Successful transplantation of biofabricated tissues and organs is critically dependant on integration with the host vascular network. Without a vascular network, constructs become dependent on diffusion of oxygen and nutrients to maintain cell viability, without significant infiltration of host vasculature occurring [243]. Unfortunately, host microvessel penetration into constructs is often insufficient, limiting the size of construct that can be viably implanted [55, 244]. Due to vascular disease processes including atherosclerosis and aneurysm formation, significant clinical demand also exists for transplantable vascular grafts [14, 241]. Attempts have therefore been made to engineer components of the host vascular network, including larger macrovasculature, such as arterioles and major arteries, as well as the corresponding, smaller-scale microvasculature [245]. Achieving successful replication of blood vessel anatomy is important to allow compatibility with native vessels and blood, reducing the risk of complications such as thrombosis and loss of patency. 


\subsubsection{Biofabrication of vasculature}

Several different bioprinting approaches for vascular tissue biofabrication having been attempted. Using inkjet technology, Nakamura et al. biofabricated tubes by extruding alginate hydrogel into a pool of $\mathrm{CaCl}_{2}$ solution, triggering rapid $\mathrm{Ca}^{+2}$ cross-linking of the alginate and leading to formation of well-defined tubes. Tubular structures with wall thickness ranging from 35 to $40 \mu \mathrm{m}$ and inner diameter ranging from 30 to $200 \mu \mathrm{m}$ were successfully produced using this methodology [246]. Inkjet printing has been utilised to produce 3D vascular-like structures through two main approaches. The dispensing nozzle of the inkjet printer can be moved in parallel to the longitudinal axis of tubular structures, allowing horizontal printing. Alternatively, vertical printing can be performed by moving the inkjet nozzle upwards in a circumferential motion [57, 247, 248]. Several examples of horizontal and vertical printing have been reported, with the thickness of vessels increased through slower print speed and higher levels of bioink extrusion [57, 247-250].

Christensen et al. utilised inkjet printing to create alginate vessels with horizontal and vertical bifurcations. Calcium chloride solution was utilised as both a cross-linking agent and support material in this study. A 3D inkjet bioprinting system was developed, with alginate droplets deposited into $\mathrm{C} \mathrm{CaCl}_{2}$ solution via an inkjet printhead. The printhead was moved in the $\mathrm{XY}$ axes to deposit alginate beads into a $\mathrm{CaCl}_{2}$ solution support bath, which was also gradually moved down by a $\mathrm{Z}$ platform, submerging each layer of deposited alginate in $\mathrm{CaCl}_{2}$. This resulted in near instantaneous gelation of deposited alginate bioink, and allowed production of tubular structures with horizontal and vertical bifurcations. 3 T3 fibroblasts incubated within the vessels had greater than $90 \%$ cell viability after $24 \mathrm{~h}$ of incubation [251]. Laser-assisted bioprinting has also been utilised to create vessels. Xiong et al. utilised solutions of $8 \%$ alginate and $2 \%$ alginate loaded with mouse fibroblasts to produce straight and $Y$-shaped tubes. Fibroblast viability immediately after printing as well as after $24 \mathrm{~h}$ incubation was above $60 \%$ in both straight and $Y$-shaped tubes [252].

Tabriz et al. developed a rapid method of fabricating tubular structures by dip-coating metal bars covered in cell-laden alginate hydrogels into cross-linking solutions, including calcium chloride or barium chloride. Following cross-linking, hollow tubular structures could be released from the metal bars (Fig. 10A). Single layers with thickness ranging from 126 to $220 \mu \mathrm{m}$ or multilayered tubular structures could be produced, with cell viability in the dip-coated tubes found to be comparable to extrusion bioprinting of similar constructs $[138,139]$. A similar methodology was developed by Wilkens et al., who implemented motors to rotate and then dip metal rods into alginate (Fig. 3I), allowing a complex structural configuration resembling natural blood vessels to be produced (Fig. 10B). Homogenous cellular layers were deposited in well-defined concentric patterns across 
multilayer vessel grafts, allowing the generation of an inner endothelial cell layer of approximately 20-30 $\mu \mathrm{m}$ to occur [140]. Zhang et al. also managed to replicate the layered structure of vasculature, by combining electrospinning and braiding techniques. Sequentially electrospinning different ratios of silk fibroin (SF) and poly(L-lactide-co- $\varepsilon$-caprolactone), they produced layers resembling the intima and media of native vascular tissue. To create an outer adventitial layer, SF was braided on top of the electrospun tubes. Mechanical properties of the obtained scaffold were similar to that of human blood vessels, whilst endothelial cells and smooth muscle cells readily proliferated on the media and intima layers. Additional heparin functionalization of the scaffolds was performed to improve the anticoagulant properties and perfusability of the tubes during incubation in whole blood [241].
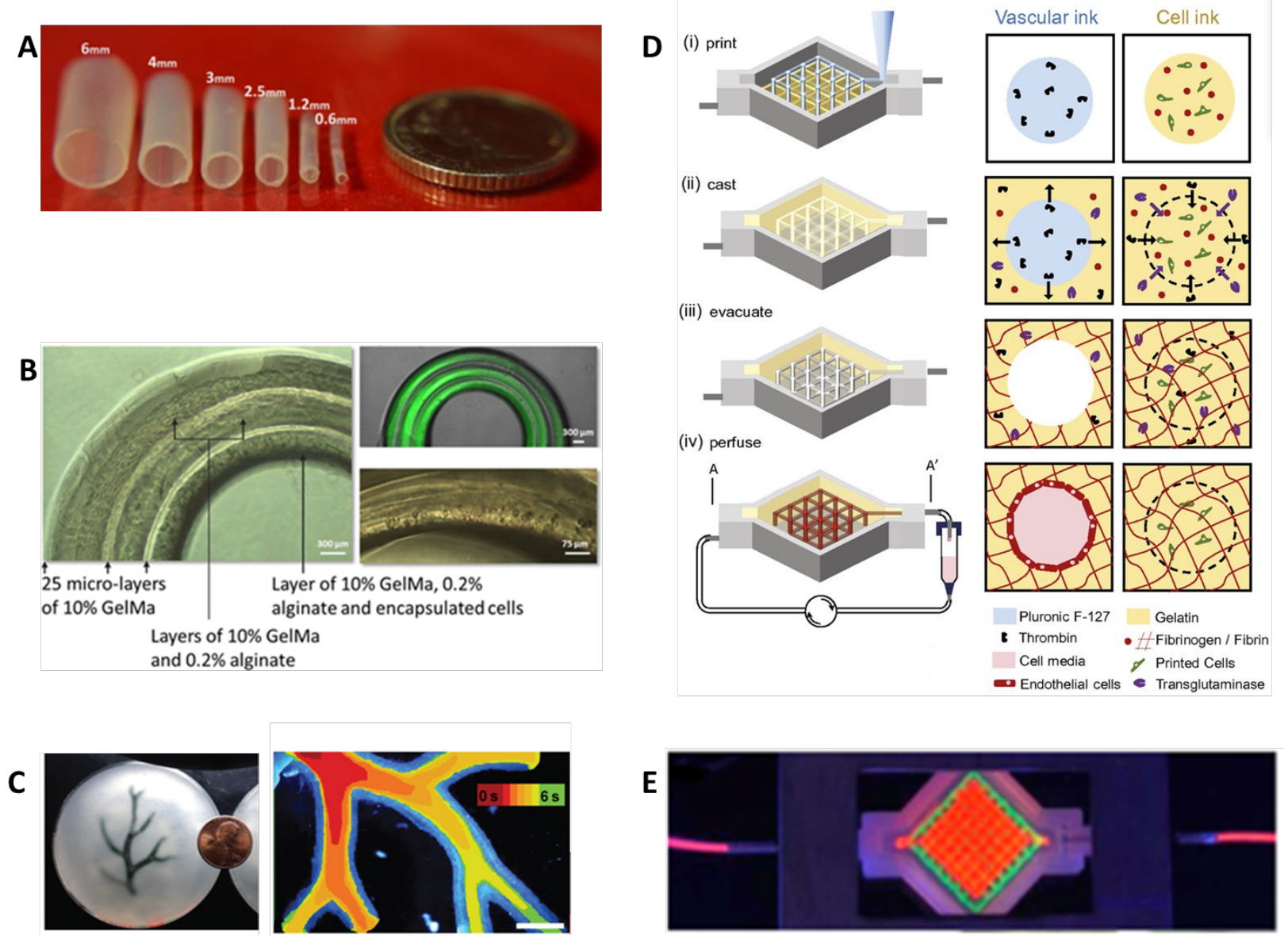

Figure 10. Biofabrication strategies to produce vascularisation (A) Alginate hydrogel tubular structures of various diameters fabricated using a dip-coating method. Scale bar: UK 5 pence coin.[139] (B) Construct with similar layer configuration to natural blood vessels fabricated using a rotating rod. The complex construct consists of 1 layer of encapsulated cells in a 10\% (w/v) GelMA, 3 intercalated sets of 25 micro-layers of 10\% (w/v) GelMA and 2 layers of 10\% $(w / v)$ GelMA with $0.2 \%(w / v)$ alginate. Fluorescent labelling demonstrates distinct layers, with a close-up of the layer with encapsulated cells seen [140]. (C) A FRESH bioprinted arterial tree model (black) embedded in a gelatin slurry support bath. A time-lapse image of dye perfused through the arterial tree shows flow through the lumen and no leakage through the 
vessel wall. Scale bars $2.5 \mathrm{~mm}$. [111]. (D) Illustration of tissue manufacturing process. (E) A printed tissue construct being actively perfused an inlet and outlet seen at either end of tissue construct. Adapted from Kolesky et al. [108].

Attempts have also been made to fabricate silicon tubes with inner, biological endothelial layers $[253,254]$. Polydimethylsiloxane (PDMS) tubes manufactured with differing diameters and wall thicknesses were seeded with human umbilical vein endothelial cells (HUVECs) on their interior surfaces. The HUVECs adhered and developed a functional endothelium capable of expressing natural endothelial products including endothelial biomarker (CD31), nitric oxide and von Willebrand factor in response to vasoactive drugs. Potential uses of these elastomeric, biomimetic blood vessels include the potential to integrate multiple organoids into a single microfluidic circuitry [253].

Hinton et al. developed a novel method capable of producing vascular structures, termed freeform reversible embedding of suspended hydrogels (FRESH) [111]. This process involves bioprinting low viscosity bioinks within a secondary support bath (Fig. 10C). Behaving as a bingham plastic, the gelatin support bath allowed print needle movement under high shear stress, however following extrusion the bioink was kept in position. The extruded structures could then be crosslinked and subsequently released from the supporting gelatin by heating to $37^{\circ} \mathrm{C}$ (Fig. 3B). This method allowed extrusion bioprinting of a range of low-viscosity bioinks including Type 1 collagen, alginate and fibrin hydrogels. High print resolution could also be achieved, with encapsulated myoblasts and fibroblasts successfully printed and developed into vascular networks.

Several groups have attempted an indirect bioprinting approach to create vascular constructs. This typically involves a sacrificial bioink being deposited in cylindrical form within a larger cell-laden hydrogel structure $[108,254,255]$. The sacrificial bioink is removed through enzymatic or thermal decrosslinking, leaving behind patent channels within a larger hydrogel matrix. The tubular, patent channels can then be seeded with endothelial cells and perfused with media. Pluronic F-127, a symmetric triblock copolymer of poly(ethylene oxide) and poly (propylene oxide), has frequently been used as a sacrificial material in composite scaffolds to aide development of vascular channels [256-259]. Despite being highly printable and mechanically robust, F-127 lacks cell compatibility when used as an encapsulating hydrogel scaffold [243, 260-262]. However, F-127 hydrogels have the very useful property of being able to undergo thermoreversible gelation at physiological temperatures. Bellow a critical micellar temperature (CMT), gelation can be reversed allowing dissociation of the gel to occur. F-127 can therefore be printed as a fluid gel into constructs, and allowed to set at room temperate to either provide support or maintain channels within a larger structure. Once desired, secondary cooling of the construct can be performed, washing the liquefied F-127 away as a fugitive ink $[263,264]$. Lewis et al. exploited these properties, printing F-127 
channels into a heterogenous matrix of cell-laden hydrogels. When subsequent cooling was performed, the F-127 dissolved leaving perfusable channels (Fig. 10D). Endothelialisation of the channels was promoted by seeding them with endothelial cells and perfusing them with media via an external pump (Fig. 10E). After 30 days, hMSCs within the hydrogel matrix remained viable with evidence of successful differentiation having occurred [108].

Byambaa et al. also utilised a fugitive ink to successfully create tissue constructs with perfusable vascular lumen [265] . They began by initially extrusion bioprinting a cylinder with $5 \%$ methacrylated GelMA hydrogel at low methacryloyl substitution (GeIMALOW). Successive layers of cylinders were then printed around the soft GeIMALOW core using 10\% methacrylated (GeIMAHIGH). The soft inner GeIMALOW core degraded at a faster rate than the outer GeIMAHIGH layers, leaving an open, perfusable $500 \mu \mathrm{m}$ diameter lumen after 12 days of in vitro incubation. VEGF impregnated into the outer GeIMAHIGH layers also encouraged outward vascular spreading as the inner lumen was perfused with growth media over a 21-day period [266].

Coaxial nozzle assemblies have also been used to fabricate cellularised hollow filaments. In this approach, a nozzle is modified to include inner and outer cores that allow gels and bioinks to be extruded into tubes, with the final size determined by the dimensions of the nozzle (Fig. 3E). By extruding a cross-linking agent as the inner core, the outer shell can be rapidly cross linked to form a self-supporting hollow tube $([122,123]$. The hollow filament size formed by coaxial nozzle-assisted 3D bioprinting systems can be controlled by changing the flow rate and concentrations of the inner cross-linking agent, outer bioink, and the nozzle diameter. For instance, the inner diameter of extruded hollow filaments can be increased by increasing the diameter of the inner core of the coaxial nozzle. Inner and outer core flow rates can be increased to produce larger inner and outer filament diameters respectively (i.e. resulting in a larger vessel lumen for perfusion and thicker vessel wall). Similarly, a decrease in each of the flow rates can be selected to cause a corresponding decreased in either inner or outer vessel diameter (i.e. resulting in a smaller vessel lumen for perfusion or thinner vessel wall) [267]. Zhang et al. utilised a coaxial approach to print alginate and chitosan hydrogel microfluidic channels. Perfusion with cell media was facilitated by the microfluidic channels, which acted as vessels embedded in bulk hydrogels [122]. Attalla et al. developed a printhead with an integrated coaxial nozzle, allowing hollow, calcium-polymerized alginate tubes to be produced. The vessel-like structures were successfully embedded into larger gel moulds, whilst alteration of the hydrogel flow rates or print-head speed allowed the diameter of the hollow channel to be precisely controlled between $500 \mu \mathrm{m}-2 \mathrm{~mm}$. Active perfusion of the channels with cell media also significantly increased cell viability [267]. Gao et al. also implemented a coaxial nozzle to 
produce hollow, cell-laden alginate tubes. A custom 3D bioprinting system was used alongside a Zshaped print platform to fabricate cell-laden hydrogel structures with microchannels. Following printing alginate vessels were immersed in $\mathrm{CaCl}_{2}$ solution to allow further alginate cross-linking to occur. Alginate structures containing microchannels had far greater fibroblast viability compared to structures without built-in microchannels [123]. A key advantage of coaxial printing is its ease of manufacture, creating very long conduits in a minimal amount time. Limitations include difficulty in creating complex, bifurcated, anatomical structures, and the creation of multiple microscale layers seen in many native tubular organ structures [49].

A novel approach to vessel assembly using metallic needles placed in a circular array to create a temporary scaffold was demonstrated by Itoh et al. [115]. Termed the Kenzan method, the metallic needles acted as a support to deposited smooth muscle cell and fibroblast spheroids (650 $\mu \mathrm{m}$, diameter). After a period of culture in a bioreactor, the spheroids fused together, allowing removal of the support needles to create a rigid tubular structure (Fig. 3C). As an alternative to metallic needles, Norotte et al. utilised acellular agarose rods to support the growth and 3D fusion of high density cellular cylinders, allowing formation of tubular tissue (Fig. 3D) [117].

Scaffold-free approaches have also emerged as viable approach to biofabricating blood vessels, through the use of cell sheets, spheroids and tissue strands $[60,268,269]$. As these pre-fabricated tissue building blocks fuse, they produce ECM and develop into larger vessel-like constructs [270]. The potential for spheroids to fuse together and form larger tissue constructs including vascular tissue has been demonstrated in several studies $[55,134,271]$. Bioprinted vascular tissue spheroids composed both of endothelial and smooth muscle cells have also been observed to undergo a cell sorting process immediately after printing, leading to the localization of endothelial cells to the inner, luminal portion of printed vascular tubes [272, 273]. Furthermore, bioprinted spheroids act as in vivo paracrine stimulators of angiogenesis $[274,275]$.

\subsection{Biofabrication of neural tissue}

\subsubsection{Nervous system general structure}

The nervous system is divided functionally and anatomically into two main parts; the central nervous system (CNS) and the peripheral nervous system (PNS). The brain and spinal cord as the CNS control the body via the branching nerves of the PNS. The PNS and CNS are composed of two principal cell types; neurons relay electrical signals in the CNS and PNS via axons to allow neurological control of 
the body to occur, whilst glial cells that exist in close contact with neurons provide myelination, mechanical and physiological support $[47,276]$.

Due to a variety of disease processes including trauma, infection, inflammation, cancer and degenerative conditions, damage can occur to the PNS and CNS leading to potentially significant morbidity and even mortality for patients. Unfortunately, the inherent regenerative capacity of the nervous system is limited. As a result, current treatment options for neurological injuries often focus on restoring the function of residual healthy neural tissue, rather than repairing and regenerating diseased and damaged cells $[277,278]$.

\subsubsection{Current treatment options for neural defects}

In terms of peripheral nerve injuries, autograft repair is the current gold standard for repair where direct end-to-end repair of transected nerve fibres is not possible. However, use of autograft tissue has limitations; neuroma and scar tissue formation, donor-site sensory disturbance and problems in matching nerve diameter and nerve type can all impair clinical outcome [279]. Allografts taken from cadaveric sources provide another option but carry risk of immune rejection and disease transmission. Grafts composed of synthetic polymers have also been used to guide nerve regrowth. However, polymers used for this purpose are often hydrophobic and do not fully support cellular regeneration and integration during repair[280]. Attempts to repair the CNS using autologous and synthetic approaches have also been limited by physical scaring and myelination issues $[57,278$, $281,282]$.

\subsubsection{Biofabrication of neural tissue}

To overcome the shortcomings of current treatment options, a variety of 3D biofabrication techniques have been used to attempt neural tissue regeneration $[50,283,284]$. A number of different general strategies have been used, including biofabrication of customizable, acellular nerve guides $[285,286], 3 D$ bioprinting encapsulated neural cells within a bioink capable of acting as a nerve guide [287] and bioprinting of tailored nerve growth factor gradients along the length of a nerve guide to direct cell growth $[283,288,289]$. Owens et al. supported multicellular cylinders containing MSCs and Schwann cells (SCs) with agarose rods to develop fully cellular bioprinted nerve grafts [290]. Cylinders comprised of $90 \%$ MSCs and 10\% SCs were supported with agarose rods, which were removed after 7 days (Fig. 11). This allowed the cellular cylinders to fuse together, forming a fully cellular nerve graft. Implantation of the cellular grafts into rat sciatic nerve defects led to neurological recovery. In a further study, a conduit composed of adipose-derived stem cells 
(ADSCs) and cryopolymerized gelatin methacryloyl (cryoGelMA) was 3D bioprinted and implanted into a $10 \mathrm{~mm}$ rat sciatic nerve defect. Analysis of the grafts after in vivo culture showed that they had supported the attachment, proliferation and survival of seeded ADSCs, with up-regulation of neurotrophic factors also found. Compared to autografts, the conduits achieved similar functional and histological outcomes of repair [291].

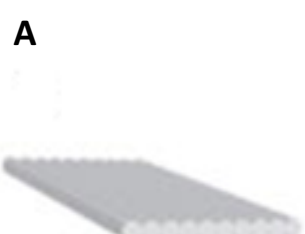

$\mathbf{E}$

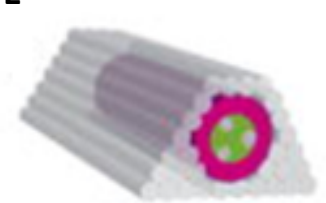

B

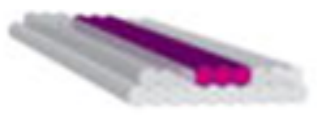

$\mathbf{F}$

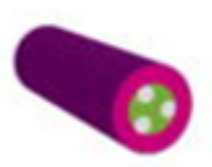

C

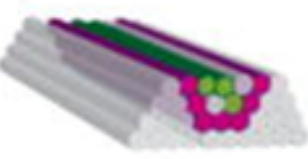

G

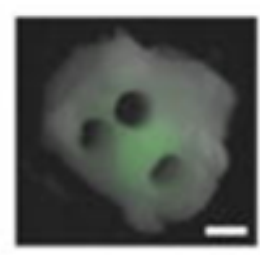

D

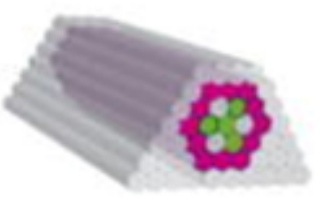

I

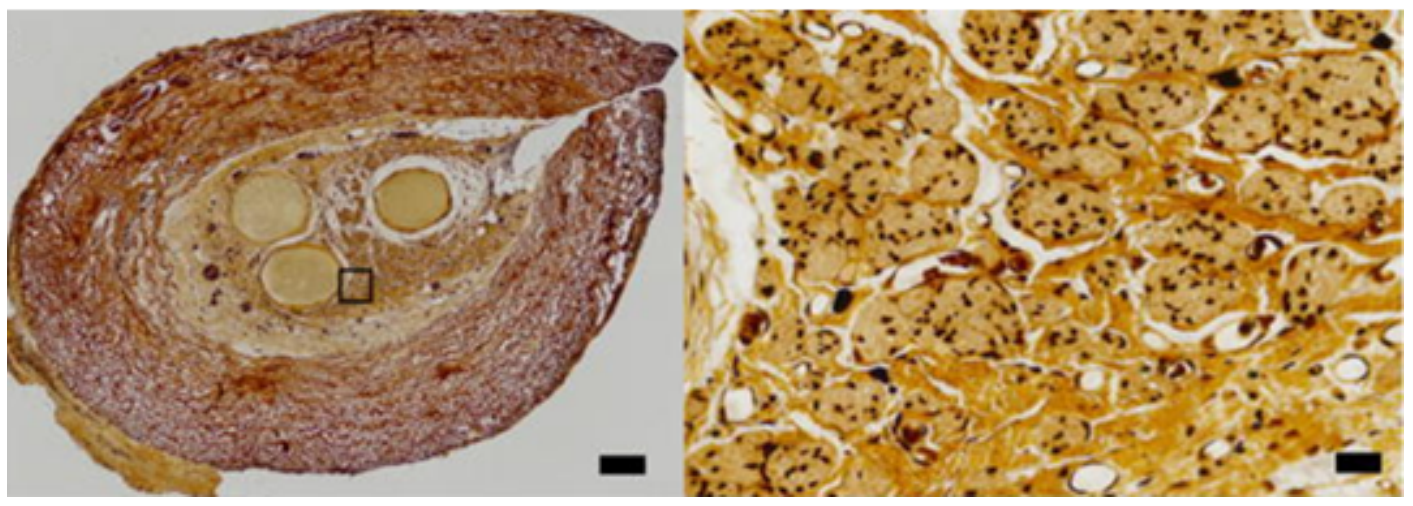

Figure 11. Nerve graft biofabrication by Owens et al. [290]. (A-F) show the layer by layer arrangement of 0.5 $\mathrm{mm}$ cellular and agarose rods. The outer red ring was made of bioink units composed of MSCs (red). Cylinders comprised of $90 \%$ BMSC and $10 \%$ SC (green) were then alternated with agarose rods, which gave rise to multiple lumina in the interior of the graft $(C-E)$. The structure was supported by an array of agarose rods (grey) (E), which held the conduit in place whilst the discrete bioink cylinders self-assembled (i.e. fuse) producing a nerve graft (F). The supporting agarose rods were then removed after 7 days. Panel (G) shows the cross section of the final graft with fluorescently labelled (green) Schwann cells seen. Removal of the agarose rods from the fused construct resulted in three hollow channels and a fully cellular graft. $(\mathrm{H})$ Histological analysis of the of the biofabricated grafts and axons (I). Axons appear as black dots in the graft. Scale bars: 200 and 40 microns for $(\mathrm{H})$ and $(\mathrm{I})$ respectively.

Gu et al. created a composite bioink using alginate, carboxymethyl chitosan (CMC) and agarose to encapsulate human neural stem cells (NSCs). The extrusion bioprinted bioink could be rapidly cross- 
linked to form a porous 3D scaffold encapsulating the NSCs. After 24 days in culture, samples stained positive for DAPI and vimentin and had minimal expression of SOX2, implying mature neurons formation [292]. Lee et al. also deployed microextrusion, bioprinting murine stem cells within collagen, fibrin and fibrin loaded with VEGF to create cylindrical shapes [293].

Aiming to develop a treatment for spinal cord injuries, Chen et al. $3 \mathrm{D}$ bioprinted collagen-heparin sulphate scaffolds and seeded them with NSCs [294]. Heparin sulphate was included to induce collagen-crosslinking, allowing the creation of a 3D scaffold with consistent porosity, uniform pore sizes and improved mechanical properties relative to a non-crosslinked collagen scaffold. Two months after implanting the scaffold in rat spinal cord lesions, collagen/heparin sulphate scaffolds led to significant recovery of locomotor function and electrophysiological signals. A high number of neurofilament (NF) positive cells were also found in the rats treated with collage-heparin scaffolds compared to a control collagen-alone scaffold treatment.

To enable CNS regeneration, Hsieh et al. investigated two thermoresponsive, biodegradable polyurethane hydrogels (PU1 and PU2) to encapsulate and bioprint NSCs [295]. The hydrogels were able to gelate at $37^{\circ} \mathrm{C}$ without any additional crosslinker, whilst varying the polymer concentration allowed fine-tuning of the hydrogel stiffness. The NSCs in 25-30\% PU2 hydrogels had the best results, with excellent proliferation and differentiation. Zebrafish with induced traumatic brain injuries were also observed to improve significantly after implantation of 3D-printed NSC-laden $25 \%$ PU2 constructs [295]. Huang et al. also made use of polyurethane, mixing it with a very low concentration of graphene (25 ppm) to prepare a nanocomposite hydrogel for NSC printing [296]. Addition of graphene to the polyurethane hydrogel significantly enhanced neural differentiation of extrusion bioprinted NSCs and cell oxygen metabolism (2- to 4-fold increase). Wei et al. included graphene nanoplatelets in a novel bioink consisting of gelatin methacrylamide (GelMA), bioactive graphene nanoplatelets and NSCs. Using a stereolithography-based 3D bioprinter, they were able to create neural constructs with well-defined architectures and homogenous cell distributions. Bioprinted NSCs showed neuron differentiation and neurite elongation within the printed constructs after two weeks of culture [297].

Lozano et al. attempted to create an accurate 3D in-vitro model of the brain using a bio-ink consisting of a novel peptide-modified biopolymer, gellan gum-RGD (RGD-GG), combined with primary cortical neurons [298]. A layered 3D structure was printed with a hand-held co-axial printer, whilst either Dulbecco's Modified Eagle's Medium (DMEM) or CaCl2 was used to support cross- 
linking of the gellan-gum. RGD modification increased cell proliferation and neural network formation, with neural cells remaining viable throughout the printed construct.

\subsubsection{Biofabrication of neural disease models}

Bioprinting has also been used to help develop neural disease models. Dai et al. encapsulated glioma stem cells in a composite bioink consisting of gelatin, alginate and fibrinogen [299]. Following bioprinting, glioma stem cells demonstrated high proliferation rates and high cell viability. Drugsensitivity analysis found that the 3D printed tumour model created was more resistant to chemotherapy than a 2D monolayer model. The 3D bioprinted glioma model therefore appeared to provide a novel and valuable model for studying drug resistance and anticancer drug susceptibility in vitro. In a further study, Dai et al. used a custom-made coaxial extrusion 3D bioprinting system to create self-assembling, multicellular brain tumour fibres (Fig. 12) [300]. Use of a co-axial system allowed the creation of a "core-shell" model, whereby an outer alginate hydrogel shell provided a scaffold to an inner core consisting of a high-density suspension of glioma stem cells. Removal of the outer alginate shell after cell maturation led to the creation of multi-cellular fibres, which maintained their structural integrity on physical manipulation. Through adjustment of the co-axial extrusion speed, the inner diameter of the shell, or the diameter of the core cell fibre, could be controlled. Surrounding stromal MSCs and glioma stem cells within the tissue fibres were also noted to interact and exchange viral vectors. This method of fabrication therefore appeared to provide valuable 3D models for studying the tumour microenvironment and tumour-stromal interactions in vitro. Other biofabrication methods including inkjet, microextrusion and laser technologies have been used to create 3D cancer models; regardless of biofabrication method, 3D cancer models have been found to mimic the tumour microenvironment better than 2D models [48, 301]. Hopefully in future this will improve understanding of cancer mechanisms and aid in the development of new clinical therapies and drug screening [302-304]. 

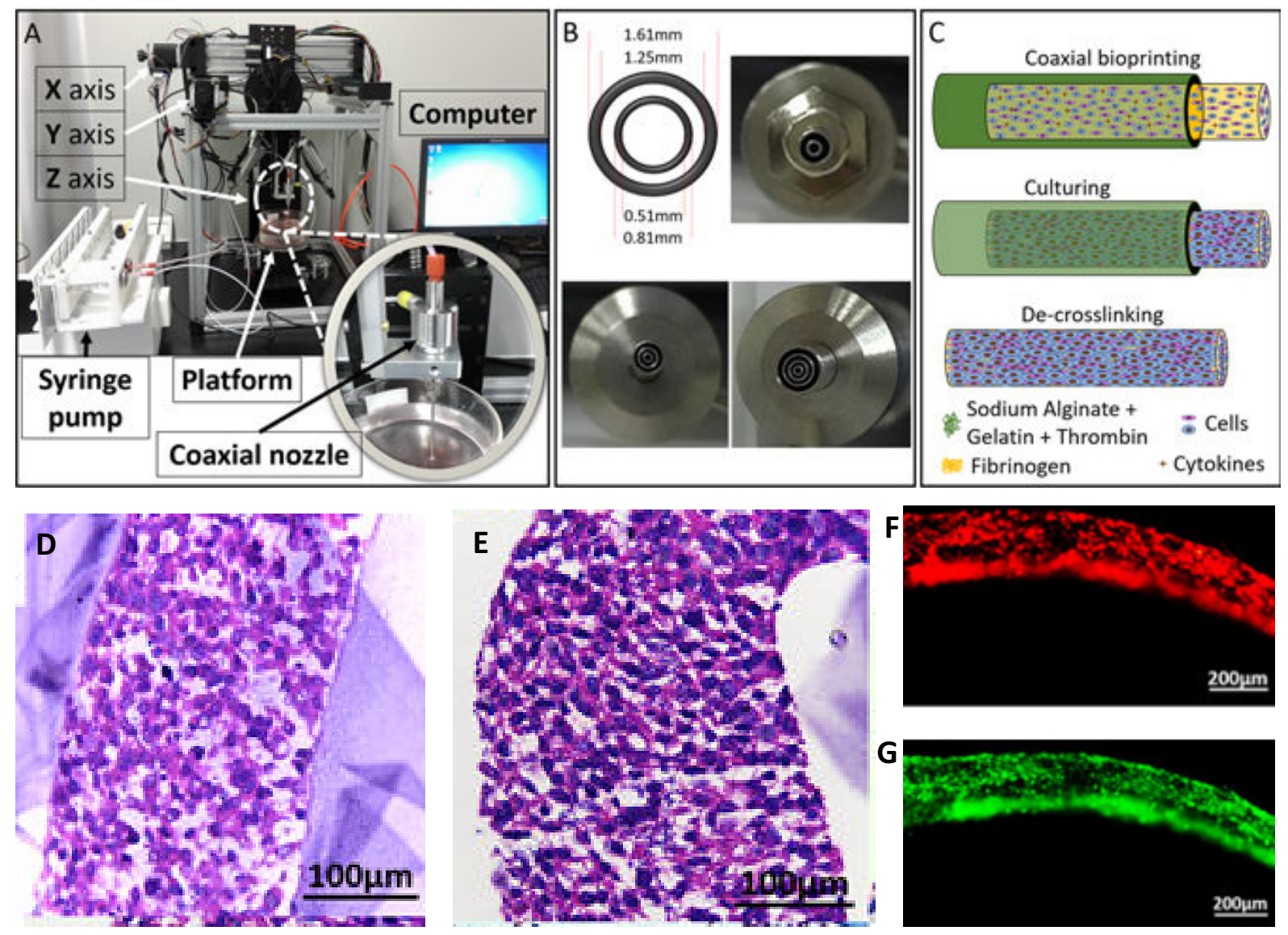

Figure 12. Use of a co-axial system to produce self-assembling, multicellular brain tumour fibres $(A) A$ coaxial 3D bioprinting system consisting of a XYZ three-axis platform, syringe pump, coaxial nozzle and computercontrol system. (B) Varying styles of coaxial printing nozzles used on the bioprinting platform. (C) Schematic of the biofabrication process of multicellular heterogeneous tumour fibres: coaxial bioprinting, in vitro culturing and de-crosslinking. (D) The coaxial 3D bioprinted tumour fibre within an alginate shell (E) The tumour fibre after removal of the alginate shell (F-G) Cell fibres containing RFP-expressing tumour cells and GFP-expressing MSCs after bioprinting and 3 days in vitro culture. Adapted from Dai et al. [300].

\subsection{Biofabrication of muscles, tendons and ligaments}

\subsubsection{Musculoskeletal (MSK) system function and current treatment options for MSK} injuries

The musculoskeletal (MSK) system facilitates locomotion by efficiently transferring the forces generated in muscles through tendons and ligaments onto bones to effect joint movement. However, due to processes including trauma, connective tissue disease, metabolic disease, infection, drug side-effects and inflammation, damage can occur to the MSK system resulting in pain and disability for patients [305]. In the case of significant tendon and ligament damage, it is often necessary for surgical repair to be performed with autograft, allograft or synthetic grafts. Autograft tissue usually provides the best clinical outcome, but is inherently limited in supply and can be associated with donor site morbidity including ongoing pain and functional impairment [306]. 
Allograft tissue repairs have limitations including risk of immune rejection, whilst synthetic grafts often inhibit vascularization and de novo tissue formation. Repair is also no guarantee of success, with for example anatomical failure of rotator cuff tendon repairs reported at near $27 \%$ after 23 months [307]. In the case of muscular degenerative conditions, the role of surgical intervention to aid regeneration and repair is limited and management is often therefore conservative [308]. Recovery and rehabilitation can be prolonged, with degenerative conditions often having poor prognosis [309].

\subsubsection{Biofabrication of MSK tissues}

Due to current treatment option limitations, several groups have attempted to biofabricate MSK tissues, often using a combination of synthetic and natural polymers to guide cell growth. Kang et al. made use of an "integrated tissue-organ printer" to bioprint skeletal muscle structures (Fig. 13) [19]. Mouse myoblast cells were bioprinted using a mixture of hydrogels (hyaluronic acid, gelatin and fibrinogen) whilst PCL was simultaneously deposited in well-defined patterns to aid myoblast alignment. After 7 days, muscle-like structures were seen to develop as the myoblasts aligned along deposited PCL patterns, with high cell viability demonstrated. Implantation of the constructs in vivo led to integration with the common peroneal nerve after 2 weeks, with local musculature also seen to respond to electrical stimuli, implying successful development of innervation. Choi et al. also made use of PCL to guide alignment of skeletal muscle cells [118]. Electrospinning a blend of PCL and collagen, they produced nanofibers with different fibre orientations. Unidirectionally oriented nanofibers were noted to significantly induce human skeletal muscle cell alignment and myotube formation when compared to cells seeded on randomly oriented nanofibers. Mozetic et al. used a different approach, extrusion bioprinting a scaffold with a composite hydrogel of pluronic/alginate loaded with murine myoblasts [310]. Using this approach, they were able to induce 3D myotube alignment and elongation whilst allowing cell survival and myogenic differentiation. Significantly improved expression of myogenic genes as compared to that achieved using conventional 2D culture was also noted. 
A

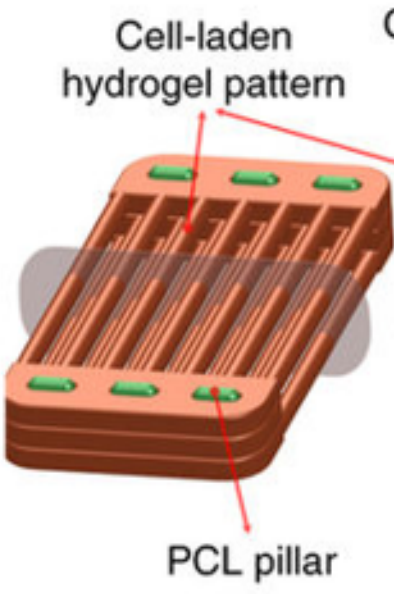

Cross-sectional view

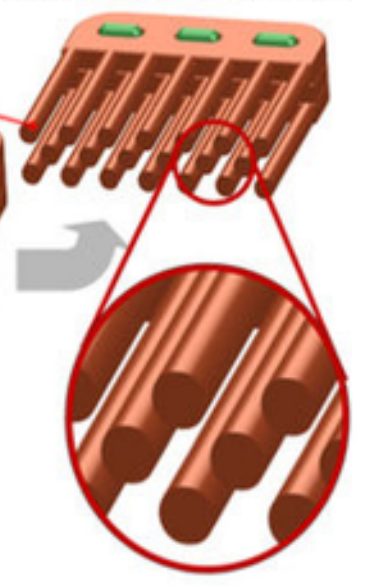

C

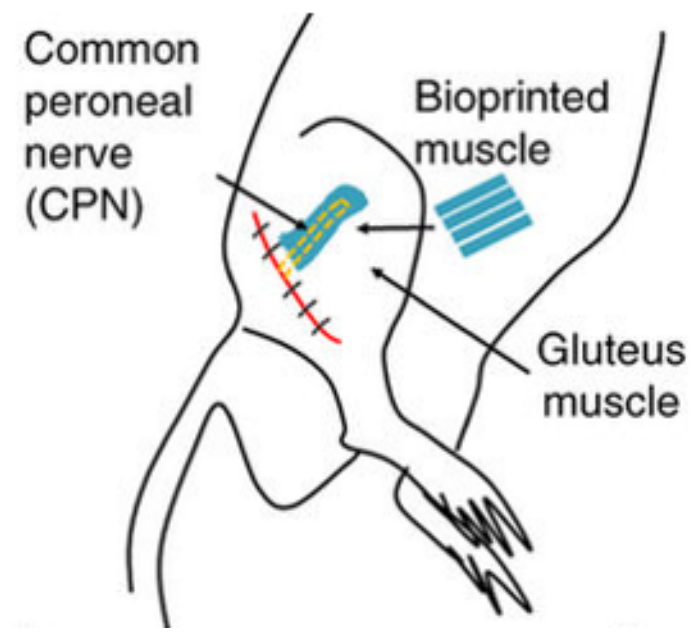

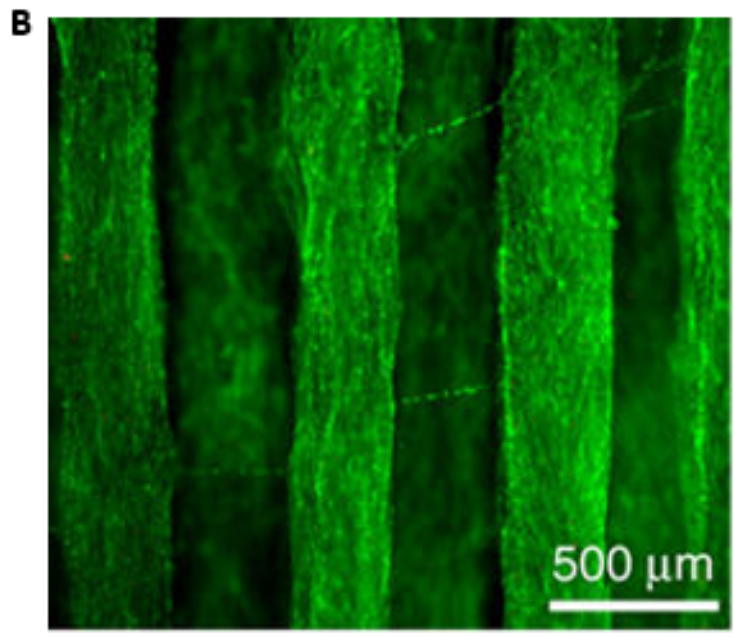

D

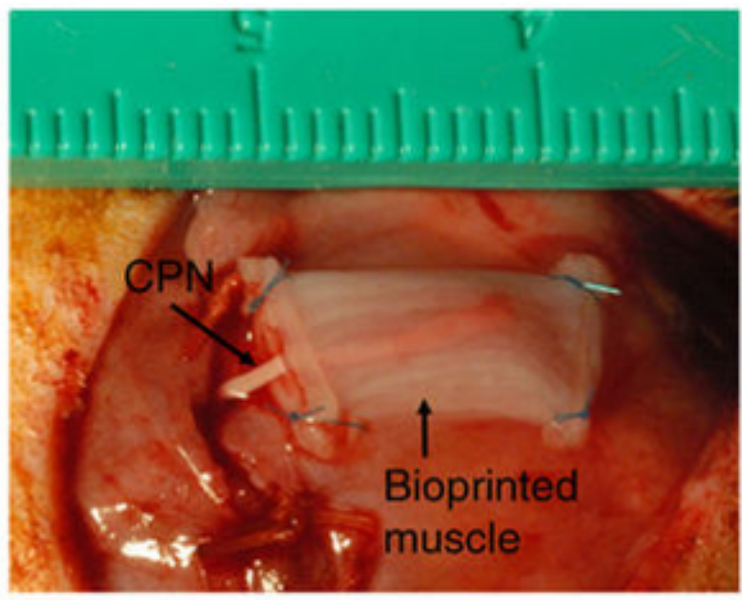

Figure 13. Biofabrication of skeletal muscle structures. (A) PCL pillar and hydrogel containing scaffold designed to encourage muscle organization. (B) Live/dead staining of encapsulated muscle cells showing high cell viability after printing (green: live cells; red: dead cells). (C) Illustration showing ectopic implantation of bioprinted muscle next to common peroneal nerve (CPN) in vivo. (D) Harvested muscle implants after two weeks, showing the presence of organized muscle fibres and innervation from the CPN. Adapted from Kang et al. [19]

Successfully attaching biofabricated muscle to bone requires the development of a seamless interface capable of transferring forces from muscle to tendon. Within normal anatomy, myotendinous junctions (MTJs) allow the seamless transfer of forces through muscles into tendons, merging two biomechanically and biologically disparate tissues together [311]. In contrast to skeletal muscle, which is mainly composed of cells with limited extracellular matrix (ECM), tendinous tissue is mainly composed of collagen ECM with a low number of embedded cells [312]. Although tendons appear simple in structure, the role of individual tendon components in repair and regeneration is still not fully understood $[313,314]$. 
Attempting to recreate the MTJ, Merceron et al. bioprinted a construct with three continuous but distinct regions allowing a transition between muscle and tendinous tissue to occur (Fig 14). A muscle section was created by printing polyurethane (PU) and muscle cells, followed by an interface between the tendon and muscle sections composed of overlapping PU-PCL fibres with muscle and tendon cells also present, which then attached to a final tendon section created from printed PCL and tendon cells [315]. PCL was chosen in the tendinous section to mimic the relatively stiff biomechanics of tendon, whilst PU was used in the muscle section to mimic the elastomeric properties of muscle, allowing repeated contraction and relaxation. Myoblasts and fibroblasts were deposited simultaneously within the hydrogel construct as it was built up layer-by-layer. Analysis of the final construct found the muscle section to be relatively elastic (elastic modulus $=0.39 \pm 0.05$ $\mathrm{MPa}$ ), the tendinous PCL-fibroblast section to be relatively stiff ( $\mathrm{E}=46.67 \pm 2.67 \mathrm{MPa}$ ) whilst the transitional section between the two had intermediate stiffness as intended ( $E=1.03 \pm 0.14 \mathrm{MPa}$ ). The constructs also supported greater than $80 \%$ cell viability one week following printing, with evidence of initial tissue development and cellular differentiation seen. Results were therefore promising, with longer term in vivo studies required to evaluate translation potential. 

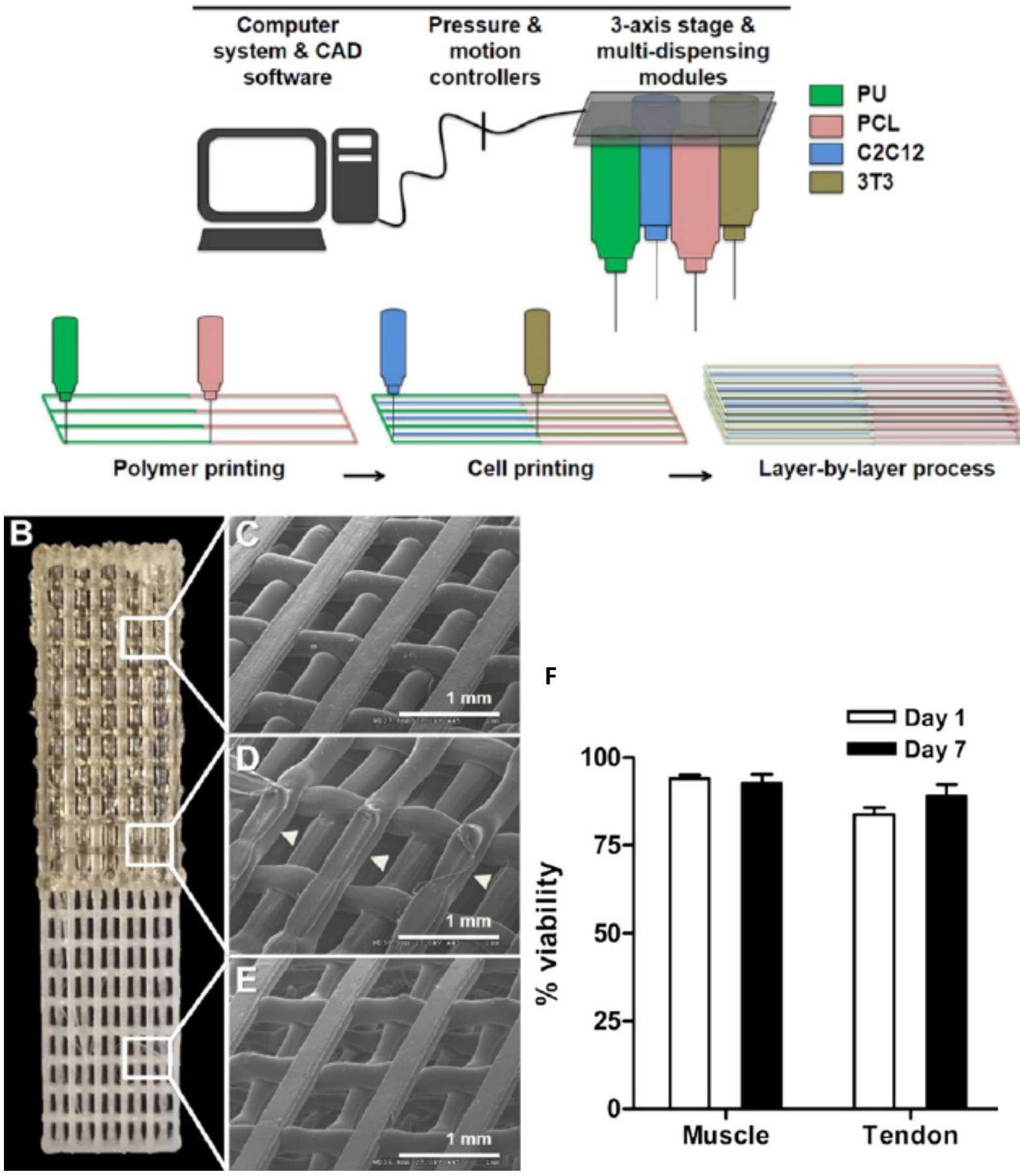

$\mathbf{F}$

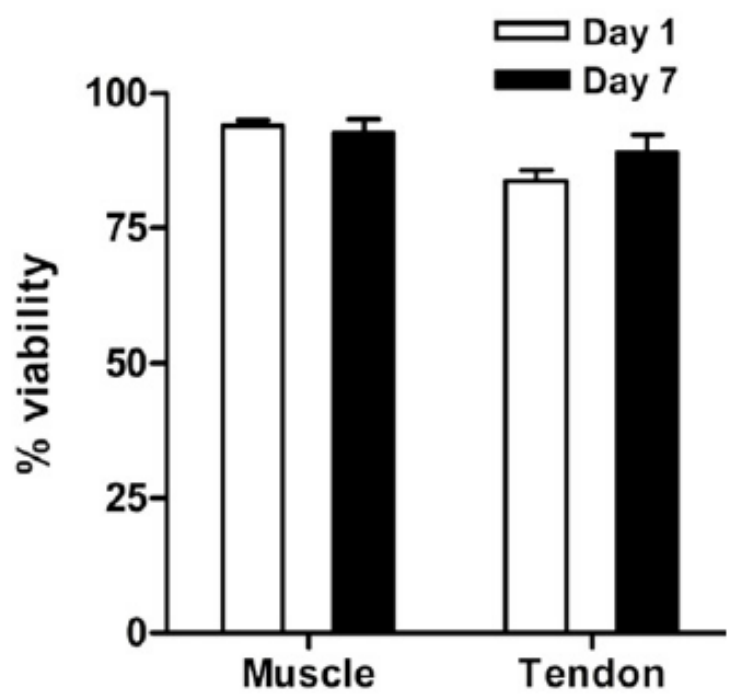

Figure 14. Biofabrication of the myotendinous junction (A) Schematic of 3D integrated organ printing (IOP) system. (B) Bioprinted myotendinous construct with PU side on top, PCL side on bottom, and 10\% overlap area at interface in centre. SEM images showing (C) PU side, (D) interface region, and (E) PCL side. Areas of welding between two polymers indicated by arrowheads. (F) Myoblast and fibroblast cell viability assessed at 1 and $7 \mathrm{~d}$ after printing using a Live/Dead cytotoxicity assay was over $80 \%$. Adapted from Merceron et al. [315]. 
Attempting to solely regenerate tendon tissue, Sensini et al. made use of electrospinning to produce a blended fibre of poly (L-lactic acid) (PLLA) and collagen (Coll), with comparison made to electrospun bundles of pure PLLA [316]. Bundles with individual fibre diameters of $0.31 \pm 0.09 \mu \mathrm{m}$ (PLLA/Coll blend) and overall diameters of 300-500 $\mu \mathrm{m}$ were produced. Tensile tests performed on the bundles found the PLLA/Coll blend found to most closely resemble native tissue, whilst good adhesion of tenocytes and high cell viability after 14 days culture was also observed.

\section{Conclusions and future perspectives}

During this review we have seen a number of successful attempts at biofabrication of soft tissues including cartilage, skin, peripheral nerves and blood vessels. A range of bioprinting techniques have been deployed, with frequent use of natural and synthetic polymers together in constructs that aim to achieve favourable bioactivity and mechanical properties. However, significant challenges remain that must be overcome to allow efficient translation of biofabricated soft tissues from the bench side to the bedside. Bioinks often have low viscosities to facilitate bioprinting; however, to replicate natural tissues it is desirable to be able to print complex structures with hierarchical microarchitectures. As a result, several novel approaches have emerged that facilitate increased print resolution and construct support following bioprinting, including techniques such as FRESH bioprinting and the use of fugitive bioinks $[108,111]$. Scaling up bespoke, novel biofabrication platforms to allow treatment of high volumes of patients and large tissue defects also remains a challenge. Mironov et al. suggest that "It is not sufficient to develop just one robotic device-a bioprinter ... [it] will require the development of series of integrated automated robotic devices, or an organ biofabrication line" [134]. To increase the scalability of biofabrication platforms, the bespoke systems often used in current research must be developed towards standardized and integrated systems capable of the high throughput performance required in clinical practice $[4,13]$. Such systems would allow the sequential development of printed constructs into vascularized living tissue or organs suitable for patient use. However, there are some remaining technological, ethical and regulatory challenges that must be overcome to enable this. To replicate the complex hierarchical nature of bodily tissues, high resolution bioprinting is required; however, current "drop on demand" methods of achieving high print resolution including laser-assisted and inkjet techniques currently lack the capacity to produce large scale, thick tissue constructs in the volume required for clinical usage $[10,14,174]$. Extrusion bioprinting, whilst perhaps lacking the cellular resolution of other techniques, offers a larger scale bioprinting platform; when combined with selfassembly techniques, this approach has already allowed successful generation of thick tissues such as cartilage [58]. 
A further challenge exists when trying to determine the bioink or scaffold biofabrication process best suited to regenerating an individual tissue; a vast array of cell sources, biomaterials, growth factors, biofabrication techniques, bioreactors and 3D culture techniques have been investigated thus far, sometimes with conflicting evidence $[3,4,13,80,93]$. Balancing all the technical requirements of tissue constructs also remains challenging; for example, increasing scaffold porosity to facilitate inwards cell migration and nutrient diffusion also reduces the mechanical strength of a construct $[13,317]$. Tuning degradation levels of bioprinted scaffolds to allow timely formation of new tissue also represents a further challenge; if a scaffold material degrades rapidly, loss of tissue architecture, blood supply and cellular organisation could occur. Similarly, if a scaffold material is too resistant to biodegradation, a host inflammatory response could be triggered against the foreign material of the scaffold, leading to scar tissue formation and poor tissue regeneration. Biofabrication of fully vascularised constructs that integrate multiple tissue types together has also yet to be achieved large-scale; patients with soft tissue defects involving full thickness tissue loss still face the prospect of major reconstructive or amputation surgery depending on injury severity.

A lack of long term in vivo studies following implantation of bioprinted cells and constructs into the human body also exists. It is therefore difficult to properly characterise the risk of implanting biomaterials or cells into a patient; breakdown products could trigger unforeseen immune reactions, as has occurred following some modern hip replacements [318]; furthermore, implanted cells could migrate or dislodge from constructs, causing ectopic tissue growth or teratoma formation depending on cell types used [24-26]. The long term in vivo performance of many novel biomaterials, assessed by their degradation profiles, tissue integration and biocompatibility remains uncertain [319]. An ethical challenge may also arise in future from the cost of implementing biofabrication technology, as wealthy patients could have greater access to the technology, bypassing transplant waiting lists by paying for their 'own' tissue or organs, whilst patients with less resources are forced to wait for donor tissue or undergo alternative procedures such as amputation or dialysis. However, as scalability of the technology is improved, the ethical dilemma of having a "two-tiered" level of access to new tissue and organs may reduce. Furthermore, biomaterials are not infrequently animal derived, which some patients may find disagreeable.

Despite these challenges, the field of 3D biofabrication offers an increasingly large number of potential solutions to help ease the treatment burden of soft tissue and cartilage defects. Biofabricated soft tissues have already been successfully implanted in vivo within several studies, thanks to the increasingly sophisticated control available over construct content and microarchitecture. When combined with the increasing range of available bioinks, bioprinting 
techniques, biomaterials and anatomical scaffold designs, future potential to biofabricate patientspecific tissue constructs to treat individual soft tissue defects is vast. As biofabrication platforms become more standardised and increase in scale, it is hoped that increasingly cost effective and reproducible treatment tailored to the individual patient will become possible in future.

\section{References}

[1] Colen SR, Shaw WW, McCarthy JG. Review of the morbidity of 300 free-flap donor sites. Plast Reconstr Surg. 1986;77:948-53.

[2] Moore AM, MacEwan M, Santosa KB, Chenard KE, Ray WZ, Hunter DA, et al. Acellular Nerve Allografts in Peripheral Nerve Regeneration: A Comparative Study. Muscle Nerve. 2011;44:221-34.

[3] Groll J, Boland T, Blunk T, Burdick JA, Cho DW, Dalton PD, et al. Biofabrication: reappraising the definition of an evolving field. Biofabrication. 2016;8:013001.

[4] Moroni L, Boland T, Burdick JA, De Maria C, Derby B, Forgacs G, et al. Biofabrication: A Guide to Technology and Terminology. Trends Biotechnol. 2018;36:384-402.

[5] Murphy SV, Atala A. 3D bioprinting of tissues and organs. Nat Biotech. 2014;32:773-85.

[6] Orciani M, Fini M, Di Primio R, Mattioli-Belmonte M. Biofabrication and Bone Tissue Regeneration: Cell Source, Approaches, and Challenges. Frontiers in Bioengineering and Biotechnology. 2017;5.

[7] Frese L, Dijkman PE, Hoerstrup SP. Adipose Tissue-Derived Stem Cells in Regenerative Medicine. Transfusion Medicine and Hemotherapy. 2016;43:268-74.

[8] Groll J, Burdick JA, Cho DW, Derby B, Gelinsky M, Heilshorn SC, et al. A definition of bioinks and their distinction from biomaterial inks. Biofabrication. 2019;11:013001.

[9] Hospodiuk M, Dey M, Sosnoski D, Ozbolat IT. The bioink: A comprehensive review on bioprintable materials. Biotechnology Advances. 2017;35:217-39.

[10] Ozbolat IT, Hospodiuk M. Current advances and future perspectives in extrusion-based bioprinting. Biomaterials. 2016;76:321-43.

[11] Petcu EB, Midha R, McColl E, Popa-Wagner A, Chirila TV, Dalton PD. 3D printing strategies for peripheral nerve regeneration. Biofabrication. 2018;10:032001.

[12] Cornelissen D-J, Faulkner-Jones A, Shu W. Current developments in 3D bioprinting for tissue engineering. Current Opinion in Biomedical Engineering. 2017;2:76-82.

[13] Turnbull G, Clarke J, Picard F, Riches P, Jia L, Han F, et al. 3D bioactive composite scaffolds for bone tissue engineering. Bioactive Materials. 2017. 
[14] Datta P, Ayan B, Ozbolat IT. Bioprinting for vascular and vascularized tissue biofabrication. Acta Biomater. 2017;51:1-20.

[15] Ventola CL. Medical Applications for 3D Printing: Current and Projected Uses. Pharmacy and Therapeutics. 2014;39:704-11.

[16] Li J, Chen M, Fan X, Zhou H. Recent advances in bioprinting techniques: approaches, applications and future prospects. Journal of Translational Medicine. 2016;14:271.

[17] Tsimbouri PM, Childs PG, Pemberton GD, Yang J, Jayawarna V, Orapiriyakul W, et al. Stimulation of 3D osteogenesis by mesenchymal stem cells using a nanovibrational bioreactor. Nature Biomedical Engineering. 2017;1:758-70.

[18] Murphy SV, Atala A. 3D bioprinting of tissues and organs. Nat Biotechnol. 2014;32:773-85.

[19] Kang H-W, Lee SJ, Ko IK, Kengla C, Yoo JJ, Atala A. A 3D bioprinting system to produce humanscale tissue constructs with structural integrity. Nat Biotech. 2016;34:312-9.

[20] Shafiee A, Atala A. Printing Technologies for Medical Applications. Trends Mol Med. 2016;22:254-65.

[21] Koch L, Deiwick A, Franke A, Schwanke K, Haverich A, Zweigerdt R, et al. Laser bioprinting of human induced pluripotent stem cells - the effect of printing and biomaterials on cell survival, pluripotency, and differentiation. Biofabrication. 2018;10:035005.

[22] Li Q, Lin H, Du Q, Liu K, Wang O, Evans C, et al. Scalable and physiologically relevant microenvironments for human pluripotent stem cell expansion and differentiation. Biofabrication. 2018;10:025006.

[23] Bioprinting and Differentiation of Stem Cells. Molecules. 2016;21:1188.

[24] Leeper NJ, Hunter AL, Cooke JP. Stem cell therapy for vascular regeneration: Adult, Embryonic, and Induced Pluripotent Stem Cells. Circulation. 2010;122:517-26.

[25] Ratajczak J, Zuba-Surma E, Paczkowska E, Kucia M, Nowacki P, Ratajczak MZ. Stem cells for neural regeneration--a potential application of very small embryonic-like stem cells. J Physiol Pharmacol. 2011;62:3-12.

[26] Hoffman LM, Carpenter MK. Characterization and culture of human embryonic stem cells. Nat Biotechnol. 2005;23:699-708.

[27] Colnot C. Cell sources for bone tissue engineering: insights from basic science. Tissue Eng Part B Rev. 2011;17:449-57.

[28] Singh VK, Kalsan M, Kumar N, Saini A, Chandra R. Induced pluripotent stem cells: applications in regenerative medicine, disease modeling, and drug discovery. Frontiers in Cell and Developmental Biology. 2015;3.

[29] Ji H, Kim HS, Kim H-W, Leong KW. Application of induced pluripotent stem cells to model smooth muscle cell function in vascular diseases. Current Opinion in Biomedical Engineering. 
[30] Illich DJ, Demir N, Stojkovic M, Scheer M, Rothamel D, Neugebauer J, et al. Concise review: induced pluripotent stem cells and lineage reprogramming: prospects for bone regeneration. Stem Cells. 2011;29:555-63.

[31] Ciuffreda MC, Malpasso G, Musaro P, Turco V, Gnecchi M. Protocols for in vitro Differentiation of Human Mesenchymal Stem Cells into Osteogenic, Chondrogenic and Adipogenic Lineages. Methods Mol Biol. 2016;1416:149-58.

[32] Pittenger MF. Mesenchymal stem cells from adult bone marrow. Methods Mol Biol. 2008;449.

[33] Pittenger MF, Mackay AM, Beck SC, Jaiswal RK, Douglas R, Mosca JD, et al. Multilineage potential of adult human mesenchymal stem cells. Science (New York, NY). 1999;284.

[34] Bertani N, Malatesta P, Volpi G, Sonego P, Perris R. Neurogenic potential of human mesenchymal stem cells revisited: analysis by immunostaining, time-lapse video and microarray. Journal of Cell Science. 2005;118:3925-36.

[35] Huang NF, Li S. Mesenchymal stem cells for vascular regeneration. Regenerative medicine. 2008;3:877-92.

[36] Bunnell BA, Flaat M, Gagliardi C, Patel B, Ripoll C. Adipose-derived Stem Cells: Isolation, Expansion and Differentiation. Methods (San Diego, Calif). 2008;45:115-20.

[37] Gao G, Yonezawa T, Hubbell K, Dai G, Cui X. Inkjet-bioprinted acrylated peptides and PEG hydrogel with human mesenchymal stem cells promote robust bone and cartilage formation with minimal printhead clogging. Biotechnol J. 2015;10:1568-77.

[38] Marco C, Joanna I, Krisztina S, Jakub J, Mariella D, Andrea B, et al. 3D bioprinting of BM-MSCsloaded ECM biomimetic hydrogels for in vitro neocartilage formation. Biofabrication. 2016;8:035002.

[39] Haishuang L, Qiang L, Yuguo L. Three-dimensional tissues using human pluripotent stem cell spheroids as biofabrication building blocks. Biofabrication. 2017;9:025007.

[40] Zhang Y, Khan D, Delling J, Tobiasch E. Mechanisms Underlying the Osteo- and AdipoDifferentiation of Human Mesenchymal Stem Cells. The Scientific World Journal. 2012;2012:793823.

[41] Steinert AF, Ghivizzani SC, Rethwilm A, Tuan RS, Evans CH, Nöth U. Major biological obstacles for persistent cell-based regeneration of articular cartilage. Arthritis Research \& Therapy. 2007;9:213.

[42] Roobrouck VD, Ulloa-Montoya F, Verfaillie CM. Self-renewal and differentiation capacity of young and aged stem cells. Experimental Cell Research. 2008;314:1937-44.

[43] Peng L, Jia Z, Yin X, Zhang X, Liu Y, Chen P, et al. Comparative analysis of mesenchymal stem cells from bone marrow, cartilage, and adipose tissue. Stem Cells Dev. 2008;17:761-73.

[44] Lee RH, Kim B, Choi I, Kim H, Choi HS, Suh K, et al. Characterization and expression analysis of mesenchymal stem cells from human bone marrow and adipose tissue. Cell Physiol Biochem.

2004;14:311-24. 
[45] Bahcecioglu G, Hasirci N, Bilgen B, Hasirci V. A 3D printed PCL/hydrogel construct with zonespecific biochemical composition mimicking that of the meniscus. Biofabrication. 2019;11:025002.

[46] Kunisch E, Knauf A-K, Hesse E, Freudenberg U, Werner C, Bothe F, et al. StarPEG/heparinhydrogel based in vivo engineering of stable bizonal cartilage with a calcified bottom layer. Biofabrication. 2018;11:015001.

[47] Thomas M, Willerth SM. 3-D Bioprinting of Neural Tissue for Applications in Cell Therapy and Drug Screening. Frontiers in Bioengineering and Biotechnology. 2017;5:69.

[48] Swaminathan S, Hamid Q, Sun W, Clyne AM. Bioprinting of 3D breast epithelial spheroids for human cancer models. Biofabrication. 2019.

[49] Holland I, Logan J, Shi J, McCormick C, Liu D, Shu W. 3D biofabrication for tubular tissue engineering. Bio-Design and Manufacturing. 2018;1:89-100.

[50] Wieringa PA, Gonçalves de Pinho AR, Micera S, van Wezel RJA, Moroni L. Biomimetic Architectures for Peripheral Nerve Repair: A Review of Biofabrication Strategies. Advanced Healthcare Materials. 2018;7:1701164.

[51] Elke K, Anne-Kathrin K, Eliane H, Uwe F, Carsten W, Friederike B, et al. StarPEG/heparinhydrogel based in vivo engineering of stable bizonal cartilage with a calcified bottom layer. Biofabrication. 2019;11:015001.

[52] Otto IA, Levato R, Webb WR, Khan IM, Breugem CC, Malda J. Progenitor cells in auricular cartilage demonstrate cartilage-forming capacity in 3D hydrogel culture. Eur Cell Mater. 2018;35:132-50.

[53] Fennema E, Rivron N, Rouwkema J, van Blitterswijk C, de Boer J. Spheroid culture as a tool for creating 3D complex tissues. Trends Biotechnol. 2013;31:108-15.

[54] Lee GH, Lee JS, Lee G-H, Joung WY, Kim SH, Lee SH, et al. Networked concave microwell arrays for constructing 3D cell spheroids. Biofabrication. 2017;10:015001.

[55] Mironov V, Visconti RP, Kasyanov V, Forgacs G, Drake CJ, Markwald RR. Organ printing: tissue spheroids as building blocks. Biomaterials. 2009;30:2164-74.

[56] Zhang K, Yan S, Cui L, Yin J. ASC spheroids formed in poly(L-glutamic acid)/chitosan scaffold to enhance hyaline-like cartilage regeneration. Frontiers in Bioengineering and Biotechnology.

[57] Zhuang P, Sun AX, An J, Chua CK, Chew SY. 3D neural tissue models: From spheroids to bioprinting. Biomaterials. 2018;154:113-33.

[58] Yu Y, Moncal KK, Li J, Peng W, Rivero I, Martin JA, et al. Three-dimensional bioprinting using selfassembling scalable scaffold-free "tissue strands" as a new bioink. Scientific Reports. 2016;6:28714.

[59] Fleming PA, Argraves WS, Gentile C, Neagu A, Forgacs G, Drake CJ. Fusion of uniluminal vascular spheroids: A model for assembly of blood vessels. Developmental Dynamics. 2010;239:spconespcone. 
[60] Mekhileri NV, Lim KS, Brown GCJ, Mutreja I, Schon BS, Hooper GJ, et al. Automated 3D bioassembly of micro-tissues for biofabrication of hybrid tissue engineered constructs.

Biofabrication. 2018;10:024103.

[61] Ahmed EM. Hydrogel: Preparation, characterization, and applications: A review. Journal of Advanced Research. 2015;6:105-21.

[62] Zhu J, Marchant RE. Design properties of hydrogel tissue-engineering scaffolds. Expert review of medical devices. 2011;8:607-26.

[63] Gao T, Gillispie GJ, Copus JS, Pr AK, Seol Y-J, Atala A, et al. Optimization of gelatin-alginate composite bioink printability using rheological parameters: a systematic approach. Biofabrication. 2018;10:034106.

[64] Ribeiro A, Blokzijl MM, Levato R, Visser CW, Castilho M, Hennink WE, et al. Assessing bioink shape fidelity to aid material development in 3D bioprinting. Biofabrication. 2017;10:014102.

[65] Byoung Soo K, Hyeonji K, Ge G, Jinah J, Dong-Woo C. Decellularized extracellular matrix: a step towards the next generation source for bioink manufacturing. Biofabrication. 2017;9:034104.

[66] Stanton MM, Samitier J, Sanchez S. Bioprinting of 3D hydrogels. Lab Chip. 2015;15:3111-5.

[67] Elise D, Kristin S, Alexandra P, Thomas S. Recombinant spider silk-based bioinks. Biofabrication. 2017;9:044104.

[68] Zongjie W, Zhenlin T, Fredric M, Keekyoung K. Comparative study of gelatin methacrylate hydrogels from different sources for biofabrication applications. Biofabrication. 2017;9:044101.

[69] Nicole D, Louis W, Tylar P, Joseph S, Caroline D, Sonya S, et al. Correlating rheological properties and printability of collagen bioinks: the effects of riboflavin photocrosslinking and pH. Biofabrication. 2017;9:034102.

[70] DeSimone E, Schacht K, Pellert A, Scheibel T. Recombinant spider silk-based bioinks. Biofabrication. 2017;9:044104.

[71] Teng G, Gregory JG, Joshua SC, Anil Kumar PR, Young-Joon S, Anthony A, et al. Optimization of gelatin-alginate composite bioink printability using rheological parameters: a systematic approach. Biofabrication. 2018;10:034106.

[72] Zhang H-B, Xing T-L, Yin R-X, Shi Y, Yang S-M, Zhang W-J. Three-dimensional bioprinting is not only about cell-laden structures. Chinese Journal of Traumatology. 2016;19:187-92.

[73] Guvendiren M, Molde J, Soares RMD, Kohn J. Designing Biomaterials for 3D Printing. ACS Biomaterials Science \& Engineering. 2016;2:1679-93.

[74] Onur B, Elena MD-J-P, Christoph M, Davide DA, Jeremy GB, Laura JB, et al. Biofabricated soft network composites for cartilage tissue engineering. Biofabrication. 2017;9:025014.

[75] Hersel U, Dahmen C, Kessler H. RGD modified polymers: biomaterials for stimulated cell adhesion and beyond. Biomaterials. 2003;24:4385-415. 
[76] Baldwin AD, Kiick KL. Polysaccharide-Modified Synthetic Polymeric Biomaterials. Biopolymers. 2010;94:128-40.

[77] Chimene D, Lennox KK, Kaunas RR, Gaharwar AK. Advanced Bioinks for 3D Printing: A Materials Science Perspective. Annals of Biomedical Engineering. 2016;44:2090-102.

[78] Liliang O, Rui Y, Yu Z, Wei S. Effect of bioink properties on printability and cell viability for 3D bioplotting of embryonic stem cells. Biofabrication. 2016;8:035020.

[79] Houzhu D, Filippos T, Robert CC. Bioprinting multidimensional constructs: a quantitative approach to understanding printed cell density and redistribution phenomena. Biomedical Physics \& Engineering Express. 2017;3:035016.

[80] Cornelissen D-J, Faulkner-Jones A, Shu W. Current developments in 3D bioprinting for tissue engineering. Current Opinion in Biomedical Engineering.

[81] Alakpa Enateri V, Jayawarna V, Lampel A, Burgess Karl V, West Christopher C, Bakker Sanne CJ, et al. Tunable Supramolecular Hydrogels for Selection of Lineage-Guiding Metabolites in Stem Cell Cultures. Chem.1:298-319.

[82] Chen F, Ni Y, Liu B, Zhou T, Yu C, Su Y, et al. Self-crosslinking and injectable hyaluronic acid/RGDfunctionalized pectin hydrogel for cartilage tissue engineering. Carbohydrate Polymers. 2017;166:3144.

[83] Khoon SL, Riccardo L, Pedro FC, Miguel DC, Cesar RA-O, Kim MAvD, et al. Bio-resin for high resolution lithography-based biofabrication of complex cell-laden constructs. Biofabrication. 2018;10:034101.

[84] Ahlfeld T, Cidonio G, Kilian D, Duin S, Akkineni AR, Dawson JI, et al. Development of a clay based bioink for 3D cell printing for skeletal application. Biofabrication. 2017;9:034103.

[85] Annika W, Kirsten B, Günter EMT, Petra JK. Bone matrix production in hydroxyapatite-modified hydrogels suitable for bone bioprinting. Biofabrication. 2017;9:044103.

[86] Yang L, Xulin J, Ling L, Zhi-Nan C, Ge G, Rui Y, et al. 3D printing human induced pluripotent stem cells with novel hydroxypropyl chitin bioink: scalable expansion and uniform aggregation.

Biofabrication. 2018;10:044101.

[87] Kim IL, Mauck RL, Burdick JA. Hydrogel design for cartilage tissue engineering: A case study with hyaluronic acid. Biomaterials. 2011;32:8771-82.

[88] Costa RM, Rauf S, Hauser CAE. Towards biologically relevant synthetic designer matrices in 3D bioprinting for tissue engineering and regenerative medicine. Current Opinion in Biomedical Engineering.

[89] Cicha I, Detsch R, Singh R, Reakasame S, Alexiou C, Boccaccini AR. Biofabrication of vessel grafts based on natural hydrogels. Current Opinion in Biomedical Engineering.

[90] Bioprinting of Thermoresponsive Hydrogels for Next Generation Tissue Engineering: A Review. Macromolecular Materials and Engineering. 2017;302:1600266. 
[91] Park H, Lee HJ, An H, Lee KY. Alginate hydrogels modified with low molecular weight hyaluronate for cartilage regeneration. Carbohydr Polym. 2017;162:100-7.

[92] Shin J, Choi EJ, Cho JH, Cho AN, Jin Y, Yang K, et al. Three-Dimensional Electroconductive Hyaluronic Acid Hydrogels Incorporated with Carbon Nanotubes and Polypyrrole by CatecholMediated Dispersion Enhance Neurogenesis of Human Neural Stem Cells. Biomacromolecules. 2017;18:3060-72.

[93] Holmes AM, Charlton A, Derby B, Ewart L, Scott A, Shu W. Rising to the challenge: applying biofabrication approaches for better drug and chemical product development. Biofabrication. 2017;9:033001.

[94] Alan F-J, Catherine F, Dirk-Jan C, John G, Jason K, Aidan C, et al. Bioprinting of human pluripotent stem cells and their directed differentiation into hepatocyte-like cells for the generation of mini-livers in 3D. Biofabrication. 2015;7:044102.

[95] Faulkner-Jones A, Greenhough S, King JA, Gardner J, Courtney A, Shu W. Development of a valve-based cell printer for the formation of human embryonic stem cell spheroid aggregates. Biofabrication. 2013;5:015013.

[96] Roth EA, Xu T, Das M, Gregory C, Hickman JJ, Boland T. Inkjet printing for high-throughput cell patterning. Biomaterials. 2004;25:3707-15.

[97] Cui X, Boland T, D'Lima DD, Lotz MK. Thermal Inkjet Printing in Tissue Engineering and Regenerative Medicine. Recent patents on drug delivery \& formulation. 2012;6:149-55.

[98] Saunders RE, Derby B. Inkjet printing biomaterials for tissue engineering: bioprinting. International Materials Reviews. 2014;59:430-48.

[99] Bose S, Vahabzadeh S, Bandyopadhyay A. Bone tissue engineering using 3D printing. Materials Today. 2013;16:496-504.

[100] Michael S, Sorg H, Peck C-T, Koch L, Deiwick A, Chichkov B, et al. Tissue Engineered Skin Substitutes Created by Laser-Assisted Bioprinting Form Skin-Like Structures in the Dorsal Skin Fold Chamber in Mice. PLOS ONE. 2013;8:e57741.

[101] Koch L, Gruene M, Unger C, Chichkov B. Laser assisted cell printing. Curr Pharm Biotechnol. 2013;14:91-7.

[102] Gurkan UA, El Assal R, Yildiz SE, Sung Y, Trachtenberg AJ, Kuo WP, et al. Engineering Anisotropic Biomimetic Fibrocartilage Microenvironment by Bioprinting Mesenchymal Stem Cells in Nanoliter Gel Droplets. Molecular Pharmaceutics. 2014;11:2151-9.

[103] Yu Y, Moncal KK, Li J, Peng W, Rivero I, Martin JA, et al. Three-dimensional bioprinting using self-assembling scalable scaffold-free "tissue strands" as a new bioink. 2016;6:28714.

[104] Moroni L, Burdick JA, Highley C, Lee SJ, Morimoto Y, Takeuchi S, et al. Biofabrication strategies for 3D in vitro models and regenerative medicine. Nature Reviews Materials. 2018;3:21-37.

[105] Holzl K, Lin S, Tytgat L, Van Vlierberghe S, Gu L, Ovsianikov A. Bioink properties before, during and after 3D bioprinting. Biofabrication. 2016;8:032002. 
[106] Ouyang L, Highley CB, Sun W, Burdick JA. A Generalizable Strategy for the 3D Bioprinting of Hydrogels from Nonviscous Photo-crosslinkable Inks. Advanced Materials. 2017;29:1604983.

[107] Seol Y-J, Lee H, Copus JS, Kang H-W, Cho D-W, Atala A, et al. 3D bioprinted biomask for facial skin reconstruction. Bioprinting. 2018;10:e00028.

[108] Kolesky DB, Homan KA, Skylar-Scott MA, Lewis JA. Three-dimensional bioprinting of thick vascularized tissues. Proceedings of the National Academy of Sciences. 2016;113:3179-84.

[109] Lee JS, Hong JM, Jung JW, Shim JH, Oh JH, Cho DW. 3D printing of composite tissue with complex shape applied to ear regeneration. Biofabrication. 2014;6:024103.

[110] Armstrong JPK, Burke M, Carter BM, Davis SA, Perriman AW. 3D Bioprinting Using a Templated Porous Bioink. Advanced Healthcare Materials. 2016;5:1724-30.

[111] Hinton TJ, Jallerat Q, Palchesko RN, Park JH, Grodzicki MS, Shue H-J, et al. Three-dimensional printing of complex biological structures by freeform reversible embedding of suspended hydrogels. Science Advances. 2015;1.

[112] Yang GH, Lee J, Kim G. The fabrication of uniaxially aligned micro-textured polycaprolactone struts and application for skeletal muscle tissue regeneration. Biofabrication. 2019;11:025005.

[113] Wu S, Peng H, Li X, Streubel PN, Liu Y, Duan B. Effect of scaffold morphology and cell co-culture on tenogenic differentiation of HADMSC on centrifugal melt electrospun poly (L-lactic acid) fibrous meshes. Biofabrication. 2017;9:044106.

[114] Polk S, Sori N, Thayer N, Kemper N, Maghdouri-White Y, Bulysheva AA, et al. Pneumatospinning of collagen microfibers from benign solvents. Biofabrication. 2018;10:045004.

[115] Itoh M, Nakayama K, Noguchi R, Kamohara K, Furukawa K, Uchihashi K, et al. Scaffold-Free Tubular Tissues Created by a Bio-3D Printer Undergo Remodeling and Endothelialization when Implanted in Rat Aortae. PLoS One. 2015;10:e0136681.

[116] Moldovan NI, Hibino N, Nakayama K. Principles of the Kenzan Method for Robotic Cell Spheroid-Based Three-Dimensional Bioprinting. Tissue Engineering Part B: Reviews. 2016;23:237-44.

[117] Norotte C, Marga FS, Niklason LE, Forgacs G. Scaffold-free vascular tissue engineering using bioprinting. Biomaterials. 2009;30:5910-7.

[118] Choi JS, Lee SJ, Christ GJ, Atala A, Yoo JJ. The influence of electrospun aligned poly(epsiloncaprolactone)/collagen nanofiber meshes on the formation of self-aligned skeletal muscle myotubes. Biomaterials. 2008;29:2899-906.

[119] Criscenti G, De Maria C, Longoni A, van Blitterswijk CA, Fernandes HAM, Vozzi G, et al. Softmolecular imprinted electrospun scaffolds to mimic specific biological tissues. Biofabrication. 2018;10:045005.

[120] Costantini M, Colosi C, Święszkowski W, Barbetta A. Co-axial wet-spinning in 3D bioprinting: state of the art and future perspective of microfluidic integration. Biofabrication. 2018;11:012001. 
[121] Liu W, Zhong Z, Hu N, Zhou Y, Maggio L, Miri AK, et al. Coaxial extrusion bioprinting of 3D microfibrous constructs with cell-favorable gelatin methacryloyl microenvironments. Biofabrication. 2018;10:024102.

[122] Zhang Y, Yu Y, Ozbolat IT. Direct Bioprinting of Vessel-Like Tubular Microfluidic Channels. Journal of Nanotechnology in Engineering and Medicine. 2013;4:0210011-7.

[123] Gao Q, He Y, Fu JZ, Liu A, Ma L. Coaxial nozzle-assisted 3D bioprinting with built-in microchannels for nutrients delivery. Biomaterials. 2015;61:203-15.

[124] Jia W, Gungor-Ozkerim PS, Zhang YS, Yue K, Zhu K, Liu W, et al. Direct 3D bioprinting of perfusable vascular constructs using a blend bioink. Biomaterials. 2016;106:58-68.

[125] Lee YB, Lee J-y, Byun H, Ahmad T, Akashi M, Matsusaki M, et al. One-step delivery of a functional multi-layered cell sheet using a thermally expandable hydrogel with controlled presentation of cell adhesive proteins. Biofabrication. 2018;10:025001.

[126] L'heureux N, Pâquet S, Labbé R, Germain L, Auger FA. A completely biological tissueengineered human blood vessel. The FASEB Journal. 1998;12:47-56.

[127] Egami M, Haraguchi Y, Shimizu T, Yamato M, Okano T. Latest status of the clinical and industrial applications of cell sheet engineering and regenerative medicine. Arch Pharm Res. 2014;37:96-106.

[128] Yang J, Yamato M, Kohno C, Nishimoto A, Sekine H, Fukai F, et al. Cell sheet engineering: recreating tissues without biodegradable scaffolds. Biomaterials. 2005;26:6415-22.

[129] J. HM, Fumiki Y, Yun-Ho J, Jiankang H, N. KN, Hirokazu K, et al. Designer Hydrophilic Regions Regulate Droplet Shape for Controlled Surface Patterning and 3D Microgel Synthesis. Small. 2012;8:393-403.

[130] Fernandez Javier G, Khademhosseini A. Micro-Masonry: Construction of 3D Structures by Microscale Self-Assembly. Advanced Materials. 2010;22:2538-41.

[131] Tasoglu S, Diller E, Guven S, Sitti M, Demirci U. Untethered micro-robotic coding of threedimensional material composition. Nature Communications. 2014;5:3124.

[132] Baraniak PR, McDevitt TC. Scaffold-free culture of mesenchymal stem cell spheroids in suspension preserves multilineage potential. Cell Tissue Res. 2012;347.

[133] Cheng NC, Wang S, Young TH. The influence of spheroid formation of human adipose-derived stem cells on chitosan films on stemness and differentiation capabilities. Biomaterials. 2012;33.

[134] Mironov V, Kasyanov V, Markwald RR. Organ printing: from bioprinter to organ biofabrication line. Curr Opin Biotechnol. 2011;22:667-73.

[135] Elena AB, Elizaveta VK, Jonathan D, Charlotte $H$, Frederico DASP, Vladislav AP, et al. Bioprinting of a functional vascularized mouse thyroid gland construct. Biofabrication. 2017;9:034105.

[136] Morimoto Y, Hsiao AY, Takeuchi S. Point-, line-, and plane-shaped cellular constructs for 3D tissue assembly. Advanced Drug Delivery Reviews. 2015;95:29-39. 
[137] Pacak CA, Cowan DB. Fabrication of Myogenic Engineered Tissue Constructs. Journal of Visualized Experiments : JoVE. 2009:1137.

[138] Ghanizadeh Tabriz A, Mills CG, Mullins JJ, Davies JA, Shu W. Rapid Fabrication of Cell-Laden Alginate Hydrogel 3D Structures by Micro Dip-Coating. Front Bioeng Biotechnol. 2017;5:13.

[139] Tabriz AG, Hermida MA, Leslie NR, Shu W. Three-dimensional bioprinting of complex cell laden alginate hydrogel structures. Biofabrication. 2015;7:045012.

[140] Wilkens CA, Rivet CJ, Akentjew TL, Alverio J, Khoury M, Acevedo JP. Layer-by-layer approach for a uniformed fabrication of a cell patterned vessel-like construct. Biofabrication. 2016;9:015001.

[141] Bhosale AM, Richardson JB. Articular cartilage: structure, injuries and review of management. British Medical Bulletin. 2008;87:77-95.

[142] Sophia Fox AJ, Bedi A, Rodeo SA. The basic science of articular cartilage: structure, composition, and function. Sports Health. 2009;1:461-8.

[143] Akkiraju H, Nohe A. Role of Chondrocytes in Cartilage Formation, Progression of Osteoarthritis and Cartilage Regeneration. J Dev Biol. 2015;3:177-92.

[144] Havelka S, Horn V, Spohrova D, Valouch P. The calcified-noncalcified cartilage interface: the tidemark. Acta Biol Hung. 1984;35:271-9.

[145] Hamilton DF, Howie CR. Knee arthroscopy: influence of systems for delivering healthcare on procedure rates. BMJ : British Medical Journal. 2015;351.

[146] Steadman JR, Rodkey WG, Singleton SB, Briggs KK. Microfracture technique forfull-thickness chondral defects: Technique and clinical results. Operative Techniques in Orthopaedics. 1997;7:3004.

[147] Goyal D, Keyhani S, Lee EH, Hui JH. Evidence-based status of microfracture technique: a systematic review of level I and II studies. Arthroscopy : the journal of arthroscopic \& related surgery : official publication of the Arthroscopy Association of North America and the International Arthroscopy Association. 2013;29:1579-88.

[148] Solheim E, Hegna J, Oyen J, Austgulen OK, Harlem T, Strand T. Osteochondral autografting (mosaicplasty) in articular cartilage defects in the knee: results at 5 to 9 years. The Knee. 2010;17:847.

[149] Hangody L, Fules P. Autologous osteochondral mosaicplasty for the treatment of full-thickness defects of weight-bearing joints: ten years of experimental and clinical experience. The Journal of bone and joint surgery American volume. 2003;85-A Suppl 2:25-32.

[150] Marcacci M, Kon E, Zaffagnini S, lacono F, Neri MP, Vascellari A, et al. Multiple osteochondral arthroscopic grafting (mosaicplasty) for cartilage defects of the knee: prospective study results at 2year follow-up. Arthroscopy : the journal of arthroscopic \& related surgery : official publication of the Arthroscopy Association of North America and the International Arthroscopy Association. 2005;21:462-70. 
[151] Saris DB, Vanlauwe J, Victor J, Haspl M, Bohnsack M, Fortems Y, et al. Characterized chondrocyte implantation results in better structural repair when treating symptomatic cartilage defects of the knee in a randomized controlled trial versus microfracture. The American journal of sports medicine. 2008;36:235-46.

[152] Zeifang F, Oberle D, Nierhoff C, Richter W, Moradi B, Schmitt H. Autologous chondrocyte implantation using the original periosteum-cover technique versus matrix-associated autologous chondrocyte implantation: a randomized clinical trial. The American journal of sports medicine. 2010;38:924-33.

[153] Minas T, Von Keudell A, Bryant T, Gomoll AH. The John Insall Award: A minimum 10-year outcome study of autologous chondrocyte implantation. Clinical orthopaedics and related research. 2014;472:41-51.

[154] Schneider TE, Karaikudi S. Matrix-Induced Autologous Chondrocyte Implantation (MACI) grafting for osteochondral lesions of the talus. Foot Ankle Int. 2009;30:810-4.

[155] Gooding CR, Bartlett W, Bentley G, Skinner JA, Carrington R, Flanagan A. A prospective, randomised study comparing two techniques of autologous chondrocyte implantation for osteochondral defects in the knee: Periosteum covered versus type I/III collagen covered. The Knee. 2006;13:203-10.

[156] Peterson L, Minas T, Brittberg M, Nilsson A, Sjogren-Jansson E, Lindahl A. Two- to 9-year outcome after autologous chondrocyte transplantation of the knee. Clinical orthopaedics and related research. 2000:212-34.

[157] Siemieniuk RAC, Harris IA, Agoritsas T, Poolman RW, Brignardello-Petersen R, Van de Velde S, et al. Arthroscopic surgery for degenerative knee arthritis and meniscal tears: a clinical practice guideline. BMJ. 2017;357.

[158] Yu SP, Hunter DJ. Managing osteoarthritis. Aust Prescr. 2015;38:115-9.

[159] Kon E, Filardo G, Berruto M, Benazzo F, Zanon G, Della Villa S, et al. Articular cartilage treatment in high-level male soccer players: a prospective comparative study of arthroscopic second-generation autologous chondrocyte implantation versus microfracture. The American journal of sports medicine. 2011;39:2549-57.

[160] Parvizi J, Nunley RM, Berend KR, Lombardi AV, Jr., Ruh EL, Clohisy JC, et al. High level of residual symptoms in young patients after total knee arthroplasty. Clinical orthopaedics and related research. 2014;472:133-7.

[161] Scott CE, Howie CR, MacDonald D, Biant LC. Predicting dissatisfaction following total knee replacement: a prospective study of 1217 patients. The Journal of bone and joint surgery British volume. 2010;92:1253-8.

[162] Scott CE, Oliver WM, MacDonald D, Wade FA, Moran M, Breusch SJ. Predicting dissatisfaction following total knee arthroplasty in patients under 55 years of age. The bone \& joint journal. 2016;98-b:1625-34.

[163] Registry. NJ. National Joint Registry 14th Annual Report, 2016. . 
[164] Burn E, Edwards CJ, Murray DW, Silman A, Cooper C, Arden NK, et al. Trends and determinants of length of stay and hospital reimbursement following knee and hip replacement: evidence from linked primary care and NHS hospital records from 1997 to 2014. BMJ Open. 2018;8.

[165] Haddad FS, Garbuz DS, Chambers GK, Jagpal TJ, Masri BA, Duncan CP. The expectations of patients undergoing revision hip arthroplasty. The Journal of Arthroplasty.16:87-91.

[166] Patel A, Pavlou G, Mujica-Mota RE, Toms AD. The epidemiology of revision total knee and hip arthroplasty in England and Wales: a comparative analysis with projections for the United States. A study using the National Joint Registry dataset. The bone \& joint journal. 2015;97-b:1076-81.

[167] Postler AE, Beyer F, Wegner T, Lützner J, Hartmann A, Ojodu I, et al. Patient-reported outcomes after revision surgery compared to primary total hip arthroplasty. Hip International. 2017;27:180-6.

[168] Turnbull GS, Scott CEH, MacDonald DJ, Breusch SJ. Gender and Preoperative Function Predict Physical Activity Levels After Revision Total Knee Arthroplasty. J Arthroplasty. 2019;34:939-46.

[169] Turnbull GS, Scott CEH, MacDonald DJ, Breusch SJ. Return to activity following revision total hip arthroplasty. Arch Orthop Trauma Surg. 2019;139:411-21.

[170] Di Bella C, Fosang A, Donati D, Wallace G, Choong P. 3D Bioprinting of Cartilage for Orthopedic Surgeons: Reading between the Lines2015.

[171] Jeuken R, Roth A, Peters R, van Donkelaar C, Thies J, van Rhijn L, et al. Polymers in Cartilage Defect Repair of the Knee: Current Status and Future Prospects. Polymers. 2016;8:219.

[172] Groll J, Yoo JJ. Special issue on bioinks. Biofabrication. 2018;11:010201.

[173] Rhee S, Puetzer JL, Mason BN, Reinhart-King CA, Bonassar L. 3D Bioprinting of Spatially Heterogeneous Collagen Constructs for Cartilage Tissue Engineering. ACS Biomaterials Science \& Engineering. 2016;2:1800-5.

[174] Current Status of Bioinks for Micro-Extrusion-Based 3D Bioprinting. Molecules. 2016;21:685.

[175] You F, Chen X, Cooper DML, Chang T, Eames BF. Homogeneous hydroxyapatite/alginate composite hydrogel promotes calcified cartilage matrix deposition with potential for threedimensional bioprinting. Biofabrication. 2018;11:015015.

[176] Onofrillo C, Duchi S, O'Connell CD, Blanchard R, O'Connor AJ, Scott M, et al. Biofabrication of human articular cartilage: a path towards the development of a clinical treatment. Biofabrication. 2018;10:045006.

[177] Daly AC, Critchley SE, Rencsok EM, Kelly DJ. A comparison of different bioinks for 3D bioprinting of fibrocartilage and hyaline cartilage. Biofabrication. 2016;8:045002.

[178] Alginate Sulfate-Nanocellulose Bioinks for Cartilage Bioprinting Applications. Annals of Biomedical Engineering. 2017;45:210. 
[179] Yang X, Lu Z, Wu H, Li W, Zheng L, Zhao J. Collagen-alginate as bioink for three-dimensional (3D) cell printing based cartilage tissue engineering. Materials science \& engineering C, Materials for biological applications. 2018;83:195-201.

[180] Markstedt K, Mantas A, Tournier I, Martínez Ávila H, Hägg D, Gatenholm P. 3D Bioprinting Human Chondrocytes with Nanocellulose-Alginate Bioink for Cartilage Tissue Engineering Applications. Biomacromolecules. 2015;16:1489-96.

[181] Lou YR, Kanninen L, Kuisma T, Niklander J, Noon LA, Burks D, et al. The use of nanofibrillar cellulose hydrogel as a flexible three-dimensional model to culture human pluripotent stem cells. Stem Cells Dev. 2014;23:380-92.

[182] Park H, Lee KY. Cartilage regeneration using biodegradable oxidized alginate/hyaluronate hydrogels. Journal of biomedical materials research Part A. 2014;102:4519-25.

[183] Yue K, Trujillo-de Santiago G, Alvarez MM, Tamayol A, Annabi N, Khademhosseini A. Synthesis, properties, and biomedical applications of gelatin methacryloyl (GelMA) hydrogels. Biomaterials. 2015;73:254-71.

[184] Costantini M, Idaszek J, Szöke K, Jaroszewicz J, Dentini M, Barbetta A, et al. 3D bioprinting of BM-MSCs-loaded ECM biomimetic hydrogels forin vitroneocartilage formation. Biofabrication. 2016;8:035002.

[185] Levato R, Webb WR, Otto IA, Mensinga A, Zhang Y, van Rijen M, et al. The bio in the ink: cartilage regeneration with bioprintable hydrogels and articular cartilage-derived progenitor cells. Acta Biomater. 2017;61:41-53.

[186] Shim JH, Jang KM, Hahn SK, Park JY, Jung H, Oh K, et al. Three-dimensional bioprinting of multilayered constructs containing human mesenchymal stromal cells for osteochondral tissue regeneration in the rabbit knee joint. Biofabrication. 2016;8:014102.

[187] Castro NJ, O'Brien J, Zhang LG. Integrating biologically inspired nanomaterials and table-top stereolithography for 3D printed biomimetic osteochondral scaffolds. Nanoscale. 2015;7:14010-22.

[188] Bernhardt A, Paul B, Gelinsky M. Biphasic Scaffolds from Marine Collagens for Regeneration of Osteochondral Defects. Marine Drugs. 2018;16:91.

[189] Simone S, Thomas B, Naomi P, Sarah B, Riccardo L, Verena S, et al. Double printing of hyaluronic acid/poly(glycidol) hybrid hydrogels with poly( $\varepsilon$-caprolactone) for MSC chondrogenesis. Biofabrication. 2017;9:044108.

[190] Khanarian NT, Jiang J, Wan LQ, Mow VC, Lu HH. A Hydrogel-Mineral Composite Scaffold for Osteochondral Interface Tissue Engineering. Tissue engineering Part A. 2012;18:533-45.

[191] Spalazzi JP, Dagher E, Doty SB, Guo XE, Rodeo SA, Lu HH. In vivo evaluation of a multiphased scaffold designed for orthopaedic interface tissue engineering and soft tissue-to-bone integration. Journal of biomedical materials research Part A. 2008;86:1-12.

[192] Visser J, Melchels FPW, Jeon JE, van Bussel EM, Kimpton LS, Byrne HM, et al. Reinforcement of hydrogels using three-dimensionally printed microfibres. Nature Communications. 2015;6:6933. 
[193] Vladislav AP, Elizaveta VK, Elena AB, Pavel AK, Frederico DASP, Nikita EN, et al. Scaffold-free, label-free and nozzle-free biofabrication technology using magnetic levitational assembly. Biofabrication. 2018;10:034104.

[194] Jin R, Moreira Teixeira LS, Dijkstra PJ, Karperien M, van Blitterswijk CA, Zhong ZY, et al. Injectable chitosan-based hydrogels for cartilage tissue engineering. Biomaterials. 2009;30:2544-51.

[195] Tan H, Li H, Rubin JP, Marra KG. Controlled Gelation and Degradation Rates of Injectable Hyaluronic Acid-based Hydrogels through a Double Crosslinking Strategy. Journal of tissue engineering and regenerative medicine. 2011;5:790-7.

[196] Wei Y, Hu Y, Hao W, Han Y, Meng G, Zhang D, et al. A novel injectable scaffold for cartilage tissue engineering using adipose-derived adult stem cells. J Orthop Res. 2008;26:27-33.

[197] Li Y, Tian H, Chen X. Hyaluronic acid based injectable hydrogels for localized and sustained gene delivery. Journal of controlled release : official journal of the Controlled Release Society. 2015;213:e140-1.

[198] Ji X, Yang W, Wang T, Mao C, Guo L, Xiao J, et al. Coaxially electrospun core/shell structured poly(L-lactide) acid/chitosan nanofibers for potential drug carrier in tissue engineering. J Biomed Nanotechnol. 2013;9:1672-8.

[199] Sargeant TD, Desai AP, Banerjee S, Agawu A, Stopek JB. An in situ forming collagen-PEG hydrogel for tissue regeneration. Acta Biomater. 2012;8:124-32.

[200] Fathi A, Mithieux SM, Wei H, Chrzanowski W, Valtchev P, Weiss AS, et al. Elastin based cellladen injectable hydrogels with tunable gelation, mechanical and biodegradation properties. Biomaterials. 2014;35:5425-35.

[201] Bidarra SJ, Barrias CC, Granja PL. Injectable alginate hydrogels for cell delivery in tissue engineering. Acta Biomater. 2014;10:1646-62.

[202] Ren K, He C, Xiao C, Li G, Chen X. Injectable glycopolypeptide hydrogels as biomimetic scaffolds for cartilage tissue engineering. Biomaterials. 2015;51:238-49.

[203] Radhakrishnan J, Subramanian A, Krishnan UM, Sethuraman S. Injectable and 3D Bioprinted Polysaccharide Hydrogels: From Cartilage to Osteochondral Tissue Engineering. Biomacromolecules. 2017;18:1-26.

[204] Jin R, Moreira Teixeira LS, Krouwels A, Dijkstra PJ, van Blitterswijk CA, Karperien M, et al. Synthesis and characterization of hyaluronic acid-poly(ethylene glycol) hydrogels via Michael addition: An injectable biomaterial for cartilage repair. Acta Biomater. 2010;6:1968-77.

[205] Yan S, Wang T, Feng L, Zhu J, Zhang K, Chen X, et al. Injectable in situ self-cross-linking hydrogels based on poly(L-glutamic acid) and alginate for cartilage tissue engineering. Biomacromolecules. 2014;15:4495-508.

[206] Ehlers EM, Behrens P, Wunsch L, Kuhnel W, Russlies M. Effects of hyaluronic acid on the morphology and proliferation of human chondrocytes in primary cell culture. Ann Anat.

2001;183:13-7. 
[207] Aibe K, Ryu J, Sano S. Effects of hyaluronic acid on cartilage metabolism in free chondrocytes. Journal of Orthopaedic Science. 1996;1:268-76.

[208] Patti AM, Gabriele A, Vulcano A, Ramieri MT, Della Rocca C. Effect of hyaluronic acid on human chondrocyte cell lines from articular cartilage. Tissue Cell. 2001;33:294-300.

[209] Akmal M, Singh A, Anand A, Kesani A, Aslam N, Goodship A, et al. The effects of hyaluronic acid on articular chondrocytes. Journal of Bone \&amp; Joint Surgery, British Volume. 2005;87-B:1143-9.

[210] Petta D, Armiento AR, Grijpma D, Alini M, Eglin D, D'Este M. 3D bioprinting of a hyaluronan bioink through enzymatic-and visible light-crosslinking. Biofabrication. 2018;10:044104.

[211] Hua Q, Knudson CB, Knudson W. Internalization of hyaluronan by chondrocytes occurs via receptor-mediated endocytosis. J Cell Sci. 1993;106 ( Pt 1):365-75.

[212] Ishida O, Tanaka Y, Morimoto I, Takigawa M, Eto S. Chondrocytes are regulated by cellular adhesion through CD44 and hyaluronic acid pathway. J Bone Miner Res. 1997;12:1657-63.

[213] Hyaluronan receptor-directed assembly of chondrocyte pericellular matrix. The Journal of Cell Biology. 1993;120:825-34.

[214] Park H, Choi B, Hu J, Lee M. Injectable chitosan hyaluronic acid hydrogels for cartilage tissue engineering. Acta Biomater. 2013;9:4779-86.

[215] Bacakova L, Novotna K, Parizek M. Polysaccharides as cell carriers for tissue engineering: the use of cellulose in vascular wall reconstruction. Physiol Res. 2014;63 Suppl 1:S29-47.

[216] Munarin F, Guerreiro SG, Grellier MA, Tanzi MC, Barbosa MA, Petrini P, et al. Pectin-based injectable biomaterials for bone tissue engineering. Biomacromolecules. 2011;12:568-77.

[217] Yu F, Cao X, Li Y, Zeng L, Yuan B, Chen X. An injectable hyaluronic acid/PEG hydrogel for cartilage tissue engineering formed by integrating enzymatic crosslinking and Diels-Alder "click chemistry". Polymer Chemistry. 2014;5:1082-90.

[218] Guo Y, Yuan T, Xiao Z, Tang P, Xiao Y, Fan Y, et al. Hydrogels of collagen/chondroitin sulfate/hyaluronan interpenetrating polymer network for cartilage tissue engineering. J Mater Sci Mater Med. 2012;23:2267-79.

[219] Lee JC, Lee SY, Min HJ, Han SA, Jang J, Lee S, et al. Synovium-derived mesenchymal stem cells encapsulated in a novel injectable gel can repair osteochondral defects in a rabbit model. Tissue engineering Part A. 2012;18:2173-86.

[220] Choi B, Kim S, Lin B, Wu BM, Lee M. Cartilaginous extracellular matrix-modified chitosan hydrogels for cartilage tissue engineering. ACS Appl Mater Interfaces. 2014;6:20110-21.

[221] Fan C, Wang D-A. A biodegradable PEG-based micro-cavitary hydrogel as scaffold for cartilage tissue engineering. European Polymer Journal. 2015;72:651-60.

[222] Hwang Y, Sangaj N, Varghese S. Interconnected macroporous poly(ethylene glycol) cryogels as a cell scaffold for cartilage tissue engineering. Tissue engineering Part A. 2010;16:3033-41. 
[223] Lee WK, Ichi T, Ooya T, Yamamoto T, Katoh M, Yui N. Novel poly(ethylene glycol) scaffolds crosslinked by hydrolyzable polyrotaxane for cartilage tissue engineering. Journal of biomedical materials research Part A. 2003;67:1087-92.

[224] Dubbini A, Censi R, Butini ME, Sabbieti MG, Agas D, Vermonden T, et al. Injectable hyaluronic acid/PEG-p(HPMAm-lac)-based hydrogels dually cross-linked by thermal gelling and Michael addition. European Polymer Journal. 2015;72:423-37.

[225] Vijayavenkataraman S, Lu WF, Fuh JYH. 3D bioprinting of skin: a state-of-the-art review on modelling, materials, and processes. Biofabrication. 2016;8:032001.

[226] Baroni A, Buommino E, De Gregorio V, Ruocco E, Ruocco V, Wolf R. Structure and function of the epidermis related to barrier properties. Clin Dermatol. 2012;30:257-62.

[227] Proksch E, Brandner JM, Jensen JM. The skin: an indispensable barrier. Exp Dermatol. 2008;17:1063-72.

[228] Peck MD. Epidemiology of burns throughout the world. Part I: Distribution and risk factors. Burns.37:1087-100.

[229] Martinez-Flores F, Chacon-Gomez M, Madinaveitia-Villanueva JA, Barrera-Lopez A, AguirreCruz L, Querevalu-Murillo W. [The clinical use of cryopreserved human skin allografts for transplantation]. Cir Cir. 2015;83:485-91.

[230] Hermans MH. Porcine xenografts vs. (cryopreserved) allografts in the management of partial thickness burns: is there a clinical difference? Burns. 2014;40:408-15.

[231] Boyce ST, Kagan RJ, Meyer NA, Yakuboff KP, Warden GD. The 1999 clinical research award. Cultured skin substitutes combined with Integra Artificial Skin to replace native skin autograft and allograft for the closure of excised full-thickness burns. J Burn Care Rehabil. 1999;20:453-61.

[232] Fang T, Lineaweaver WC, Sailes FC, Kisner C, Zhang F. Clinical application of cultured epithelial autografts on acellular dermal matrices in the treatment of extended burn injuries. Ann Plast Surg. 2014;73:509-15.

[233] Mori N, Morimoto Y, Takeuchi S. Perfusable and stretchable 3D culture system for skinequivalent. Biofabrication. 2018;11:011001.

[234] Lee V, Singh G, Trasatti JP, Bjornsson C, Xu X, Tran TN, et al. Design and fabrication of human skin by three-dimensional bioprinting. Tissue Eng Part C Methods. 2014;20:473-84.

[235] Cubo N, Garcia M, Del Canizo JF, Velasco D, Jorcano JL. 3D bioprinting of functional human skin: production and in vivo analysis. Biofabrication. 2016;9:015006.

[236] Ng WL, Qi JTZ, Yeong WY, Naing MW. Proof-of-concept: 3D bioprinting of pigmented human skin constructs. Biofabrication. 2018;10:025005.

[237] Binder KW, Zhao W, Aboushwareb T, Dice D, Atala A, Yoo JJ. In situ bioprinting of the skin for burns. Journal of the American College of Surgeons.211:S76. 
[238] Skardal A, Mack D, Kapetanovic E, Atala A, Jackson JD, Yoo J, et al. Bioprinted amniotic fluidderived stem cells accelerate healing of large skin wounds. Stem Cells Transl Med. 2012;1:792-802.

[239] Tennant M, McGeachie JK. Blood vessel structure and function: a brief update on recent advances. The Australian and New Zealand journal of surgery. 1990;60:747-53.

[240] Jones EA, le Noble F, Eichmann A. What determines blood vessel structure? Genetic prespecification vs. hemodynamics. Physiology (Bethesda, Md). 2006;21:388-95.

[241] Zhu W, Qu X, Zhu J, Ma X, Patel S, Liu J, et al. Direct 3D bioprinting of prevascularized tissue constructs with complex microarchitecture. Biomaterials. 2017;124:106-15.

[242] Kolesky DB, Truby RL, Gladman AS, Busbee TA, Homan KA, Lewis JA. 3D bioprinting of vascularized, heterogeneous cell-laden tissue constructs. Advanced materials (Deerfield Beach, Fla). 2014;26:3124-30.

[243] Chang CC, Boland ED, Williams SK, Hoying JB. Direct-write bioprinting three-dimensional biohybrid systems for future regenerative therapies. J Biomed Mater Res B Appl Biomater. 2011;98:160-70.

[244] Patra S, Young V. A Review of 3D Printing Techniques and the Future in Biofabrication of Bioprinted Tissue. Cell biochemistry and biophysics. 2016:1-6.

[245] Nguyen T-U, Shojaee M, Bashur CA, Kishore V. Electrochemical fabrication of a biomimetic elastin-containing bi-layered scaffold for vascular tissue engineering. Biofabrication. 2018;11:015007.

[246] Arai K, Iwanaga S, Toda H, Genci C, Nishiyama Y, Nakamura M. Three-dimensional inkjet biofabrication based on designed images. Biofabrication. 2011;3:034113.

[247] Xu C, Zhang Z, Christensen K, Huang Y, Fu J, Markwald RR. Freeform Vertical and Horizontal Fabrication of Alginate-Based Vascular-Like Tubular Constructs Using Inkjetting. Journal of Manufacturing Science and Engineering. 2014;136.

[248] Xu C, Zhang M, Huang Y, Ogale A, Fu J, Markwald RR. Study of Droplet Formation Process during Drop-on-Demand Inkjetting of Living Cell-Laden Bioink. Langmuir : the ACS journal of surfaces and colloids. 2014;30:9130-8.

[249] Xu T, Zhao W, Zhu J-M, Albanna MZ, Yoo JJ, Atala A. Complex heterogeneous tissue constructs containing multiple cell types prepared by inkjet printing technology. Biomaterials. 2013;34:130-9.

[250] Pataky K, Braschler T, Negro A, Renaud P, Lutolf MP, Brugger J. Microdrop printing of hydrogel bioinks into 3D tissue-like geometries. Advanced materials (Deerfield Beach, Fla). 2012;24:391-6.

[251] Christensen K, Xu C, Chai W, Zhang Z, Fu J, Huang Y. Freeform inkjet printing of cellular structures with bifurcations. Biotechnology and Bioengineering. 2015;112:1047-55.

[252] Ruitong X, Zhengyi Z, Wenxuan C, Yong H, Douglas BC. Freeform drop-on-demand laser printing of 3D alginate and cellular constructs. Biofabrication. 2015;7:045011. 
[253] Zhang W, Zhang YS, Bakht SM, Aleman J, Shin SR, Yue K, et al. Elastomeric free-form blood vessels for interconnecting organs on chip systems. Lab Chip. 2016;16:1579-86.

[254] Li X, Liu L, Zhang X, Xu T. Research and development of 3D printed vasculature constructs. Biofabrication. 2018;10:032002.

[255] Ravi S, Chaikof EL. Biomaterials for vascular tissue engineering. Regenerative medicine. 2010;5:107.

[256] Muller M, Becher J, Schnabelrauch M, Zenobi-Wong M. Printing thermoresponsive reverse molds for the creation of patterned two-component hydrogels for 3D cell culture. J Vis Exp. 2013:e50632.

[257] Di Biase M, Saunders RE, Tirelli N, Derby B. Inkjet printing and cell seeding thermoreversible photocurable gel structures. Soft Matter. 2011;7:2639-46.

[258] Fedorovich NE, Swennen I, Girones J, Moroni L, van Blitterswijk CA, Schacht E, et al. Evaluation of Photocrosslinked Lutrol Hydrogel for Tissue Printing Applications. Biomacromolecules.

2009;10:1689-96.

[259] Fedorovich NE, Schuurman W, Wijnberg HM, Prins HJ, van Weeren PR, Malda J, et al.

Biofabrication of osteochondral tissue equivalents by printing topologically defined, cell-laden hydrogel scaffolds. Tissue Eng Part C Methods. 2012;18:33-44.

[260] Lippens E, Swennen I, Girones J, Declercq H, Vertenten G, Vlaminck L, et al. Cell survival and proliferation after encapsulation in a chemically modified Pluronic(R) F127 hydrogel. J Biomater Appl. 2013;27:828-39.

[261] Tharmalingam T, Ghebeh H, Wuerz T, Butler M. Pluronic enhances the robustness and reduces the cell attachment of mammalian cells. Mol Biotechnol. 2008;39:167-77.

[262] Khattak SF, Bhatia SR, Roberts SC. Pluronic F127 as a cell encapsulation material: utilization of membrane-stabilizing agents. Tissue Eng. 2005;11:974-83.

[263] Chandaroy P, Sen A, Alexandridis P, Hui SW. Utilizing temperature-sensitive association of Pluronic F-127 with lipid bilayers to control liposome-cell adhesion. Biochim Biophys Acta.

2002;1559:32-42.

[264] Lee SY, Tae G, Kim YH. Thermal gellation and photo-polymerization of di-acrylated Pluronic F 127. J Biomater Sci Polym Ed. 2007;18:1335-53.

[265] Byambaa B, Annabi N, Yue K, Trujillo-de Santiago G, Alvarez MM, Jia W, et al. Bioprinted Osteogenic and Vasculogenic Patterns for Engineering 3D Bone Tissue. Adv Healthc Mater. 2017.

[266] Thompson DW, Butterworth JT. The nature of laponite and its aqueous dispersions. Journal of Colloid and Interface Science. 1992;151:236-43.

[267] Attalla R, Ling C, Selvaganapathy P. Fabrication and characterization of gels with integrated channels using 3D printing with microfluidic nozzle for tissue engineering applications. Biomedical microdevices. 2016;18:17. 
[268] De Moor L, Merovci I, Baetens S, Verstraeten J, Kowalska P, Krysko DV, et al. High-throughput fabrication of vascularized spheroids for bioprinting. Biofabrication. 2018;10:035009.

[269] Wu Y, Hospodiuk M, Peng W, Gudapati H, Neuberger T, Koduru S, et al. Porous tissue strands: avascular building blocks for scalable tissue fabrication. Biofabrication. 2018;11:015009.

[270] Visconti RP, Kasyanov V, Gentile C, Zhang J, Markwald RR, Mironov V. Towards organ printing: engineering an intra-organ branched vascular tree. Expert Opin Biol Ther. 2010;10:409-20.

[271] Mironov V, Zhang J, Gentile C, Brakke K, Trusk T, Jakab K, et al. Designer 'blueprint' for vascular trees: morphology evolution of vascular tissue constructs. Virtual and Physical Prototyping. 2009;4:63-74.

[272] Neagu A, Jakab K, Jamison R, Forgacs G. Role of physical mechanisms in biological selforganization. Phys Rev Lett. 2005;95:178104.

[273] Jakab K, Norotte C, Damon B, Marga F, Neagu A, Besch-Williford CL, et al. Tissue engineering by self-assembly of cells printed into topologically defined structures. Tissue engineering Part $A$. 2008;14:413-21.

[274] Laschke MW, Menger MD. Spheroids as vascularization units: From angiogenesis research to tissue engineering applications. Biotechnol Adv. 2017;35:782-91.

[275] Heiss M, Hellstrom M, Kalen M, May T, Weber H, Hecker M, et al. Endothelial cell spheroids as a versatile tool to study angiogenesis in vitro. Faseb j. 2015;29:3076-84.

[276] Deber CM, Reynolds SJ. Central nervous system myelin: structure, function, and pathology. Clin Biochem. 1991;24:113-34.

[277] Cho K-S, Yang L, Lu B, Ma HF, Huang X, Pekny M, et al. Re-establishing the regenerative potential of central nervous system axons in postnatal mice. Journal of cell science. 2005;118:86372.

[278] Akter F, Ibanez J, Kotter M. Chapter 4 - Neural Tissue Engineering. Tissue Engineering Made Easy: Academic Press; 2016. p. 29-42.

[279] Wolford LM, Stevao ELL. Considerations in nerve repair. Proc (Bayl Univ Med Cent). 2003;16:152-6.

[280] Kornfeld T, Vogt PM, Radtke C. Nerve grafting for peripheral nerve injuries with extended defect sizes. Wien Med Wochenschr. 2019;169:240-51.

[281] Liu K, Tedeschi A, Park KK, He Z. Neuronal Intrinsic Mechanisms of Axon Regeneration. Annual Review of Neuroscience. 2011;34:131-52.

[282] Scheib J, Höke A. Advances in peripheral nerve regeneration. Nature Reviews Neurology. 2013;9:668.

[283] Eugen BP, Rajiv M, Erin M, Aurel P-W, Traian VC, Paul DD. 3D printing strategies for peripheral nerve regeneration. Biofabrication. 2018;10:032001. 
[284] Ning L, Sun H, Lelong T, Guilloteau R, Zhu N, Schreyer DJ, et al. 3D bioprinting of scaffolds with living Schwann cells for potential nerve tissue engineering applications. Biofabrication.

2018;10:035014.

[285] Zhu W, Tringale KR, Woller SA, You S, Johnson S, Shen H, et al. Rapid continuous 3D printing of customizable peripheral nerve guidance conduits. Materials Today. 2018;21:951-9.

[286] Vijayavenkataraman S, Thaharah S, Zhang S, Lu WF, Fuh JYH. Electrohydrodynamic jet 3Dprinted PCL/PAA conductive scaffolds with tunable biodegradability as nerve guide conduits (NGCs) for peripheral nerve injury repair. Materials \& Design. 2019;162:171-84.

[287] Liqun N, Haoying S, Tiphanie L, Romain G, Ning Z, David JS, et al. 3D bioprinting of scaffolds with living Schwann cells for potential nerve tissue engineering applications. Biofabrication. 2018;10:035014.

[288] Chia-Wei Y, Li-Wen W, Hsi-Chin W, Yi-Kong H, Jane W, Ming-Hong C, et al. Development of biomimetic micro-patterned device incorporated with neurotrophic gradient and supportive Schwann cells for the applications in neural tissue engineering. Biofabrication. 2017;9:015024.

[289] Curley JL, Gary CC, Elaine LH-R, Michael JM. Sensory axon guidance with semaphorin 6A and nerve growth factor in a biomimetic choice point model. Biofabrication. 2014;6:035026.

[290] Owens CM, Marga F, Forgacs G, Heesch CM. Biofabrication and testing of a fully cellular nerve graft. Biofabrication. 2013;5:045007.

[291] Hu Y, Wu Y, Gou Z, Tao J, Zhang J, Liu Q, et al. 3D-engineering of Cellularized Conduits for Peripheral Nerve Regeneration. Sci Rep. 2016;6:32184.

[292] Gu Q, Tomaskovic-Crook E, Lozano R, Chen Y, Kapsa RM, Zhou Q, et al. Functional 3D Neural Mini-Tissues from Printed Gel-Based Bioink and Human Neural Stem Cells. Adv Healthc Mater. 2016;5:1429-38.

[293] Lee YB, Polio S, Lee W, Dai G, Menon L, Carroll RS, et al. Bio-printing of collagen and VEGFreleasing fibrin gel scaffolds for neural stem cell culture. Exp Neurol. 2010;223:645-52.

[294] Chen C, Zhao ML, Zhang RK, Lu G, Zhao CY, Fu F, et al. Collagen/heparin sulfate scaffolds fabricated by a $3 \mathrm{D}$ bioprinter improved mechanical properties and neurological function after spinal cord injury in rats. J Biomed Mater Res A. 2017;105:1324-32.

[295] Hsieh F-Y, Lin H-H, Hsu S-h. 3D bioprinting of neural stem cell-laden thermoresponsive biodegradable polyurethane hydrogel and potential in central nervous system repair. Biomaterials. 2015;71:48-57.

[296] Huang C-T, Kumar Shrestha L, Ariga K, Hsu S-h. A graphene-polyurethane composite hydrogel as a potential bioink for 3D bioprinting and differentiation of neural stem cells. Journal of Materials Chemistry B. 2017;5:8854-64.

[297] Wei Z, Harris BT, Zhang LG. Gelatin methacrylamide hydrogel with graphene nanoplatelets for neural cell-laden 3D bioprinting. Conf Proc IEEE Eng Med Biol Soc. 2016;2016:4185-8. 
[298] Lozano R, Stevens L, Thompson BC, Gilmore KJ, Gorkin R, Stewart EM, et al. 3D printing of layered brain-like structures using peptide modified gellan gum substrates. Biomaterials.

2015;67:264-73.

[299] Dai X, Ma C, Lan Q, Xu T. 3D bioprinted glioma stem cells for brain tumor model and applications of drug susceptibility. Biofabrication. 2016;8:045005.

[300] Dai X, Liu L, Ouyang J, Li X, Zhang X, Lan Q, et al. Coaxial 3D bioprinting of self-assembled multicellular heterogeneous tumor fibers. Sci Rep. 2017;7:1457.

[301] Du Z, Mi S, Yi X, Xu Y, Sun W. Microfluidic system for modelling 3D tumour invasion into surrounding stroma and drug screening. Biofabrication. 2018;10:034102.

[302] Chengyang W, Zhenyu T, Yu Z, Rui Y, Lingsong L, Wei S. Three-dimensional in vitro cancer models: a short review. Biofabrication. 2014;6:022001.

[303] Knowlton S, Onal S, Yu CH, Zhao JJ, Tasoglu S. Bioprinting for cancer research. Trends in Biotechnology. 2015;33:504-13.

[304] Wang C, Tang Z, Zhao Y, Yao R, Li L, Sun W. Three-dimensional in vitro cancer models: a short review. Biofabrication. 2014;6:022001.

[305] Sharma P, Maffulli N. Biology of tendon injury: healing, modeling and remodeling. Journal of musculoskeletal \& neuronal interactions. 2006;6:181-90.

[306] Romanini E, D'Angelo F, De Masi S, Adriani E, Magaletti M, Lacorte E, et al. Graft selection in arthroscopic anterior cruciate ligament reconstruction. J Orthop Traumatol. 2010;11:211-9.

[307] McElvany MD, McGoldrick E, Gee AO, Neradilek MB, Matsen FA. Rotator Cuff Repair: Published Evidence on Factors Associated With Repair Integrity and Clinical Outcome. The American journal of sports medicine. 2014;43:491-500.

[308] Beiner JM, JokI P. Muscle contusion injuries: current treatment options. The Journal of the American Academy of Orthopaedic Surgeons. 2001;9:227-37.

[309] Tabebordbar M, Wang ET, Wagers AJ. Skeletal muscle degenerative diseases and strategies for therapeutic muscle repair. Annu Rev Pathol. 2013;8:441-75.

[310] Mozetic P, Giannitelli SM, Gori M, Trombetta M, Rainer A. Engineering muscle cell alignment through 3D bioprinting. Journal of Biomedical Materials Research Part A. 2017;105:2582-8.

[311] Frontera WR, Ochala J. Skeletal Muscle: A Brief Review of Structure and Function. Calcified Tissue International. 2015;96:183-95.

[312] Juhas M, Bursac N. Engineering skeletal muscle repair. Curr Opin Biotechnol. 2013;24:880-6.

[313] Ackermann PW, Franklin SL, Dean BJ, Carr AJ, Salo PT, Hart DA. Neuronal pathways in tendon healing and tendinopathy--update. Front Biosci (Landmark Ed). 2014;19:1251-78.

[314] Millar NL, Murrell GA, McInnes IB. Inflammatory mechanisms in tendinopathy - towards translation. Nat Rev Rheumatol. 2017;13:110-22. 
[315] Tyler KM, Morgan B, Young-Joon S, Hyun-Wook K, Sang Jin L, James JY, et al. A 3D bioprinted complex structure for engineering the muscle-tendon unit. Biofabrication. 2015;7:035003.

[316] Sensini A, Gualandi C, Cristofolini L, Tozzi G, Dicarlo M, Teti G, et al. Biofabrication of bundles of poly(lactic acid)-collagen blends mimicking the fascicles of the human Achille tendon. Biofabrication. 2017;9:015025.

[317] Orciani M, Fini M, Di Primio R, Mattioli-Belmonte M. Biofabrication and Bone Tissue Regeneration: Cell Source, Approaches, and Challenges. Front Bioeng Biotechnol. 2017;5:17.

[318] Drummond J, Tran P, Fary C. Metal-on-Metal Hip Arthroplasty: A Review of Adverse Reactions and Patient Management. J Funct Biomater. 2015;6:486-99.

[319] Wang X, Yan Y, Zhang R. Recent trends and challenges in complex organ manufacturing. Tissue Eng Part B Rev. 2010;16:189-97.

Acknowledgement:

We acknowledge the funding support from the Royal Society International Exchange Scheme. 